\title{
NORFACE
}

MIGRATION

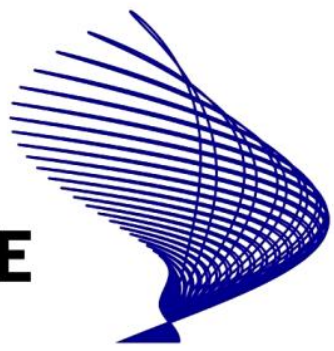

NORFACE MIGRATION Discussion Paper No. 2011-11

\section{Migration and Education}

Christian Dustmann and Albrecht Glitz 


\title{
Migration and Education
}

\section{Christian Dustmann and Albrecht Glitz ${ }^{1}$}

Handbook of the Economics of Education, Vol. 4

\section{Edited by E. A. Hanushek, S. Machin and L. Woessmann}

\begin{abstract}
Sjaastad (1962) viewed migration in the same way as education: as an investment in the human agent. Migration and education are decisions that are indeed intertwined in many dimensions. Education and skill acquisition play an important role at many stages of an individual's migration. Differential returns to skills in origin- and destination country are a main driver of migration. The economic success of the immigrant in the destination country is to a large extent determined by her educational background, how transferable these skills are to the host country labour market, and how much she invests into further skills after arrival. The desire to acquire skills in the host country that have a high return in the country of origin may also be an important reason for a migration. From an intertemporal point of view, the possibility of a later migration may also affect educational decisions in the home country long before a migration is realised. In addition, the decisions of migrants regarding their own educational investment, and their expectations about future migration plans may also affect the educational attainment of their children. But migration and education are not only related for those who migrate or their descendants. Migrations of some individuals may have consequences for educational decisions of those who do not migrate, both in the homeand in the host country. By easing credit constraints through remittances, migration of some may help others to go to school. By changing the skill base of the receiving country, migration may change incentives to invest in certain types of human capital. Migrants and their children may create externalities that influence educational outcomes of non-migrants in the destination country. This chapter will discuss some of the key areas that connect migration and education.
\end{abstract}

Keywords: Migration, Education, Human Capital, Return Migration, Immigrant Selection, Second-generation Immigrants

\footnotetext{
${ }^{1}$ We would like to thank Jérôme Adda, Andrew Mountford, Ian Preston and Yoram Weiss for helpful comments, and Andrew Aitken, Gianandrea Lanzara, Anna Raute and Anna Rosso for excellent research assistance.
} 


\section{Table of Contents}

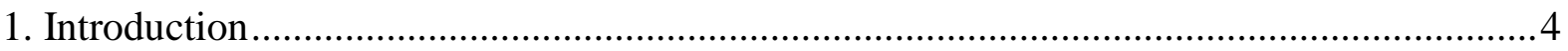

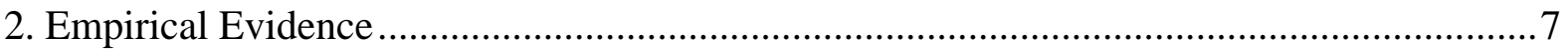

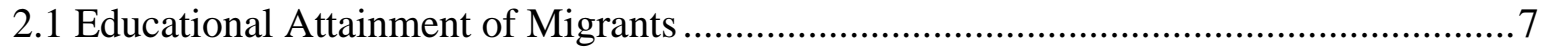

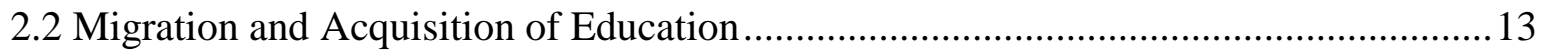

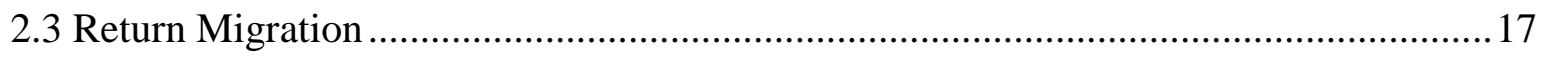

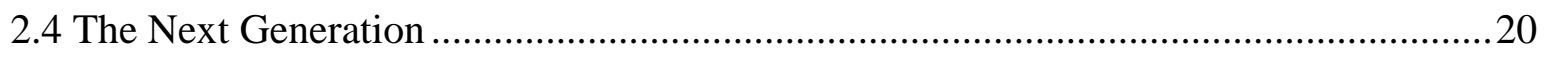

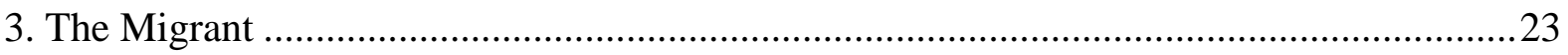

3.1 The Migration Decision and Human Capital Investment............................................23

3.2 A Simple Model of Return Migration and Investment in Human Capital .....................26

3.2.1 Skill Enhancement and Return Decisions of Migrants.......................................28

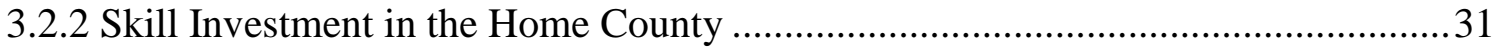

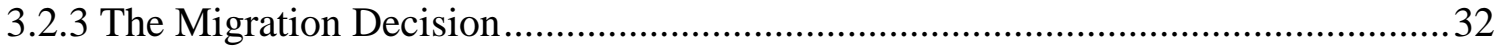

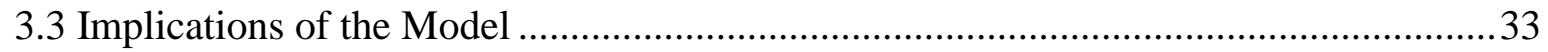

3.3.1 The Optimal Investment in Skills and the Optimal Migration Duration ..................33

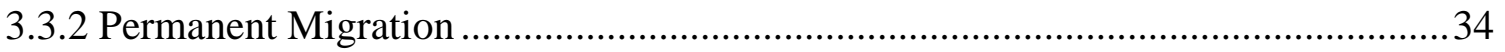

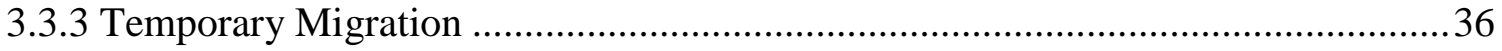

3.3.4 Choosing the Optimal Migration Period and Investment in Human Capital ...........37

3.3.5 Choosing the Optimal Investment in Learning in the First Period.........................40

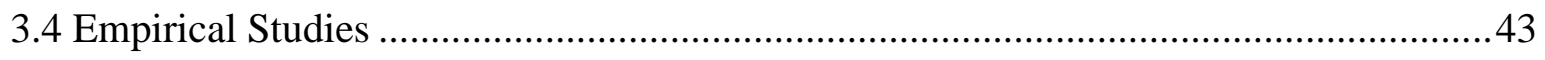

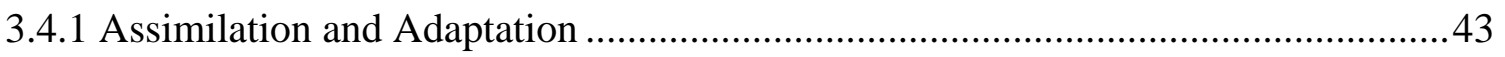

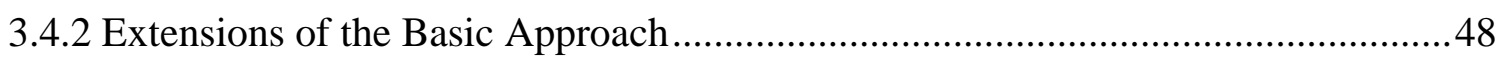

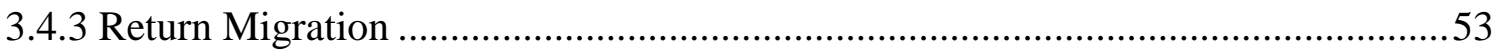

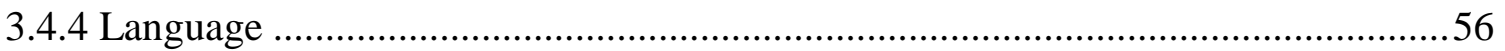

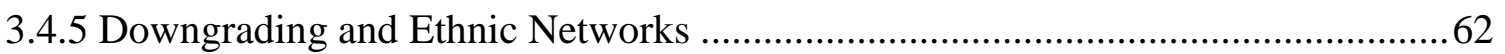

3.4.6 Observed Post-Migration Schooling Investment and Learning Centres .................64 
4. The Effect of Migration on the Skill Base and Educational Attainment of Non-Migrants .66

4.1 The Selection of Migrants .67

4.1.1 A Multiple Skill Model of Migrant Selection ....................................................69

4.1.2 Skill Prices, Productive Capacity and Selection.................................................... 75

4.1.4 Explaining Different Selection Patterns ............................................................. 77

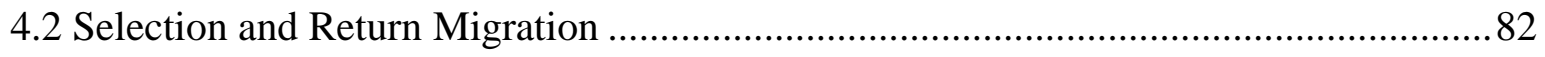

4.3 Learning, Multi-Dimensional Skills, and Return Migration ...................................... 84

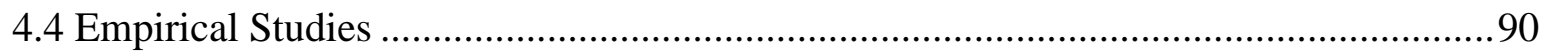

4.4.1 Emigration and Human Capital Investment in the Sending Country ......................90

4.4.2 Immigration and Human Capital Investment in the Receiving Country ................95

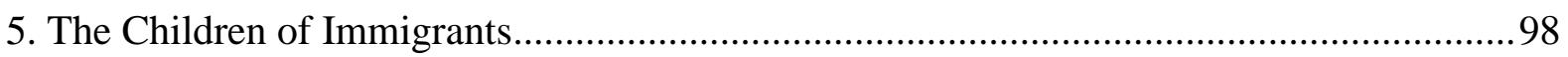

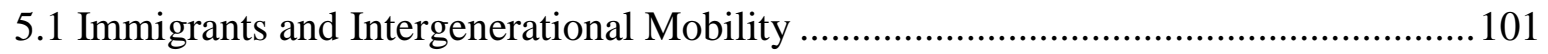

5.2 A Model of Intergenerational Mobility of Immigrants ............................................. 105

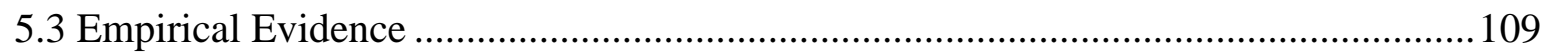

5.3.1 Schooling Outcomes of Immigrant Children........................................................ 110

5.3.2 Intergenerational Transmission of Human Capital.............................................113

5.3.3 Intergenerational Transmission and Language ................................................ 117

5.3.4 Intergenerational Transmission and Ethnic Networks......................................118

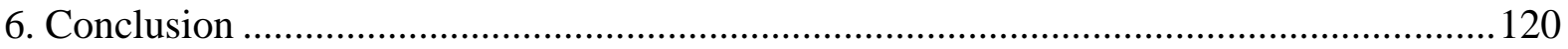

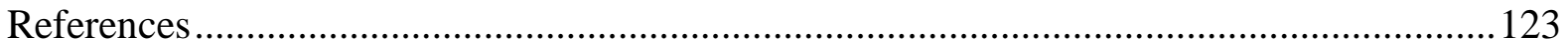




\section{Introduction}

Starting with homo erectus about 2 million years ago, the first humans were organised in groups of hunters and gatherers. These groups were nomadic, and the economic foundation of their existence was making migrations a necessity, forcing them to move continuously according to food supplies. Constant migration was the normality. Today, populations that pursue a nomadic lifestyle are the exception. The abandonment of the hunting and gathering lifestyle by humans about 10,000 years ago, when this lifestyle was replaced by agriculture, changed the technology of subsistence production. It led to social and political structures that built on non-nomadic forms of economising. If migrations took place nevertheless, then for two main reasons: either because people were forced to move by natural disasters or manmade circumstances (such as persecution due to distinct political or religious views), or because economic prospects seemed more favorable in other regions. Immigrant-receiving countries today draw distinctions between these two different motives for movement. The Geneva Convention of 1951 defines a refugee as any person "who owing to a well-founded fear of being persecuted for reasons of race, religion, nationality, membership of a particular social group or political opinion, is outside the country of his nationality and is unable or, owing to such fear, is unwilling to avail himself of the protection of that country - or return to it". Its signatories committed to not sending an individual back into a situation of possible persecution. According to United Nations figures, 7.1 percent of all international migrants in 2005 are refugees from their countries of origin. ${ }^{2}$

\footnotetext{
${ }^{2}$ Source: United Nations, Department of Economic and Social Affairs, Population Division. International Migrant Stock: The 2008 Revision, 2009.
} 
In this chapter, we will deal mainly with migrations due to the second motive: movements that are due to individual decisions based on some optimising considerations. We will focus our discussion on international migrations, although much of what we discuss also holds for migrations within national borders. ${ }^{3}$ Deliberate migrations are driven by economic motives and considerations, and can therefore be subjected to economic analysis and investigation. Hicks noted in his Theory of Wages in 1932 (p. 76) that it is differences in net economic advantages, chiefly differences in wages, [that] are the main causes of migration.

Education, in turn, is a main determinant of wages, both in the country of origin and the potential destination country. ${ }^{4}$ Although the decisions about how much education to obtain and whether to migrate are often sequential, individuals may in many cases make these choices simultaneously, choosing education at home with a view to migrating later. Once migrated, choices about skill acquisition in the host country are crucial for the economic payoff of the migration decision. These investment decisions are, in turn, related to future migration plans and therefore the forms that migrations take over the individuals' life cycles. Furthermore, acquisition of education may be the sole reason for a migration - student migrations are an example. Some countries, such as the U.S., the UK and Australia, are established "learning centres", offering educational products to an international market. The acquisition of skills abroad that are more productive at home may also take place on the job for instance through the acquisition of language skills or learning of particular production technologies. Thus, individual migration decisions and decisions about educational

\footnotetext{
${ }^{3}$ We follow the convention in most of the literature in economics, and define an "immigrant" as an individual that resides and works in a country other than the country where he/she was born. This is the standard definition of immigrants in the Anglo-Saxon countries; however some countries (like Germany) define immigrants based on nationality rather than country of birth.

${ }^{4}$ We will use the terms country of destination and host country, and the terms country of origin and home country interchangeably throughout this chapter.
} 
attainment are strongly intertwined, and we will shed light on this relationship in the third section of the chapter.

But migrations may also affect educational attainments of those who do not choose to move, both in the destination and the origin countries. Migrations may lead to a change in the skill base of both sets of countries, affecting average levels of education and possibly generating educational externalities and new incentives for human capital investments. For instance, if immigration is selective in the sense that only better able individuals move, then this may enhance the skill base in the destination country, while it may deplete the skill base in the country of origin, with consequences for the populations of those who have chosen not to move. However, there may be situations where migration enhances the skill base of both countries. Immigration may lead to a specialisation of non-migrant workers in the destination country in areas where they have a competitive advantage. It may also lead to an improvement of the economic situation of migrants' families, for instance through remittances, thus enabling children to attend school instead of working. Remittances may also help to create educational infrastructures that foster educational attainment of those who do not have family members who migrate. We will discuss immigrant selection and the interrelation between migration and education of those who do not move in the fourth section of this chapter.

Finally, migration is a long-term process, with many immigrants bringing their children with them or founding families in their host countries. In this context, it is important to understand how the children of immigrants are accommodated by the host country's education system and how they perform in it relative to native children? What is the role intergenerational transmission of human capital plays for the longer run integration process and how does it affect the immigrants' long-term convergence to the native population? These are key questions in the current debate about immigration, in particular in those 
countries that only recently received large immigrant populations. We will discuss the educational achievement of the children of immigrants and their intergenerational mobility in the fifth section of this chapter.

There are therefore three related cornerstones to this chapter. These cover the key economic aspects of the individual migration decision, their connection to education and skill selection of immigrants, and the nature of intergenerational spillovers. The analysis of these three cornerstones provides a comprehensive overview of the economic connections between migration and education.

Before considering these three inter-related areas in detail, we begin in Section 2 by setting the scene with the presentation of some empirical evidence about immigrant populations in OECD countries, their educational attainment, their labor market performance, and how they compare to natives and to those in their home countries who decided not to move. We will demonstrate the large diversity of immigrant populations in different countries, which is often due to historical reasons, such as colonial pasts, historical trade links, or particular recruitment policies at earlier points in time. At the same time, the descriptive evidence we present shows many common features across populations of immigrants in different destination countries. Some of these features we will return to later in the individual sections that deal with the migrant, the non-migrants, and the children of immigrants where we will embed them into a more structural framework. In order to ensure comparability, we focus on OECD countries for which detailed and standardised data are available.

\section{Empirical Evidence}

\subsection{Educational Attainment of Migrants}


When thinking about the educational attainment of migrants, two points of reference naturally come to mind, the educational attainment of the migrants relative to the native population in the destination country, and the educational attainment of the migrants relative to their compatriots who remained in their country of origin. To provide an overview, Table 1a shows the educational attainment of the foreign-born (FB) population in the 10 most important immigrant receiving OECD countries around the year 2000. ${ }^{5}$ These 10 countries together host 86 percent of the around 76 million foreign-born individuals aged 15 and older that live in one of the 28 OECD countries for which data are available (data for Chile and Iceland are not available). Not surprisingly, given the heterogeneity in countries of origin and migration policies in place, there is substantial variation in the educational composition of the foreign-born population across destination countries. In Canada, for example, only 22 percent of the foreign-born aged 25-64 report lower secondary education ("low education") as their highest educational attainment, while in France, Italy and Spain about 50 percent of the foreign-born have at most completed lower secondary education. At the other end of the educational spectrum, the share of foreign-born individuals with tertiary education ("high education") exceeds 30 percent in Australia, Canada, the UK and the U.S., whereas in Germany and Italy, this share is below 20 percent. The composition of the foreign-born population in terms of their educational attainment becomes particularly relevant when seen in relation with the educational attainment of the native-born population (NB). Based on such comparisons, one can broadly divide the OECD destination countries into a group

\footnotetext{
${ }^{5}$ We report OECD data for the year 2000, as these are the most recent ones that include comparable information on educational attainment. With the exception of Germany and France, the overall stocks of migrants have further increased across the OECD countries listed in Table 1a between the year 2000 and 2008, with an overall growth rate of approximately 37 percent (based on data from the International Migration Database). The most noticeable change over this period took place in Spain where the foreign-born population more than tripled to around 6.4 million in 2008. However, with the exception of Japan, whose stock of foreign workers increased particularly fast in this period, the countries listed in Table 1a remain the main OECD destination countries also in 2008 .
} 
characterised by a high-skilled foreign-born population consisting of Australia, Canada, and the UK, and a group characterized by a low-skilled foreign-born population consisting of France, Germany, the Netherlands, Switzerland, and the U.S., with Spain's and Italy's foreign- and native-born populations showing relatively comparable educational structures. For example, in Australia, Canada and the UK, the share of the foreign-born population with high education exceeds the share of the native-born population with high education by 5.5 percentage points, 7.3 percentage points and 16.1 percentage points, respectively. On the other hand, in France, Germany and the U.S., the share of the foreign-born population with low education exceeds the share of the native-born population with only low education by 14.6 percentage points, 25.5 percentage points and 22.8 percentage points, respectively. ${ }^{6}$

\section{[Table 1a: Educational Attainment of Immigrants in receiving countries]}

But the relative educational attainment of the foreign-born in their destination countries is only one side of the coin. The other natural comparison group consists of the migrants' compatriots who have remained in their country of origin. Table $1 \mathrm{~b}$ provides some evidence for the 11 biggest immigrant-sending countries within the group of OECD countries. ${ }^{7}$ Though again subject to substantial variation, a prominent feature in these figures

\footnotetext{
${ }^{6}$ For a detailed analysis of worldwide international mobility by educational attainment, see Docquier and Marfouk (2006).

${ }^{7}$ The figures are constructed from OECD data by aggregating across all OECD countries all foreign-born by country of origin, restricting the sample of origin countries to OECD countries, and then selecting the 11 countries from which the largest number of foreign-born individuals originated. Since not all potential countries of origin are separately recorded for each OECD country, this is not entirely accurate, but, given that for each OECD country the most important countries of origin are separately reported (and often many more), this procedure should correctly pick up the 11 biggest OECD immigrant-sending countries. Of course there are additional important non-OECD countries of origin such as (in descending order) China, India, the Philippines, Russia, and Vietnam for which, however, we do not observe the educational attainment of the population in the home country in the OECD data.
} 
is that for the majority of origin countries, the share of movers with high education is substantially larger than the share of stayers with high education. For example, while about 23 percent, 22 percent, and 34 percent of the native-born British, French, and Americans still living in their country of birth have high education (Column (7)), the corresponding shares among the group of those who left these countries are 40 percent, 40 percent and 61 percent (Column (4)), respectively. It appears that for these countries of origin, the better-educated individuals are the more mobile ones. However, for other countries the picture looks different. For example, for Mexico, the main source country of U.S. immigration, the share of movers with only low education is relatively similar to that of the stayers (around 70 percent), whereas the share of movers with high education (around 7 percent) is significantly lower than in the group of stayers (15 percent). Turkey, which is the main country of origin for Germany, and Portugal exhibit similar patterns. For these countries, those who decide to emigrate appear to come predominantly from the middle of the educational spectrum.

\section{[Table 1b: Educational Attainment of Emigrants in Sending Countries]}

The aggregate figures in Table $1 \mathrm{a}$ and Table $1 \mathrm{~b}$ conceal the substantial variation in immigrants' educational attainment that exists across origin countries for any given destination country (Table 1a) and across destination countries for any given origin country (Table 1b). Focusing on the former, Table 2 shows for each of the 10 main immigrantreceiving OECD countries the foreign-born populations with the highest and lowest educational attainment. For instance, looking at the last row of the table, of all the main countries of origin of immigration to the U.S., the foreign-born originating from Mexico are the least well educated with about 69 percent having only low education (Column (3)). On the other hand, the most highly educated group in the U.S. are Indians of whom around 75 
percent have high education (Column (8)). For Germany, the country of origin with the highest share of immigrants with only low education is Turkey with 73 percent (Column (3)), compared to French immigrants of whom only 9.8 percent have low education (Column (1)). The (unweighted) standard deviations reported in Columns (5) and (10) provide a summary measure of the extent of educational heterogeneity of each countries' immigrant population across different countries of origin, showing that in many cases a given destination country attracts immigrants with high educational background from some countries, but with poor educational background from other countries.

\section{[Table 2: Variance/Min/Max of Share of Tertiary/Primary Education, by Country of Immigration/Country of Origin]}

Table 3 shows for each of the 11 main immigrant-sending countries in the OECD the destination countries that receive the highest and the lowest educated group of its emigrating population. For instance, looking at the first row of the table, only 5.0 percent of all Mexicans living in Sweden have low education (Column (1)), whereas this is the case for 69.0 percent of all Mexicans living in the U.S. (Column (3)). Similarly, only 7 percent of Poles living in the Czech Republic have high education (Column (6)) whereas the corresponding share in the UK is 48.7 percent (Column (8)). Clearly, highly heterogeneous subgroups of individuals from a given country of origin decide to move to specific host countries, as again summarised by the standard deviations reported in Columns (5) and (10). We will discuss possible reasons for these differences below.

[Table 3: Educational Attainment of same origin group in different destination countries] 
The educational attainment of the foreign-born population serves as a key indicator of their performance in the host country's labour market. However, even if the foreign-born population in a given host country is as well educated as the native-born population in terms of the level of formal qualification or completed years of schooling, they are unlikely to perform equally well in the labour market. The educational skills immigrants bring with them may not be easily transferable to the host country labour market (e.g. due to language deficiencies), and a highly skilled immigrant is unlikely to command the same wage as a native-born worker with the same educational background, at least in the first years after arrival.

We illustrate this in Column (1) of Table 4, which shows the median wage of the foreign-born relative to the median wage of the native-born in a selected set of OECD destination countries. Columns (2) to (4) show the corresponding wage ratios separately by education group. With the exception of Australia, the foreign-born earn overall less than the native-born, in particular in the U.S. where the median wage gap amounts to 21 percent. While in the lowest education group, immigrants tend to earn slightly more than comparable natives (with the exception of France and Sweden), they earn substantially less than natives in the medium- and high-education group. In Canada, France and Portugal, for example, immigrants with high education earn at least 10 percent less than natives with high education. Overall, wages of immigrants seem to rise more slowly with educational attainment than wages of natives, suggesting that immigrants face a lower return to schooling in the host country than natives do.

Columns (5) to (8) focus on the high education group and show relative wages of foreign-born men and women with high education, now distinguishing between individuals that received their tertiary education in their home country and those that received it in the host country. The difference between the relative returns reported here thus addresses, at least 
in part, the issue of transferability of human capital from the origin to the destination country. ${ }^{8}$ The less transferable the skills acquired in the home country, the lower their return relative to the return obtained from domestically acquired tertiary education. With the exception of men in France and Australia, the figures show that wages are always higher for foreign-born graduates with host country specific tertiary education, in some cases even exceeding the wages earned by native-born graduates with tertiary education.

[Table 4: Relative Median Wage, by country and education level]

\subsection{Migration and Acquisition of Education}

As pointed out in the previous section, it is important to distinguish between education acquired in the home country before migrating, and education acquired in the host country. In particular minors, who arrive together with their parents, and young adults, who immigrate to attend one of the host country's universities, add to their existing stock of human capital by acquiring further formal host country specific education. With education being a tradable good, some countries have specialized in its production. For instance, Australia's third largest export article (after coal and iron ore) is international education. ${ }^{9}$

\footnotetext{
${ }^{8}$ While a lack of transferability of human capital will be necessarily reflected in lower relative wage ratios, it cannot be easily distinguished from differences in the quality of education obtained because of different educational systems and institutions in the origin and destination countries. Although the OECD data reported in Tables 1 to 4 are based on the International Standard Classification of Education (ISCED 1997) which, in principle, is based on the educational content of the programmes assessed rather than institutional idiosyncrasies, an accurate and consistent measurement of actual educational achievements across different countries remains difficult (see also Hanushek and Zhang, 2009).

${ }^{9}$ In 2007/08, international education contributed 13.7 billion AUD to the Australian economy, measured through export earnings, which is the sum of international student expenditure on tuition fees, goods and services related to living in Australia and tourism associated with visits from relatives (see http://www.idp.com/research/statistics/education_export_statistics.aspx).
} 
This specialisation in the provision of educational services is apparent from Table 5, which shows for the 10 biggest immigrant receiving OECD countries the share of foreign students enrolled in tertiary education. Across all destination countries, foreign students constitute a significant fraction of the student population, with their share often exceeding 10 percent. In Switzerland and the UK, about one in five students is a foreign student, a fraction that increases further to around 45 percent when restricting attention to advanced research programs such as doctorates. In terms of absolute numbers, the UK and the U.S. are the two main destination countries for foreign students, hosting around 460 and 620 thousand students in 2008, respectively. Column (4) in Table 5 shows by how much the number of foreign students in tertiary education has changed over the decade between 1998 and 2008 . Across the board, foreign student numbers have increased substantially. This is not only true in countries that started from a relatively low base such as Italy and the Netherlands (where student numbers increased by 160 percent and 200 percent, respectively) but also in countries that were already popular destinations in 1998 such as Australia, the UK and the U.S. (where numbers increased by 111 percent, 121 percent and 45 percent, respectively). Overall, in the ten OECD countries listed in Table 5, the number of foreign students increased by 80.8 percent between 1999 and 2008 which, given an increase in the corresponding overall stock of immigrants over the same period of around 42.5 percent $^{10}$, indicates that the acquisition of formal education in foreign countries is not only a widespread phenomenon, but one that has also been rapidly gaining importance in recent years.

\footnotetext{
${ }^{10}$ The calculation of this figure is based on data from the International Migration Database and refers to the change of the sum of the foreign-born population in Australia, Canada, France, the Netherlands, Spain, and the U.S. and the population with foreign citizenship in Germany, Italy, Switzerland and the UK between 1999 and 2008. The missing immigrant stocks for Canada and France were linearly extrapolated from available figures in 2001 and 2006 (Canada) and 1999 and 2006 (France).
} 
The last column in Table 5 shows estimated retention rates of graduates in their host countries following the completion of their studies. While the calculation of these figures is not unproblematic (for details, see OECD, 2010), the estimates show that between 15 to 30 percent of all foreign graduates remain in their host countries after graduation, evidently to a large extent for work purposes. ${ }^{11}$ These numbers suggest that the acquisition of education in countries that have established themselves as "learning centres" is a main reason for migration, and that individuals choose to return to their countries of origin in order to apply the skills accumulated (see Dustmann et al., 2010a, for modeling of such migrations, and our discussion in Sections 3.2 and 4.3). Of course, these numbers may also partly be driven by regulations that do not allow individuals to remain after the completion of their studies. Indeed, in many countries, particularly in Europe, existing policies make it difficult for foreign students to stay and obtain a work permit. In recent years, the transition from study to work has been facilitated in many student destination countries, for example by enabling students to work while studying, or by extending the period granted to search for work following the completion of study (see ICMPD, 2006, for a comparative study on retention policies in a large number of industrialised countries). For instance, several countries have recently started to issue a special residence permit to foreign graduates for the purpose of seeking a job, including the UK (for one to two years, introduced in 2004/2005), Germany (for one year, introduced in 2005) and France (for 6 months, introduced in 2006). ${ }^{12}$ Other special provisions introduced to facilitate the transition from study to work for foreign

\footnotetext{
${ }^{11}$ Retention rates are calculated as the number of international students who change their legal migration status between 2006 and 2007, for example from "student" to "work" or to "family formation", divided by the number of international students who do not renew their student permit. On average 61 percent of international students change their status for work-related reasons (OECD, 2010).

${ }^{12}$ While in France and Germany these jobs have to correspond to the graduate's qualification and are subject to labour market testing, permit holders in the UK are free to take up any employment they like. Contrary to the U.S. and Canada, the applicants in these countries do not already need to have a job offer at hand.
} 
graduates include the allocation of extra points for a degree from a national institution of higher education (Canada, Australia and New Zealand), a waiver of an obligatory work experience record (Australia and the Czech Republic), the exemption from the regular quota for "key workers" (Austria), and a specific category with a special quota for foreign graduates (Australia, Italy, U.S.). These policy changes are a reflection of the increasing global competition in attracting and retaining highly skilled workers. Kato and Sparber (2010) show that students are indeed responsive to such immigration policies. Studying the effect of the sharp reduction in the number of available $\mathrm{H}-1 \mathrm{~B}$ visas - the primary means of legal employment for college-educated foreign nationals in the U.S. - in 2003, they find that this restrictive immigration policy has had a negative impact on the quality of prospective international applicants to U.S. colleges. The intuition is that only the high ability students are affected by the new policy since low ability foreign students are unlikely to find U.S. employment even in the absence of visa quotas. Faced with a reduced prospect of gaining access to the U.S. labour market after graduation, the "best and brightest" of the global talent pool appear to choose other host countries to provide them with both valuable education and the possibility of applying this education in the local labour market.

For the U.S., which is host to the largest number of foreign students in the world, there are no overall retention rates of graduate students available. However, Finn (2007) shows that for the group of foreigners who have earned a doctorate in an American university, the retention rate five years after they received their degree is around 65-70 percent. In a cross-country comparison, this is likely to be at the upper end of the spectrum of retention rates.

[Table 5: Foreign students currently in tertiary education in receiving countries] 
In terms of the students' origin, there is once again substantial heterogeneity across destination countries. Looking at Table 6, three factors appear important for the choice of students where to obtain education: geographical distance, language, and former colonial ties. For instance, the majority of students in Australia (79.3 percent) originate from Asia, and in particular from China, which supplies a quarter of all foreign students. In Europe, Italy and Switzerland are countries that attract mostly foreign students from other European countries whereas France has a large share of students from its former colonies in Africa (43.5 percent of which 25.5 percent are from Morocco and 17.7 percent from Algeria), and Spain has a relatively large share of students from Spanish-speaking South America (40.7 percent of which 21.4 percent are from Colombia and 16.7 percent from Peru). In the two biggest student-receiving countries, the UK and the U.S., most foreign students originate from Asia (39.5 percent and 67.2 percent, respectively, of which 28.1 percent and 26.3 percent are from China).

Figure 1 shows the development of the overall number of foreign students studying in the 10 main OECD destination countries listed in Table 5 between 1999 and 2008. There is a clear upward trend, in particularly from 2001 onwards, with student numbers increasing from a little more than 1.2 million in 1999 to more than 2.2 million in 2008. Most of this increase is driven by increasing numbers of students from Asia and, to a lesser extent, Europe and Africa. Although we cannot tell from these data whether these students came to their destination countries for the sole purpose of studying, or whether they already arrived as young children with their parents and are expecting a more permanent stay, the important role of many destination countries in providing education to non-citizens is clearly discernible.

[Table 6: Origin of foreign students]

\subsection{Return Migration}


The figures in the previous section suggest that many migrations today are undertaken for the purpose of acquiring education. According to the International Passenger Survey, for example, about 40 percent of all migrants arriving in the UK in the year 2009 cited as their main reason for migration the desire to pursue formal studies, up from around 23 percent in the year 2000. Migrations of this type are likely to be temporary. But temporary migrations are a more general phenomenon and widespread also among classical labour migrations. There are about 2.5 million temporary workers arriving in the OECD countries per year, mostly seasonal workers and young working holiday-makers with work permits for a duration of less than one year (OECD, 2008). The temporary character of these migrations has important implications for the type of immigrants' educational attainments and their investments in human capital as we will see in Section 3.3. While until recently the analysis of immigrants' earnings and human capital investments has largely assumed migrations to be permanent, modern migrations seem to be characterized by different patterns. Indeed, numbers suggest that a large fraction of the foreign-born population will at some point return to their home country.

One way to study the time dimension of migration is to look at the duration of stay in the host country. Columns (1) to (3) of Table 7 show the share of the foreign-born population in the main OECD destination countries that have been in their host country for less than 5 years, more than 10 years, and more than 20 years. Clearly these cross-sectional figures can only be indicative of the temporary nature of migrations since, for example, a high share of short durations could be either due to actual short migration durations or due to a large number of very recent arrivals (as, for example, in the case of Italy and Spain). However, with the exception of France, the share of migrants that have already been living in their host countries for more than 20 years (and could therefore be considered as permanent) does hardly ever significantly exceed 50 percent. In the U.S., for example, only 35.7 percent of the 
foreign-born population has already lived in the country for more than 20 years. As these figures may be driven by changing cohort sizes of the inflows of immigrants, it is useful to look at the outflows of the foreign populations from their host countries. Column (4) in Table 7 shows the outflow/inflow ratio of foreign nationals over the period 1998 and 2008. This ratio ranges from 9.8 percent in Australia, over 51.3 percent in Switzerland, to 86.0 percent in Germany. This suggests that there are indeed significant flows of foreign individuals out of their host countries. These out-migrations may be back to the countries of origin, but could also be to an alternative host country. Outflow/inflow ratios are still only a crude measure of return migration, as they do not necessarily relate to the same individuals. For a more precise measure, one requires data that follow immigrant entry cohorts over time. Column (5) in Table 7 provides some estimates of the share of foreign-born individuals that re-emigrate from their host country within the first 5 years of arrival. The estimates show the generally substantial extent of re-emigration, ranging from 19.1 percent in the U.S. to 39.9 percent in the UK. ${ }^{13}$ Evidently, relatively short migration spells are a widespread phenomenon and, although the destination of the re-emigrating population is generally not observable, one can assume that a large fraction constitutes return migration to the country of origin. ${ }^{14}$ As we will see later, this particular migration pattern has important implications for an immigrant's

\footnotetext{
${ }^{13}$ The OECD also provides corresponding re-emigration rates for Ireland (60.4 percent), Belgium (50.4 percent) and Norway (39.6 percent). Additional studies that estimate comparable 5 year re-emigration rates are Borjas and Bratsberg (1996) for the U.S. (17.5 percent), Bijwaard (2004) for the Netherlands (35 percent), Shortland (2006) for New Zealand (23 percent), Dustmann and Weiss (2007) for the UK (40 percent males, 55 percent females), Bratsberg et al. (2007) for Norway (50 percent), Jensen and Pedersen (2007) for Denmark (55 percent), and Aydemir and Robinson (2008) for Canada (23.7 percent, males).

${ }^{14}$ Nekby (2004) is one of the few who distinguishes between return migration and secondary migration to a third country, using data for Sweden for the period 1991 to 2000. According to her results, the share that constitutes return migration is around 90 percent for Nordic immigrants, 70 percent for Western Europeans and North Americans, 50 percent for Eastern Europeans, 40 percent for Asians, and around 30 percent for Africans. Bratsberg et al. (2007) estimate the return migration share for Norway and find similar magnitudes. Over the period 1967 to 2003, the share of those who left Norway to return to their home country is 93 percent for Danes and Swedes, 86 percent for U.S. Americans, 87 percent for UK immigrants, 78 percent for Turks, 81 percent for Iraqis, 70 percent for Somalis, and 33 percent for Vietnamese immigrants.
} 
behaviour both in the host and in the home country, and therefore requires particular attention. For an informative overview of the return migration issue including a detailed description of methodological approaches to measure it, see OECD (2008, Part III).

[Table 7: Return migration (after 5 years); ratio inflow/outflow]

\subsection{The Next Generation}

The focus of the descriptive evidence presented so far has been on the educational attainment and investment as well as the labour market performance of the working-age immigrant population. Given that a substantial fraction of immigrants will remain in the host country for a considerable amount of time, their children, whether born in the home country before arrival or thereafter, will spend a large part or even their entire childhood in the host country, passing through its educational system and making educational investment decisions along the way. These decisions have wider consequences, not only for the performance of this next generation of immigrants in both the host and - in the case of a later return migration - the home country, but also for the host country more generally, for example through the immigrants' impact on the fiscal balance (see, for example, Storesletten, 2000, and Dustmann et al., 2010b) or their integration prospects (see, for example, Constant and Zimmermann, 2008). Given the often substantial differences in family backgrounds and language proficiencies, it is not surprising that in many destination countries immigrant children do significantly worse at school than their native counterparts. To illustrate this, we use data from the PISA (Programme for International Student Assessment) study that provides internationally comparable measures of proficiency in reading, mathematics and science of students aged 15 in 18 OECD countries, as well as information on a large set of 
student and school characteristics. ${ }^{15}$ Table 8 shows the raw differences in test scores in reading and mathematics between native children and children with an immigrant background, which include both children born abroad and children born in the host country. Both in reading and in mathematics, students with an immigrant background score significantly lower than native students. With an average native score in these tests of about 500 , the test score gaps are substantial with a relative magnitude of around 10 percent in a number of countries (Germany, Italy, the Netherlands, and Switzerland). The only exceptions to these patterns are Australia, Canada and, to a lesser extent, the UK, where students with an immigrant background do as well as, or better (in the case of Australia), than their native student counterparts. An obvious explanation for this heterogeneity across destination countries is the difference in socio-economic characteristics between the corresponding immigrant populations, largely driven by the selectiveness of each host countries' migration policies. Australia, Canada, and the UK are all countries that have been applying a point system to select the immigrants they admit which strongly favours individuals with characteristics conducive to their performance in the labour market, such as education and language skills. Through the intergenerational transmission of human capital, these beneficial characteristics are likely to be reflected in their children's performance at school. For illustration, we report the test score gaps (relative to natives) of students with an immigrant background that do not speak the language of instruction at home in Columns (3) and (4) of Table 8. In all but three cases (Canada, Italy and Spain in mathematics), these gaps are substantially larger than the gaps for the entire immigrant student population. For example, in the UK, those who do not speak English at home score 36.5 points below the native average in reading and 26.6 points below the native average in mathematics while overall the test

\footnotetext{
${ }^{15}$ For detailed information on the PISA study, see OECD (2007).
} 
score gaps only amount to 11.5 and 14.6 points respectively. We will analyse the role language and parents' education play in explaining the achievement gaps between immigrant and native students more systematically in Section 5.3.

\section{[Table 8: Pisa Results]}

Do the lower test scores of immigrant children at age 15 carry over into their adulthood? One measure to assess this is to compare the average school leaving age of firstand second-generation immigrant adults relative to the native population. Figure 2 reproduces estimates for men obtained by Algan et al. (2010) for France, Germany and the UK using the latest available data sources. The corresponding results for women show broadly similar patterns. The differences in the average age left education shown in the left-hand side scatterplot are estimated coefficients on dummy variables for the main immigrant groups in each country, obtained from a censored linear regression. Additional controls in these regressions are a quadratic in year of birth, region dummies and time dummies. Each point represents the educational gap relative to natives of first-generation immigrants (x-axis) and second-generation immigrants (y-axis) for a particular country (or country group) of origin. For reference, we include a 45-degree line as well as a fitted linear regression line. The scatterplot shows that for those immigrant groups in Germany and France who started with the biggest disadvantage relative to natives there is some improvement in the educational attainment from one generation to the next (in the sense of a later age at which individuals leave education). However, there is still a significant difference in schooling remaining for these groups in the second generation. This persistence in educational differences between natives and immigrants translates into differences in labour market outcomes, as illustrated in the right-hand side scatterplot in Figure 2, which shows estimated relative earnings gaps, again taken from the Algan et al. (2010) study, where the only included control variables in 
the estimated linear earnings equations are a quartic in potential experience, region dummies and time dummies. Most importantly, the regressions do not control for the differences in educational attainment illustrated in the left-hand side scatterplot. The figures show that for most immigrant groups there is some improvement in earnings from one generation to the next, in part due to the improved educational attainment. However, the majority of adult second-generation immigrants in these countries still experience a substantial wage disadvantage (of the order of 10 percent on average) relative to their native counterparts. Both scatterplots also reveal a significant correlation between first- and second-generation immigrants' education levels and earnings. Despite some convergence, those immigrant groups that started with the biggest disadvantage relative to natives in the first generation continue to be the most disadvantaged in the second generation. We will get back to this issue in our discussion of intergenerational mobility of immigrants in Section 5.

[Figure 2: Trend Education of $2^{\text {nd }} / 1^{\text {st }}$ generation immigrants, selected countries]

\section{The Migrant}

\subsection{The Migration Decision and Human Capital Investment}

In this section, we investigate the key drivers of individuals' decisions of whether or not to emigrate, whether and when to return, and how these decisions interact with decisions about education and skill acquisition. In its simplest possible form, the migration decision is based on a comparison of expected lifetime earnings in the current region of residence and in an alternative region, to which the migrant has the possibility to emigrate. In most cases, 
there is more than one possible destination region in the choice set of potential migrants. For simplicity, we will abstract from that, and consider only one potential destination country. ${ }^{16}$

What are the factors that determine the emigration decision? Abstracting for the moment from amenities that arise from living in the home or potential host country, the decision problem of the potential migrant is based on the comparison of the net monetary returns of that decision. In the simplest possible model, where migrations are permanent and the acquisition of human capital is completed before the migration, these will depend on the skill prices in the origin and destination country, as well as the degree to which skills acquired in the origin country are transferable to the economy of the destination country. In a more dynamic setting, the migrant compares lifetime net discounted earnings in the two countries, allowing for the possibility that additional human capital investment is undertaken.

After migration, individuals will potentially acquire further skills in the host country. As skills obtained in the home country are not always fully transferable to the host country labour market, new immigrants should have lower earnings than natives, even when they belong to the same skill group as measured, for instance, by the years of schooling obtained. However, the subsequent transfer of existing skills, facilitated, for example, through the acquisition of complementary skills like language, and the acquisition of new skills lead to an increase in earnings, possibly at a faster rate than that of comparable native workers. A large literature has developed around measuring this process (starting with Chiswick's 1978 seminal paper), and we will review some of this literature in Section 3.4.

As we have shown in Section 2, many migrations are temporary, with immigrants remaining for a limited amount of time in the host country, and then returning back home.

\footnotetext{
${ }^{16}$ Papers by Dahl (2002), Grogger and Hanson (2008), Bishop (2008), Ortega and Peri (2009), Kennan (2010) and Kennan and Walker (2010) consider the choice problem of individuals when deciding between more than one potential destination region.
} 
This behaviour can be optimal despite consistently more favourable economic conditions in the destination country (see Dustmann, 2003, and Dustmann, 1994a, 1995, for an early analysis of different return motives). But if immigrants plan to return to their home countries (or to move on to a third country), then this may affect many aspects of their behaviour, including their human capital investment. In particular, any investment decisions into further skills will now depend not only on the return to these skills in the host country, but also on the return to these skills back in the home country. Differences in the expected duration of migration introduce heterogeneity into the earnings paths of immigrants that are identical in all other measurable characteristics (such as age, education, and past employment history). Thus, understanding the distinct forms of migration is key to understanding immigrants' human capital investment behaviour.

Return decisions may be driven by preferences (if, for instance, the home country provides the migrant with amenities that are valuable itself or complementary to consumption) or purchasing power considerations (if, for instance, the host country currency has a high value in the home country). However, they may also be the outcome of an optimising strategy that consists of obtaining human capital in the destination country in order to apply it in the origin country. Examples of this type of human capital are university education or foreign language skills. In that case, return migration is the outcome of an optimal human capital investment plan over the individual's life cycle. In addition, the possibility of a migration later in the individual's life may already induce human capital investment in the home country. One reason may be that skills acquired at home have a high return in the host country. Another reason may be that skills acquired at home are a prerequisite for the possibility to acquire further valuable skills abroad, either directly because of minimum education requirements due to immigration policies or because of the sequential nature of skill accumulation. 


\subsection{A Simple Model of Return Migration and Investment in Human}

\section{Capital}

In what follows, we set up a simple model that serves to clarify some key ideas of migrants' decision processes. The model shows how individuals reach a decision of whether or not to emigrate and how this decision is intricately linked to the human capital they accumulate over their life cycle. It illustrates how the possibility of a temporary migration affects optimal human capital investment profiles, what these profiles imply for individuals' earnings and their growth over time, and how these patterns depend on initial observable skills and ability. The model will also help us to structure the vast empirical literature that exists on migrants' education- and skill investment decisions in their home and host countries. This literature has focussed particularly on the analysis of earnings profiles of immigrants as a reflection of their human capital investments, on how these profiles depend on the time horizon of the migration as well as the language proficiency of the migrant, and on the issues of skill transferability, skill downgrading, and the role of ethnic networks.

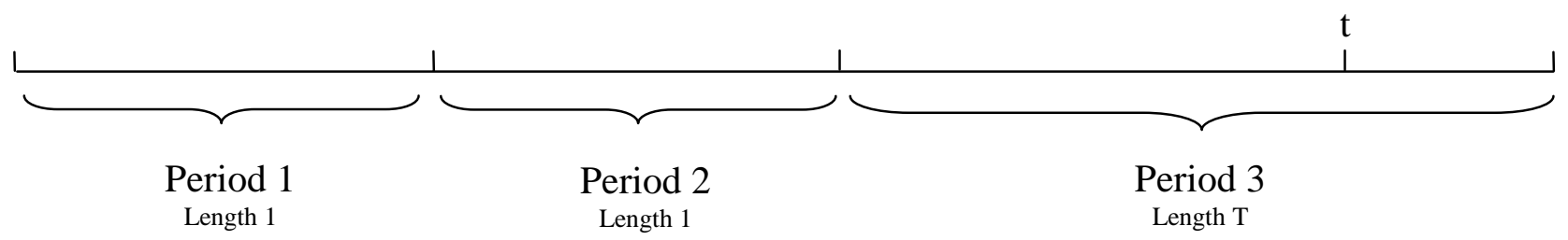

Figure 3: Timing of Model 
Our model has essentially three periods. Life is finite and time flows continuously. The duration of life is $\mathrm{T}+2$. We have illustrated the timing of the model in Figure 3 . The first two periods are "learning periods", and they are of unit length. In period 1, individuals live in the home country. In that period, individuals do not work, but can acquire education, and choose how much to acquire. Acquisition of education is costly, and individuals differ in their efficiency to acquire education. After the first period, individuals decide whether or not to emigrate. ${ }^{17}$ In the second period, individuals live either in the home- or in the host country, depending on whether they have chosen to emigrate after the first period. During this second period, individuals have another opportunity to acquire education. They divide their time between learning, and working in the labour market. Thus, abstracting from direct costs of education such as fees, the cost of acquiring further education is equal to the opportunity cost of forgone earnings. We think about this period as a period where post-secondary education is obtained. This may take the form of vocational training or college education. The third period has length $T$. If individuals decide not to emigrate after period 1 , they will spend both the second and the entire third period in the home country. If individuals decide to emigrate, then they have the possibility to return to the home country either right after the second period, or after a duration $t$ in the host country, with $t \leq T$. Therefore, the length of the migration is given by $t+1$, and the remaining time in the home country after re-migration is $T-t$. A permanent migration corresponds to the case where $t=T$.

In case no migration takes place, individuals stay at home until death, which occurs at $T$. Although there is no explicit learning in the third period, we allow the return back in the home country of human capital acquired in the host country in period 2 to increase with the length of stay in the host country.

\footnotetext{
${ }^{17}$ For simplicity, we assume that immigrants have only the opportunity to emigrate after the first period.
} 
In our model, individuals make a number of choices. These choices are made at the start of the first period, and at the start of the second period. To solve the model, we first consider the decision problem at the start of the second period. In case that no migration takes place, the individual decides about the optimal investment in learning in the home country in period 2. In case a migration does take place, the individual decides about the optimal investment in learning in the host country as well as the optimal time to spend in the host country. Given these decisions, we then go back to the start of the first period, where individuals decide about the optimal investment in their education while they are still in the home country. This decision depends on the returns to any such investment in the future, given the optimal decisions about human capital investment and the duration of migration at the start of the second period. Finally, the migration decision is based on a comparison of the net present value of their lifetime earnings if migration does or does not take place.

We will first consider the decisions at the start of the second period. We will then consider the educational investment decision before a potential migration has taken place, and the migration decision itself.

\subsubsection{Skill Enhancement and Return Decisions of Migrants}

In case migration takes place, the individual maximises period 2 and period 3 earnings by choosing the optimal investment in period $2, s_{D}^{*}$, and the optimal time of return, $t^{*}$ :

$$
\max _{s, t} F^{D}(s, t)=\omega_{D} X(1-s)+t\left[\omega_{D}(X+f(s, A, X))\right]+(T-t)\left[\omega_{O}(X+\gamma(t) f(s, A, X))\right],
$$


where $\omega_{j}, j=O, D$, is the rate of return to human capital $X$ (acquired in the home country in period 1) in either origin country $O$ or destination country $D, s$ is the time investment in human capital acquisition in the second learning period (the first period in the host country in case of a migration), and $t$ and $T$ denote the time in the host country and the total length of the last period of life, respectively. We assume throughout this section the typical case in which $\omega_{D}>\omega_{O}$. The function $f(s, A, X)$ translates human capital investment $s$ in the host country in the second period into skills, where $A$ is the ability of the individual. We make the following standard assumptions: $f_{s}>0, f_{s s}<0, f_{s A}>0$, $f_{s X}>0, f(0, A, X)=0$. This means that skills are produced with decreasing returns, and that ability and the existing stock of human capital are complementary to the production of new human capital (see Ben-Porath, 1967, and, for empirical evidence of such complementarity, Chiswick and Miller, 1994, or Friedberg, 2000). The parameter $\omega_{o} \gamma(t)$ is the rate of return to human capital, acquired in the host country, back in the home country. Notice that $\gamma(t)$ may increase with the time the migrant stays abroad after the second learning period, which reflects the possibility that staying abroad increases immigrants' rate of return on human capital in the home country through on-the-job learning. Note further that if $\gamma(0)<\frac{\omega_{D}}{\omega_{O}}$, human capital acquired in the host country in the second period, is less valuable back home at the beginning of the third period than in the host country. Conversely, if $\gamma(0)>\frac{\omega_{D}}{\omega_{O}}$, human capital acquired in the host country has a higher return back home.

In case migration does not take place, the individual only decides about human capital investment in the second period, $s_{O}^{*}$ : 


$$
\max _{s} F^{o}(s)=\omega_{O} X(1-s)+T\left[\omega_{O}(X+g(s, A, X))\right]
$$

where $g(s, A, X)$ translates human capital investment in the home country in the second period into skills and is subject to the same standard assumptions as $f(s, A, X)$.

In this model, return migration is induced by the possibility to acquire human capital in the host country that is yielding a high rate of return in the home country (see Dustmann, 1994a, 1995, Borjas and Bratsberg, 1996, Domingues Dos Santos and Postel-Vinay, 2003, and Dustmann et al., 2010a, for a similar formulation). ${ }^{18}$ A return to the home country may happen at the beginning of the third period if $\gamma(0)>\frac{\omega_{D}}{\omega_{O}}$. An example are "student migrations", where a migration takes place to acquire skills abroad that have a higher return in the home country. ${ }^{19}$ Return migration can also be induced by a high return in the home country to human capital acquired in the host country "on the job". ${ }^{20}$ In our model, this is

\footnotetext{
${ }^{18}$ We will only discuss human capital accumulation as a return motive in this chapter. There are other motives for why immigrants may want to return, such as higher purchasing power of the host country currency in the home country, or consumption amenities in the home country. See Dustmann (1994a, 1995) for a detailed discussion.

${ }^{19}$ There is relatively little direct empirical evidence on the returns of foreign education in the home country of an immigrant after he or she returned. One obvious problem for empirical analysis is selection of both those who decide to study abroad and those who return to their home country, which makes it difficult to identify a causal effect. Oosterbeek and Webbink (2006) exploit a discontinuity in the awarding of a specific grant to Dutch students for studying abroad. Their OLS estimates show a wage gain for graduates who studied abroad of around 4 to 7 percent relative to graduates who did not. However, their RD estimates, though of broadly similar magnitude, are inconclusive due to large standard errors. Wiers-Jenssen and Try (2005) find a wage premium for Norwegian workers who graduated abroad of around 3.5 percent while Palifka (2003), using survey data covering a complete cohort of graduates from a single Mexican university, finds a premium of around 20 percent six months after graduation for graduates who spent at least some time studying abroad.

${ }^{20}$ There is evidence that, for migrants who returned to their home country, work experience acquired abroad enhances earnings by more than work experience acquired in the home country. Reinhold and Thom (2009) analyse earnings of Mexican emigrants who returned from the United States. They find that, for these immigrants, the labour market experience accumulated in the U.S. increases earnings by twice as much as experience accumulated in Mexico. Papers by Barrett and O'Connell (2001) and Iara (2006) report similar findings for Ireland and migrants who returned to Eastern Europe from Western European countries. Co et al. (2000) report a wage premium for having been abroad for female return migrants to Hungary.
} 
reflected by $\gamma^{\prime}(t)>0$. Even if $\gamma(0)<\frac{\omega_{D}}{\omega_{O}}$ so that an immediate return after period 2 is not optimal, returning before $T$ may be an optimal strategy.

\subsubsection{Skill Investment in the Home County}

After having chosen the optimal duration abroad $t^{*}$ and the optimal investment in learning $s^{*}$, where we denote the payoff of these choices as $F^{D}\left(t^{*}, s_{D}^{*}\right)$ in case of emigrating and $F^{O}\left(s_{O}^{*}\right)$ in case of not emigrating, we will now consider the first period problem. Before making the migration decision, individuals have the possibility to acquire education in the home country in the first period. To allow for this, we will make $X$, the human capital stock after the first period, a function of first period investment $i: X=X(i)$. We assume that skills acquired in the first period are concave with respect to investment: $X_{i}>0, \quad X_{i i} \leq 0$. The choice of $i$ will depend on the possibility of a future migration. In case of migrating, the value function is then given by

$$
\text { (3) } \quad V^{D}=\max _{i} F^{D}\left(s_{D}^{*}(i), t^{*}(i), i\right)-C(i, A) \text {, }
$$

where $C(i, A)$ is the cost of investing into education in the home country, which has the properties $C_{i}>0, C_{i i}>0, C_{A}<0, C_{i A}<0:$ costs are increasing in investment, convex, and lower as well as increasing at a slower rate for high ability individuals. In case of remaining in the home country, the value function is given by

(4) $\quad V^{O}=\max _{i} F^{O}\left(s_{O}^{*}(i), i\right)-C(i, A)$. 


\subsubsection{The Migration Decision}

The choice whether or not to migrate will depend on the comparison of the optimal value functions:

$$
V=\max \left[V^{D}-k+\eta_{D}, V^{O}+\eta_{o}\right]
$$

Assume that $\eta_{j}, j=O, D$, are iid extreme value distributed error terms capturing heterogeneity in the choice, and $k$ are the cost of migration. It follows that for a given individual the probability of a migration is given by

$$
\operatorname{Prob}_{\text {migrate }}=\frac{1}{1+e^{V^{O}+k-V^{D}}} .
$$

Thus, if we assume that abilities follow a distribution $G$, with support $[0, \bar{A}]$, then the proportion of individuals who migrate from country $O$ to country $D$ is given by

$$
\text { Proportion }_{\text {migrate }}=\int_{0}^{\bar{A}} \operatorname{Prob}_{\text {migrate }}(A) d G(A) \text {. }
$$

This model is simple, but instructive, as it allows for a variety of cases that have been studied in the empirical literature. For a permanent migration, the second period problem in (1) corresponds to the simple human capital model that underlies the early empirical papers on immigrant assimilation (see, for example, Chiswick, 1978). Adding the possibility of return migration with a pre-determined migration period leads to more complex empirical specifications, as we will illustrate below. The problem becomes even more difficult if the migrant chooses the time of return optimally. The model also allows consideration of the relationship between migration and return migration, and human capital accumulation in the host country. It includes the special case of student migrations, where some countries are "learning centres", as documented in Table 5, and provide education that has a high return in the home country. 
The choices made in the first period add additional insight into learning incentives induced by migration possibilities. For instance, acquisition of education in the home country in the first period may be a pre-requisite for acquiring further and higher education in the host country in period 2. Furthermore, the model allows for the possibility that human capital in the home country is acquired because it has a high return in the host country. In the following section, we will explore some of the implications of this model for empirical work. We will then discuss the empirical literature, using the model as a framework of reference.

\subsection{Implications of the Model}

\subsubsection{The Optimal Investment in Skills and the Optimal Migration Duration}

We first consider the problem of the individual at the beginning of the second period. For those who do not migrate, the optimal investment in the second period $s_{O}^{*}$ is simply obtained by differentiating (2) with respect to $s$ and equating the additional forgone earnings in the learning period from an extra unit of time investment, $\omega_{O} X$, to the benefit arising from a higher earnings potential in the subsequent period, $\omega_{o} g_{s} T$.

For those who migrate, the problem at the beginning of the second period corresponds to the decision about how much to invest in host country human capital, and when and whether to return to the home country. The FOC's are given by

$$
\begin{gathered}
\frac{d F^{D}(s, t)}{d s}:-\omega_{D} X+f_{s}\left[t \omega_{D}+(T-t) \gamma(t) \omega_{O}\right]=0 \\
\frac{d F^{D}(s, t)}{d t}: \omega_{D}(X+f(.))-\omega_{O}(X+\gamma(t) f(.))+\omega_{O}(T-t) \gamma^{\prime}(t) f(.)=0 .
\end{gathered}
$$

The equilibrium condition for the optimal investment in human capital while being in the host country in Equation (6-a) says that the cost in terms of forgone earnings in the 
learning period from an additional unit of time investment (first term) must be equal to the benefit arising from a higher earnings potential in the subsequent period (as in the case of no migration). This, in turn, depends on the time spent in the host country $t$, on the increase in productivity in the second period through investments in human capital in the first period $f_{s}$, and on the transferability of human capital acquired abroad to the home country labour market $\gamma(t)$, which may depend on the time spent in the host country.

The optimal migration duration derived from Equation (6-b) depends - for the optimally chosen human capital investment - on a comparison between spending a marginal unit of time in the host country, and spending the same unit of time back in the home country. The individual chooses the optimal $s$ and $t$ simultaneously. The optimal human capital investment $s_{D}^{*}$ will change in response to changes in exogenous parameter (for instance the rent on human capital $\omega_{D}$ ) directly, and indirectly, because any parameter change affects the optimal migration duration, $t^{*}$, which in turn changes investment. Given our assumptions about $f($.$) and \gamma(t)$, it is straightforward to show that, in case of an interior solution, a unique optimum for $s$ and $t$ exists. To derive the comparative statics is likewise straightforward. We will now investigate some special cases, which relate to the empirical literature in the area.

\subsubsection{Permanent Migration}

Assume first that the migration is permanent, i.e. $t=T$. One way to generate a permanent migration in our model is to assume that $\gamma=1, \quad \gamma^{\prime}=0$, and $\omega_{D}>\omega_{O}$ : human capital acquired abroad has the same value at home, the value is not increasing with experience abroad, and the rental rate on human capital is higher in the host country. In that 
case, the optimal investment in human capital during the second period is chosen so that $\omega_{D} X=\omega_{D} f_{s} T:$ forgone earnings in the second period are equalised to the gain from human capital investment in the third period. Given our assumptions of the function $f($.$) , we$ immediately obtain a number of results: First, human capital investment $s$ in the host country increases in $T$. A direct implication of this is that immigrants who arrive early in life will invest more into their skills, as their pay-off period is longer (Friedberg, 1992, Schaafsma and Sweetman, 2001, and Wilkins, 2003, explore this issue empirically). Secondly, investment may increase or decrease with the stock of human capital $X$ upon arrival. Well-educated immigrants may lose considerably when spending time in learning activities. On the other hand, as human capital is productive in its own production, well-educated immigrants acquire additional skills more effectively. The larger the complementarity between skills upon arrival and acquisition of additional skills ( $\left.f_{s X}\right)$, the more likely it is that human capital investment after immigration is higher for well-educated immigrants (see Borjas, 2000, for a detailed discussion). Finally, the higher the ability $A$ of immigrants, the higher is their human capital investment. $^{21}$

How is wage growth for permanent migrants in the host country related to these parameters? Wage growth from period 2 to period 3 is given by $\Delta w=\omega_{D}(f()+.s X)$. Thus, for a given investment $s$, wages grow faster the higher the skills the individual has upon arrival. However, the effect of an increase in the initial skill level at arrival on skill investment itself is ambiguous, so that the overall effect of higher education upon arrival on wage growth is

\footnotetext{
${ }^{21}$ The results follow from totally differentiating (6-a) after setting $t=T$, where the total differential is given by $d s f_{s s} T=d x\left(1-f_{s X} T\right)-d T f_{s}-d A f_{s A} T$.
} 
likewise ambiguous. ${ }^{22}$ Wage growth is unambiguously positively related to the level of the immigrant's ability, as this raises third period wages per unit of investment, and human capital investment itself. Finally, wage growth is higher for immigrants who arrive at a younger age, as their investment in the first period is higher. Thus, our simple model predicts that immigrants who are positively selected in terms of ability should experience higher wage growth. Furthermore, immigrants who are younger at arrival have steeper wage profiles. The effect of the level of initial skills on the final investment is ambiguous. We will contrast these results with the empirical literature in Section 3.4.

\subsubsection{Temporary Migration}

The next case we will consider is that of a temporary migration, where the length of the migration period is exogenously determined. This could, for instance, be the result of a contract migration, or migrations that are restricted to a limited time period for other reasons. Let $\bar{t}$ denote the exogenously set migration duration We assume that the optimally chosen migration duration would be longer than the pre-determined one, so that the constraint is binding, and (for simplicity) that $\gamma(\bar{t})=\gamma<\frac{\omega_{D}}{\omega_{O}}$ so that human capital acquired in the host country is less valuable back home than in the host country. ${ }^{23}$ In that case, the optimal investment in skills $s$ is chosen so that $-\omega_{D} X+f_{s}\left[\bar{t} \omega_{D}+(T-\bar{t}) \gamma \omega_{O}\right]=0$.

${ }^{22} d \Delta w_{D}=\omega_{D}\left[\left(f_{X}+s\right)+\left(f_{s}+X\right) \frac{d s}{d X}\right] d X$

${ }^{23}$ We do not consider here the case $\gamma>\frac{\omega_{D}}{\omega_{O}}$, as this may lead to a return before $\bar{t}$. 
As before, investment into human capital increases in ability $A$, and the effect of a higher level of skills upon arrival is ambiguous. Furthermore, an increase in the migration duration $\bar{t}$ increases human capital investments: the longer immigrants are allowed to stay in the host country, the higher is their human capital investment in host country specific skills. Finally, notice that investments in human capital depend on the degree to which these skills are transferable to the home country labour market, i.e. the magnitude of $\gamma$. If $\gamma$ is small, then, for any given migration duration $\bar{t}$, investments will be low. It is immediately obvious that temporary migrations pose a serious problem for empirical analysis: as we will discuss below, both $\bar{t}$ and $\gamma$ are usually not observed. Both introduce heterogeneity in earnings profiles that is likely to be correlated with many of the typical regressors in an earnings equation.

We can now again investigate wage growth from period 2 to period 3 in the host country. As before, individuals with higher ability $A$ will have faster wage growth, and the effect of an increase in the skill level $X$ upon arrival is ambiguous. However, wage growth will now be the larger the higher the transferability of human capital from the host country labour market to the home country labour market, $\gamma$. Furthermore, wage growth will be steeper the longer the contract migration period $\bar{t}$. Thus, if migrations are non-permanent, there will be heterogeneity in the slope of immigrant's wage profiles which is determined by the transferability of human capital, as well as the length of the migration period.

\subsubsection{Choosing the Optimal Migration Period and Investment in Human Capital}

So far we have assumed that the migration is permanent, or that $t$ is exogenously given. We will now relax that assumption. The optimal migration period is determined by condition (6-b) in conjunction with the choice of the optimal second period investment $s$ : 
The first term in (6-b)' is the return to each unit of time spent in the country of destination. It is constant for the optimally chosen $s$. The second term is the opportunity cost of staying abroad: it is the forgone earnings in the home country by staying abroad. If $\gamma^{\prime}(t)>0$, then this term increases with $t$. Finally the third term is the additional gain from staying one more unit of time abroad through accumulation of additional skills that increase the value of human capital in the home country. If $\gamma^{\prime \prime}(t) \leq 0$, this additional gain will unambiguously decrease with time $t$ spent in the host country. The reason is that although on the job experience in the host country is valued back home, there is less and less time remaining to reap the returns from applying human capital acquired in the host country back in the home country.

In our simple model, and assuming that $\omega_{O}<\omega_{D}$ (i.e. the rental rate on home country specific human capital is higher in the host country), a return migration will occur for two reasons. First, the return on human capital acquired in the second period in the host country is higher at home, $\gamma(0)>\frac{\omega_{D}}{\omega_{O}}$, and the accumulation of home country relevant skills by staying in the host country is sufficiently slow, so that directly after the second period $\omega_{D}(X+f())<.\omega_{O}(X+\gamma(0) f())-.\omega_{O} T \gamma^{\prime}(0) f($.$) . In this case, the (constant) marginal gain$ from delaying return by one period is lower than the marginal cost of staying. Although emigration itself is optimal after the first period, the individual decides to return immediately after the second period. This situation is depicted in the left panel of Figure 4 below. Migrations that are characterised by this pattern are student migrations, or migrations that 
take place predominantly for the purpose to acquire particular skills or experience in the country of destination. In Column (5) of Table 5 in Section 2, we demonstrate that these student migrations are frequent, and that many - typically around 70 percent - are terminated after education has been acquired.

But even if $\omega_{D}(X+f())>.\omega_{O}(X+\gamma(0) f())-.\omega_{O} T \gamma^{\prime}(0) f($.$) (which means that it is$ optimal for the migrant to initially remain in the host country after the second period), a return migration may occur if human capital acquired while working abroad increases the earnings potential of the immigrant in her home country $\left(\gamma^{\prime}(t)>0\right)$. In this case, the marginal costs of staying in the host country increase with time spent there due to the increasing forgone earnings in the home country, and the immigrant may choose an optimal $t^{*}$ so that $0<t^{*}<T .^{24}$ The right panel of Figure 4 illustrates this situation.

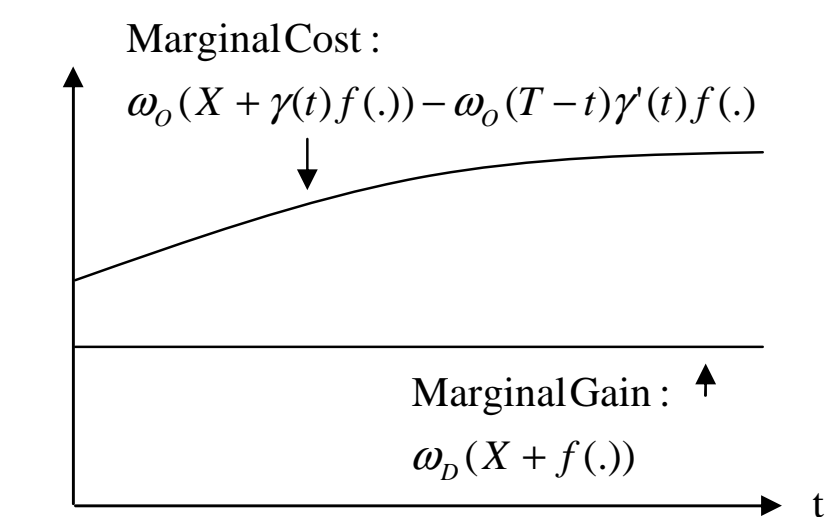

$t^{*}=0$

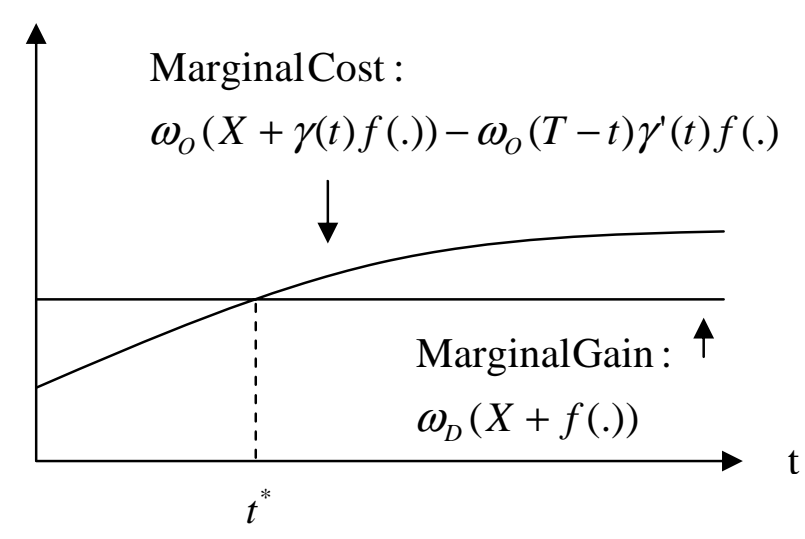

${ }^{24}$ A sufficient condition for the marginal costs of staying to be increasing in $t$ is that $\gamma^{\prime \prime}(t) \leq 0$ : the gain from remaining an additional unit of time abroad (in terms of enhancing the home country skill stock) decreases with time in the host country. 


\section{Figure 4: Immediate and Postponed Return Migration}

It is apparent that, if the return time is optimally chosen, the analysis of immigrants' earnings paths becomes more complex than before, as the optimal migration duration may affect human capital investment, and is in turn affected by the optimal skill accumulation. The earnings paths of immigrants who choose their migration duration optimally will therefore depend on parameters that determine their return choice as well. This further complicates the analysis of immigrants' earnings profiles, as we will discuss below. ${ }^{25}$

\subsubsection{Choosing the Optimal Investment in Learning in the First Period}

So far we have not considered the decisions in the first period. Having solved the second period problem by choosing the optimal migration period $t^{*}$ and the optimal investment $s^{*}$, the individual will now choose the optimal investment in learning in the first period. Assuming that individuals are endowed with a base level of productivity (which could include compulsory schooling: $X(0)=X^{0}$ ), the optimal investment in the case of migrating is given by (invoking the envelope theorem):

$\omega_{D}\left(1-s_{D}^{*}(i)\right) X_{i}+t^{*}(i) \omega_{D} X_{i}\left(1+f_{X}\right)+\left(T-t^{*}(i)\right) \omega_{O} X_{i}\left(1+\gamma\left(t^{*}(i)\right) f_{X}\right)=B^{D}(i)=C_{i}(i, A)$, and in case of non-migrating by:

\footnotetext{
${ }^{25}$ Derivation of the partial effects is straightforward, although tedious. For the assumptions made, and for $\omega_{D}-\omega_{O}>0$, an increase in $\omega_{D}$ decreases investments in human capital $s$, while an increase in $\omega_{O}$ leads to an increase in investments. Those with higher ability $A$ will invest more, while the effect of an increase in human capital upon arrival $X$ on $s$ is ambiguous.
} 


$$
\omega_{O}\left(1-s_{O}^{*}(i)\right) X_{i}+T \omega_{O} X_{i}\left(1+g_{X}\right)=B^{O}(i)=C_{i}(i, A)
$$

where $X_{i}=\frac{\partial X}{\partial i}$

Thus, in the migration case, the individual will compare the marginal cost of investing in the first period (which are costs invoked by effort, and possibly monetary cost) with the marginal benefit, which is the impact of an extra unit of investment in the first period on future lifetime earnings. ${ }^{26}$ Given our assumptions about the cost function and the learning technology in the first period, the individual will invest in learning in period 1 if the expressions on the left hand side of Equation (7-a) and (7-b) are larger than the marginal cost for the first unit of investment. Note that - as the marginal cost schedule decreases in ability higher able individuals will always invest more in learning. Once the optimal investment in the first period $i^{*}$ has been obtained for both the migration case (together with $s_{D}^{*}$ and $t^{*}$ ) and the non-migration case (together with $s_{O}^{*}$ ), the migration decision of the individual is based on a comparison of $V^{D}-k$ and $V^{O}$.

This framework allows us to explore a number of interesting cases. Let us first consider the simple case where migration is permanent and no investment in human capital after period 1 is allowed $(s=0)$. In this case, conditions (7-a) and (7-b) simplify to $\omega_{D} X_{i}(1+T)=C_{i}(i, A)$ and $\omega_{O} X_{i}(1+T)=C_{i}(i, A)$. If (as we assume throughout) $\omega_{D}>\omega_{O}$, the return to period 1 investment is clearly larger in the case of a migration, and investment in learning in the first period will be higher for the case of a permanent migration than for the case of non-migrating. This is the core of the argument by Mountford (1997). In his model,

\footnotetext{
${ }^{26}$ To simplify the analysis, we assume here that the preference shocks $\eta_{D}$ and $\eta_{O}$ are drawn after the investment decision is made.
} 
individuals have an (exogenous) probability of migrating $\pi$, so that the optimal investment is given by

$$
\left(\pi \omega_{D}+(1-\pi) \omega_{O}\right) X_{i}(1+T)=C_{i}(i, A)
$$

There are two insights from this relationship. First, there is (for a given $\pi$ ) a particular ability level A, only above which it will be worthwhile to invest into learning. Secondly, even if the probability of emigration is small, individuals will invest more into learning, as long as the return in the country of destination is sufficiently high. Thus, an increase in $\pi$ may lead to more accumulation of human capital than in the non-migration case. Furthermore, although emigrants take with them the human capital they acquire in the home country (which is usually associated with a brain drain), some of those who acquired more skills remain in the home country, and may therefore increase the overall per capita level of skills in that country, compared to the case where no migration is possible. This may then lead to a brain gain, rather than a brain drain. Thus, the country of origin could overall benefit from a migration of skilled workers - see Mountford (1997) for an insightful discussion. In Section 4.4, we discuss papers that investigate the empirical relevance of this hypothesis.

Another situation that is encompassed by this model is the acquisition of human capital in the home country as a pre-requisite to enter the destination country. Suppose the potential host country has particular entry requirements such as a specific educational degree. The newly introduced point-based immigration system in the UK, and similar existing systems in Australia and Canada reflect exactly this scenario. Thus, if (for optimally chosen $s^{*}$ and $\left.t^{*}\right)$ the value of migrating is sufficiently higher than the value of non-migrating, then individuals will invest in education in the home country to obtain the critical level of $X^{\text {min }}$ which then allows an emigration in the next period, given that: 


$$
V^{D}-\left.k\right|_{X(i)>X^{\min }}>V^{O} .
$$

Again, such a policy will lead to a selection of high ability immigrants to invest into the minimum necessary level of education, as for them the cost of acquiring education is lower.

Another (but similar) situation occurs if learning in the second period in the country of destination requires a certain level of education to be obtained at home. For instance, $\mathrm{PhD}$ studies in the U.S. may require a Bachelor's degree in the country of origin. In that case, optimal investment in the home country will take this requirement into account.

\subsection{Empirical Studies}

\subsubsection{Assimilation and Adaptation}

The first generation of papers that studies the performance of immigrants in their countries of destination, starting with Chiswick (1978), concentrates on the earnings profiles of immigrants after arrival in their destination country, viewing these as a reflection of the human capital investments undertaken by the migrants and the skill transferability between origin and destination country. These studies do not distinguish between permanent and temporary migrations and there is no consideration of immigrants having undertaken investments in the home country with a view of obtaining returns in the host country as illustrated in the previous section. The key question these studies address is whether immigrants perform similarly, worse, or better than natives with the same set of characteristics. This depends on two factors: First, their quality, and secondly, their effort to invest in further knowledge. 
Why is this important and why have so many papers been published that address this issue? Foremost because the relative position of immigrants in the distribution of earnings determines the contribution they make to the host country economy. Higher earners contribute more to tax and benefit systems, and may increase per capita GDP. For many years, the study of immigrant assimilation was perhaps the largest empirical literature on immigration in the economic discipline (see Table 10 for a comprehensive list of studies).

Chiswick's (1978) work suggests that immigrants - although starting with a lower level of earnings than comparative natives - experience a higher earnings growth, and eventually out-perform natives after about $10-15$ years. ${ }^{27} \mathrm{He}$ obtains these results by "augmenting" a simple Mincer wage equation and allowing immigrants to have - conditional on education and potential experience at entry - different entry wages than natives, as well as different earnings growth. Earnings of immigrants grow due to two types of work experience: Experience accumulated in the home country and experience accumulated in the host country. Experience accumulated in the host country has two components: new, host-country specific human capital, and human capital that allows already existing knowledge to be used in the destination country. An example for the latter is accumulation of language proficiency. Chiswick concludes that the foreign-born seem to be able to compensate any potential earnings disadvantage arising from initially lower host country specific human capital by greater investments in training, higher work motivation, and greater ability, due to being positively selected. Some subsequent papers supported these findings (Carliner, 1980, and De Freitas, 1980); thus, at least for the U.S., the early literature on immigrant assimilation draws a picture of immigrants as being high achievers, who - after initial disadvantages -

\footnotetext{
${ }^{27}$ Holding other characteristics constant, Chiswick's results show that the earnings of the foreign-born are 9.5 percent lower than those of the native-born after 5 years, equal after 13 years, and 6.4 percent higher after 20 years in the country.
} 
outperform natives through ability, hard work, and investment into their human capital and productivity.

However, this positive picture of immigration to the U.S. was soon challenged by a series of papers starting with Borjas (1985). Borjas argues that estimation of earnings equations based on simple cross-sectional data - as in Chiswick (1978) - does not allow a distinction between cohort- and years of residence effects. An immigrant who has been in the U.S. for 10 years in 1970 has arrived in 1960, while an immigrant who has been in the U.S. for 20 years in 1970 has arrived in 1950 . Thus, if the composition of immigrants has changed (as it had at the time, since the abolition of country quotas originally established by the U.S. Immigration Act of 1924, through the Immigration and Nationality Act of 1965, significantly increased the share of immigrants from South- and Central America), earnings profiles based on cross-sectional data may over- or underestimate the earnings growth of immigrants. In the case of the U.S., Borjas argues, entry wages of subsequent cohorts have gone down, so that a cross-sectional analysis over-estimates the earnings paths of immigrants. He shows that distinction between cohort- and years of residence effects is possible by simply adding an additional census year to the data. More specifically, Borjas' (1985) proposes the so-called synthetic panel methodology in which earnings of migrants and natives are given by the following two equations: ${ }^{28}$

$$
y_{i t}^{I}=\alpha^{I}+\beta^{I} E D_{i}+\gamma^{I} E X_{i t}+\delta^{I} Y S M_{i t}+\sum_{m} \lambda_{m}^{I} C_{i m}+\sum_{k} \pi_{k}^{I} \mathrm{~T}_{i k}+\varepsilon_{i t}^{I}
$$

$$
y_{i t}^{N}=\alpha^{N}+\beta^{N} E D_{i}+\gamma^{N} E X_{i t}+\sum_{k} \pi_{k}^{N} \mathrm{~T}_{i k}+\varepsilon_{i t}^{N}
$$

\footnotetext{
${ }^{28}$ Originally, many studies did not allow the effect of education and experience to vary between immigrants and natives, assuming $\beta^{I}=\beta^{N}$ and $\gamma^{I}=\gamma^{N}$.
} 
where $y_{i t}^{I}$ and $y_{i t}^{N}$ are log earnings of individual $i$ in year $t, \mathrm{~T}_{i k}$ is an indicator variable for the year in which individual $i$ is observed that is set equal to unity if $k=t$, and $\pi_{k}^{I}$ and $\pi_{k}^{N}$ are time effects on log earnings for immigrants and natives, respectively. The variable $C_{i m}$ is an indicator variable for the year $m$ in which individual $i$ arrived in the host country, and ED, EX, and YSM measure educational attainment, potential (overall) labour market experience, and potential labour market experience in the U.S., respectively. ${ }^{29}$ The parameter of interest is given by $\theta=\delta^{I}+\gamma^{I}-\gamma^{N}$, with immigrants' earnings converging to those of natives when $\theta>0 .{ }^{30}$ The coefficient $\beta^{I}$ shows the return to education obtained in the home country on the host country labour market (assuming the migrant worker arrived in the host country as an adult). It thus reveals, in conjunction with $\beta^{N}$, the transferability of human capital between home and host country. This setup is called the synthetic panel approach since it typically uses repeated cross-sectional data, for instance from U.S. Censuses, to construct a pseudo-panel of cohorts that can be followed over time without actually observing any worker more than once.

A fundamental problem with estimating Equation (8-a) is that years since migration equal the difference between calendar year of observation and the cohort entry year, so that these variables are perfectly collinear. This means that the coefficients $\delta^{I}, \lambda_{m}^{I}$, and $\pi_{k}^{I}$ cannot be separately identified without imposing additional identification restrictions.

\footnotetext{
${ }^{29}$ To simplify the notation, we ignore higher-order terms of years since migration and experience.

${ }^{30}$ In a similar setting, LaLonde and Topel (1992) define assimilation differently as occurring if $\delta^{I}>0$, hence comparing the economic value of spending an additional year in the host country relative to a year spent in the source country.
} 
To identify the model, Borjas $(1985,1995 a)$ assumes equal time effects for immigrants and natives, i.e. $\pi_{t}^{N}=\pi_{t}^{I}$, while allowing cohort quality to vary freely over time. In this case, time effects are effectively estimated from the native earnings equation which in turn ensures identification of the cohort effects in the immigrant equation. In contrast, Chiswick (1978) who only had one cross section of data at his disposal, assumed in addition to constant time effects that cohort effects did not change over time, so that, after normalisation, $\lambda_{m}^{I}=0$ for all $m \cdot^{31}$

Using data from the 1970 and 1980 U.S. Census, Borjas (1985) shows, that the quality of immigrants admitted to the U.S. declined over time. As a consequence, the positive impact of the years since migration variable in cross-sectional earnings equations is picking up not only the intended effect of U.S.-specific human capital accumulation, but also the effect of the higher quality of earlier immigrant cohorts. Separating these effects by looking at within-cohort earnings growth reveals that the assimilation profiles of immigrants' earnings are significantly flatter than previously estimated, with the true growth rate being up to 20 percentage points lower in some immigrant cohorts, so that the point of overtaking happens much later in the life cycle, if at all. Borjas (1995a) confirmed these results in a follow-up study that included the 1990 U.S. Census: the decline in cohort quality continued into the 1980s, albeit at a slower rate than in the 1970s, and, for the bulk of first-generation immigrants, earnings parity with the typical native-born worker will never be reached over the life cycle.

${ }^{31}$ Assume for simplicity that cohort effects are linear, so that $\sum_{m} \lambda_{m}^{I} C_{i m}=\lambda^{I} C_{i m}$. As $C_{i m}=T_{i k}-Y S M_{i t}$, the parameter Chiswick estimates on $Y S M$ is $\delta^{I}-\lambda^{I}$; clearly if $\lambda^{I}<0$ (cohort quality deteriorates), the estimate is upward biased. 
Motivated by these first studies, a large literature has developed that examines the earnings paths of immigrants for different countries and different time periods. In Table 10 we provide an extensive overview, focussing on the estimated returns to education and experience, both in the home and the host country, and the transferability of home country human capital to the host country labour market.

\section{[Table 10: Summary of Assimilation Studies.]}

\subsubsection{Extensions of the Basic Approach}

Although more flexible than Chiswick's (1978) cross-sectional approach, there are a number of restrictive assumptions underlying the synthetic panel methodology in its standard formulation in Equations (8-a) and (8-b). First, it assumes that - although the entry wage of different immigrant cohorts may differ - their wage growth is the same. Our model in Section 3.2 shows that this assumption may be quite restrictive. We show that immigrants who are more able do not necessarily start off with higher earnings, as they may initially invest more into their human capital, but that their wage growth is likely to be steeper than those of less able immigrants. ${ }^{32}$ If we distinguish cohort quality by the amount of measured human capital, $X$, then wage growth is - as described in our model - likewise affected. Thus, the assumption that wage growth is the same for different entry cohorts if these differ in terms of their average ability or their measured human capital appears quite strong. As in the benchmark study by Borjas (1995a), it should be justified in each individual case, in particular since the common interpretation of the estimated entry wages of different

\footnotetext{
${ }^{32}$ This seems to suggest that it is important to use wages rather than earnings for assimilation studies. However, even wages may reflect an increased human capital investment, if contracts are of the Lazear (1979) type in which employees accept lower wages in return for training.
} 
immigrant cohorts as a measure of their "quality" hinges crucially upon the validity of this assumption. Duleep and Regets $(1999,2002)$ and Green and Worswick (2004) provide a detailed discussion of the issues involved in the estimation of immigrant earnings profiles in the context of a human capital investment model. They make a strong case for not relying on entry earnings as a measure of relative cohort quality, with Green and Worswick (2004) suggesting instead a more comprehensive measure based on the estimated present value of all future earnings in the host country.

Another strong assumption in the standard synthetic panel methodology is that business cycle and time effects for natives and immigrants are the same. This assumption implies that macroeconomic trends and transitory shocks as well as aggregate labour market conditions affect immigrants' and natives' earnings in the same way. This is unlikely, as immigrants and natives have - as we illustrate in Section 2 - usually different skills, and are allocated to different occupations and industries. Dustmann et al. (2010e) illustrate for Germany and the UK that the economic cycle has - even conditional on education, potential experience, and industry allocation - a stronger impact on the employment of immigrants than on the employment of non-immigrants, and that these differences are more pronounced for non-OECD immigrants than for OECD immigrants. Two studies by Barth et al. (2004, 2006) for Norway and the U.S., respectively, argue that failure to consider these differences may severely bias the assessment of the earnings assimilation process of immigrant workers. As a solution, the authors suggest to augment the earnings equations by including measures of local unemployment and allowing their impact on earnings to vary between immigrants and natives. Conditional on unemployment, time effects can then be assumed to be equal for both groups. Using data from the Current Population Survey (CPS) from 1979 to 2003, Barth et al. (2006) show that wages of immigrants in the U.S. are indeed more sensitive to changes in local unemployment than wages of natives. As a result, since the native-immigrant wage 
gap contracts during economic expansions, the standard estimation strategy with equal time effects yields upwardly biased estimates of both the cohort quality of recent immigrant arrivals in the U.S. and of immigrant wage growth as the wage effects of the improving labour market conditions in the 1990s are erroneously attributed to immigrant quality and wage assimilation.

In the light of our model presented in Section 3.2, another shortcoming of the standard model stated in Equations (8-a) and (8-b) is that there is no distinction between returns to education obtained in the home country and education obtained in the host country. This strategy yields meaningful estimates under the assumption that all immigrants arrive in the host country after they finished education. In this case $\beta^{I}$ measures the returns to education obtained in the home country. However, if some immigrants arrive at an age when they are still in the process of obtaining formal education, the estimated parameter $\beta^{I}$ compounds the potentially different returns to education obtained in home and host country. In a study for Israel, Friedberg (2000) explicitly distinguishes education obtained in the host country from education obtained in the home country. She shows that the return to an additional year of schooling obtained in Israel is 10.0 percent for natives and 8.0 percent for immigrants whereas the return to schooling obtained in the immigrants' home countries is only 7.1 percent. She also finds very low returns to work experience accumulated before arrival. An additional year of experience in the country of origin yields a return of only 0.1 percent compared to 1.1 percent for an additional year of experience in Israel's labour market and a 1.7 percent return to experience for natives. The finding of low returns to home country education and experience in comparison with host country education and experience has been confirmed in a number of additional studies for a variety of destination countries, for example Kossoudji (1989), Schoeni (1997) and Bratsberg and Ragan (2002) for the U.S., Beggs and 
Chapman (1988a, 1988b) for Australia, Kee (1995) for the Netherlands, Schaafsma and Sweetman (2001) for Canada, Cohen-Goldner and Eckstein (2008) for Israel, Sanromá et al. (2009) for Spain, and Basilio and Bauer (2010) for Germany (for details of these studies, see Table 10). Thus, transferability of human capital from home to host country appears to be quite low in many migration contexts. The only exception appears to be human capital that was acquired in developed countries of origin, which typically yields relatively high returns in developed host countries (see, for example, Schoeni, 1997, Friedberg, 2000, or Bratsberg and Ragan, 2002). This could be either because home and host country are more similar in terms of cultural, institutional and technological aspects of their economies so that skills are easily transferable, or because more developed countries of origin simply have higher quality education systems. Interestingly, immigrants from developed countries also receive higher returns to human capital acquired in the host countries after their arrival compared to migrants from less developed countries, pointing towards complementarities between education obtained at home and education obtained in the host country (see, for example, Sanromá et al., 2009, and Basilio and Bauer, 2010). Such complementarities are also supported by the observation that obtaining education in the host country tends to have a positive effect on the return to home country specific education (Friedberg, 2001). One reason is that host country education enables the migrant to transfer their pre-migration skills more effectively to the host country labour market.

A related literature concerned with the transferability of human capital has studied the extent of over-education of immigrants defined as the difference between the formal qualifications held by the immigrants and the typical qualifications required in the occupations they hold (see, for example, Chiswick and Miller, 2007, 2008, Green et al., 2007, Lindley and Lenton, 2006, Nielsen, 2007, Sanromá et al., 2008). The main findings from this literature show that immigrants are more likely to be over-educated than natives but that with 
time in the host country this difference in over-education relative to natives decreases, a pattern reminiscent of the assimilation of immigrants' earnings to those of natives over time.

One important implication arising from the theoretical model set up in Section 3.2 is that the expected time the migrant will spend in the host country has an important effect on the decision to invest in host country specific human capital, as it determines the time horizon over which the benefits from such investments can be reaped by the immigrant. The longer the horizon, the higher are the investment incentives. Even under the assumption that migrations are permanent, this implies that immigrants who arrive at a younger age should have more incentives to invest in host country specific human capital and thus experience a larger initial earnings gap and steeper earnings profile. Wilkins (2003) confirms these predictions using Australian survey data for 1997, distinguishing four age at migration groups: $0-14,15-24,25-34$, and $35+$ years of age. His results show that, for a given stock of human capital at the time of migration, initial wages of immigrants who arrive as children are significantly lower, at least 15 percent, than those of any other age at migration group, but that their wage growth with time in Australia is significantly higher. ${ }^{33}$ More explicitly focusing on the human capital acquisition, Gonzalez (2003) shows that for Mexicans arriving in the U.S. before the age of 19 , each year of delayed entry results in about 0.25 to 0.30 less years of overall schooling, and, because this reduction in schooling is due to less U.S.specific education, significantly lower future earnings. This negative relationship between the eventual educational attainment of immigrants that arrive in the host country in their youth and their age at arrival is a fairly consistent finding in the literature (see, for example, Hirschman, 2001, Chiswick and DebBurman, 2004, Cortes, 2006, and Perreira et al., 2006).

\footnotetext{
${ }^{33}$ Friedberg (1992) and Borjas (1995a) find that age at migration has an important overall negative effect on immigrant earnings in the United States. According to their results, a worker who arrived at age 30 earns about 5 percent less than one who already arrived at age 20, all else equal. See also Schaafsma and Sweetman (2001) and van Ours and Veenman (2006) for related work for Canada and the Netherlands, respectively.
} 


\subsubsection{Return Migration}

Relaxing the assumption that all migrations are permanent and allowing for nonpermanent migrations, the estimation of immigrant earnings profiles becomes far more complex. Consider first the case of a temporary migration, where the return time is exogenously given and where this constraint is binding (in the sense that the migrant would otherwise wish to stay longer). As we have shown in Section 3.3.3, in that case the immigrant's investment in learning in the host country depends on the level of skills upon arrival as well as on the expected economic opportunities in the home country, which are directly affected by the return to any human capital investment when back home. Estimating equations as stated in (8-a) and (8-b) would therefore omit an important set of conditioning variables. The evolution of earnings of the migrant in the host country (measured by the return to experience and the return to the number of years since migration) should depend on the length of the migration. This in turn should also depend on the labour market characteristics in the home country, introducing additional heterogeneity if immigrants come from different origin countries. Neglecting these variables may lead to biased estimates of earnings profiles. ${ }^{34}$

The situation becomes more complex when return migrations are chosen by the immigrant. In that case, investment into human capital in the host country and the optimal migration time are chosen simultaneously, and should be modelled accordingly. Table 7 in

\footnotetext{
${ }^{34}$ For instance, our model in section 3.2 suggests lower initial earnings (due to larger human capital investments), but a steeper earnings profiles for immigrants who have a longer expected duration in the host country. Thus, assimilation profiles will depend on the duration of migration. Omission of variables that capture this in the estimation of earnings profiles will lead to sample-specific returns to time in the host country, which depend on the distribution of anticipated migration durations. Our model also suggests that an increase in migration durations will lead to steeper earnings paths for higher able immigrants, which adds further identification problems.
} 
Section 2 shows that return migrations are very common, and in most cases, returns and total migration durations are chosen by the migrant. In principle, the re-migration decision and the human capital investment decision have to be estimated simultaneously. This poses a number of difficulties for the empirical researcher. Although the simple model we describe above is deterministic, re-migration decisions in the real world are unlikely to remain unrevised over the migrants' migration history. Thus, even if (as is possible now in some register data sets) completed migration histories were observable, the completed migration duration may have been different than the migration duration that was intended when human capital decisions were made. But what matters for economic decisions is the expected migration duration at the time a decision is taken, and not the completed migration duration.

The data thus required are information on the expected duration of a migration rather than on the completed duration of a migration. Unfortunately, these return intentions are usually unobserved. An exception is the German Socio-Economic Panel, which asks a boost sample of immigrants in each wave how long they would like to remain in Germany, and whether or not they would like to return home at all. In an early paper, Dustmann (1993) uses this information to estimate earnings profiles of immigrants. Only about a third of all male immigrants intend to stay in Germany for 30 more years or forever, while slightly more than 60 percent of immigrants intend to return to their home countries within the next ten years, most of them before they reach retirement age. Allowing assimilation profiles to vary by the intended years of stay in Germany, he finds that "permanent" immigrants have indeed steeper earnings profiles than "temporary" immigrants. After five years of residence, an additional year in the host country improves immigrants' earnings by 0.4 percent if the total intended duration of stay is 10 years, 1.05 percent if it is 20 years, and 1.26 percent if it is 30 years. Dustmann (1997, 1999, and 2000) provides additional evidence of differential labour market behaviour of immigrants with different return intentions. 
Following this line of argument, Cortes (2004) suggests that one of the main reasons for the steeper earnings profile of refugee migrants compared to economic migrants in the U.S. is the implicit difference in their expected duration of stay. As refugees are typically unable or unwilling to return to their home countries for fear of persecution or violent conflict, they have a longer time horizon in the host country and therefore more incentives to invest in country-specific human capital. Her empirical findings support this hypothesis, as do those of Khan (1997) who finds a higher propensity of Cuban and Vietnamese refugees in the U.S. to invest in schooling compared to other foreign-born immigrants.

Thus, although - as we show in Section 2 - return migrations today are likely to be the rule rather than the exception, the empirical literature has so far largely ignored the implications for the estimation of immigrants' earnings profiles. Careful estimation of earnings profiles of immigrants with different migration plans, taken in conjunction with their human capital investment decisions, requires modelling of the processes of human capital investments and return plans simultaneously. This needs to be addressed within a welldefined structural setting.

An additional problem with return migration, apart from the behavioural reasons stated above, is that it is likely to be selective, in the sense that those who return are not randomly chosen. Returning migrants may be either those who do not perform very strongly in the host country labour market, or those who perform above average. In the latter case, for example, the average quality of a given immigrant cohort in the host country will decrease over time, leading to an underestimation of the true earnings profiles of immigrants of that cohort relative to natives. Lubotsky (2007) addresses this problem by using longitudinal earnings data from U.S. Social Security records that allow following individual migrants over time. His results show that in the U.S. case, out-migrants are negatively selected, implying that previous studies have systematically overestimated the wage progress of immigrants who 
remained in the U.S., by a factor of around $2 .{ }^{35}$ We will discuss some reasons for selective immigration and out-migration in Section 4.1.

\subsubsection{Language}

One dimension of human capital that deserves particular attention in the context of migration is language capital. Language is, on the one hand, a crucial human capital factor for the productivity of immigrants in the host country. Not only is language important in its own right, but it is complementary to many other skill components. For instance, a qualified physician is unlikely to be able to work as a general practitioner when she does not master the language of the host country. On the other hand, investments in language skills are likely to be of little use in the home country. For instance, a migrant from Bosnia to Sweden is unlikely to benefit much from speaking Swedish after having returned home. ${ }^{36}$ Thus, while being very important as a complement to existing and future skills, language may at the same time be less transferable to other countries' labour markets in the future. In any case, the improvement in language skills over the time spent in the host country is an important driver of the observed earnings assimilation profiles of immigrants in their host countries.

A key question in this context concerns the return to language capital: what is the percentage increase in earnings if an immigrant speaks the host country language well as compared to speaking it poorly? This parameter has important policy implications, as it helps assessing the benefits of language schemes, or of selective migration policies that

\footnotetext{
${ }^{35}$ It is, however, not clear that the hypothetical assimilation profile of immigrants had no return migration taken place is the interesting policy parameter. If the interest in wage profiles of immigrants is driven by their potential contributions to the economy and the tax- and benefit system, what matters are those immigrants who remain in the host country.

${ }^{36}$ English may be an exception, with the acquisition of English being an important reason for a migration in the first place. It is not completely surprising in this context that the most popular destination countries for tertiary education are all English-speaking countries: Australia, the UK and the U.S. (see Table 5).
} 
discriminate according to language proficiency. However, this parameter is difficult to measure, for several reasons. First, immigrants who acquire language proficiency may be positively selected, thus introducing a classical selection bias in estimations that regress economic outcomes on language proficiency measures. Secondly, most available language measures are self-reported. This introduces two types of measurement error: a classical measurement error, due to the interviewer reporting with error, and a systematic measurement error, due to the fact that individuals have different "scales" on which they assess their own language skills: the same proficiency may be evaluated as "poor" by one individual, and as "good" by another individual. We will discuss below attempts that address these problems, after reviewing the literature and its main findings.

In much of the literature, the return to language proficiency is obtained by estimating a standard earnings equation where a measure of language skills is added as an additional regressor (see, for instance, early work by Carliner, 1981, McManus et al., 1983, Grenier, 1984, Kossoudji, 1988, Tainer, 1988, Rivera-Batiz, 1990, 1992, Chiswick, 1991, Chiswick and Miller, 1992, 1995, and Dustmann, 1994b). These studies rely on self-reported language information in survey questionnaires, typically on either a 4-point or 5-point scale, and ignore the problems pointed out above. In all these papers, language proficiency is found to be strongly positively associated with earnings in the host country. For instance, for a sample of illegal immigrants in the U.S., Chiswick (1991) estimates that immigrants who can read the English language well or very well have earnings that are about 30 percent higher than those of immigrants with low English reading skills. He also finds that reading skills dominate speaking skills and that the latter does not have an additional separate effect on earnings. For a more representative sample of adult foreign-born immigrants in the U.S., Chiswick and Miller (1992) report that English language fluency is associated with around 17 percent higher earnings. Dustmann (1994b) estimates that immigrants in Germany who speak 
German well or very well earn about 7 percent more than immigrants who speak German on an intermediate level, badly or not at all. Similarly, those who have good or very good German writing skills earn between 7.3 percent (males) and 15.3 percent (females) more than those with bad or no German writing skills. ${ }^{37}$

Language proficiency is also found to have a complementary effect on the transferability of pre-immigration human capital in the form of education and experience. Chiswick and Miller $(2002,2003)$ show that language skills enhance the return to human capital obtained before migration, so that a migrant's greater proficiency in the languages spoken in the host country enhances the effects on earnings of her pre-immigration schooling and labour market experience. These results hence support the hypothesis that language is an important complementary skill to other forms of human capital: if immigrants cannot conduct a conversation in the host country language, human capital acquired prior to immigration cannot be translated into higher earnings in the host country.

The importance of language as a factor to enhance the productivity of other forms of human capital is also demonstrated in studies that investigate the capacity of different immigrant communities in acquiring further human capital. Sanromá et al. (2009) show that returns to schooling obtained in Spain are significantly higher for immigrants from Latin America (4.4 percent), who speak Spanish, than for immigrants from other less developed countries such as those situated in Eastern Europe (3.6 percent). Beggs and Chapman (1988b) show that the return to schooling in the Australian labour market in 1981 was 9.0 percent for the native-born, 8.4 percent for immigrants from English-speaking countries, and only 4.9 percent for immigrants from non-English speaking countries. These findings are suggestive

\footnotetext{
${ }^{37}$ Additional studies show an earnings advantage associated with host country language fluency of 12 percent in Canada (Chiswick and Miller, 1992), 8 percent in Australia (Chiswick and Miller, 1995), and 12 percent in Israel (Chiswick, 1998, and Chiswick and Repetto, 2001).
} 
for language being important for the acquisition of further skills, although estimates may be compromised by selection, and do not isolate the effect of language from other country of origin specific factors that may be driving the differential returns to human capital.

Language proficiency is also a key factor in explaining the educational outcomes of the children of immigrants. Dustmann et al. (2010f) show that the single most important factor explaining achievement gaps between children of immigrants and natives in the UK is language spoken at home. In Section 5.3.1, we will discuss the importance of language for children born to foreign-born parents in more detail.

As we discuss above, a key difficulty in determining the impact language has on economic outcomes is selection, possibly leading to an upward bias in the return to language proficiency in straightforward earnings equations, and measurement error in self-reported language measures. Dustmann and van Soest $(2001,2002)$ were the first to argue that measurement error may lead to a substantial downward bias in simple OLS regressions, which possibly over-compensates the upward bias through selection. To illustrate the possible magnitude of the attenuation bias, they use repeated information on self-reported language proficiency from a panel of immigrants in Germany. Assuming that from year $t$ to year $t+1$ deterioration in language proficiency is not possible, Dustmann and van Soest (2001) estimate that 85 percent of the within-individual variance, and at least 24 percent of the overall variance in language measures is due to unsystematic measurement error, in the sense that it varies unsystematically over time. They discuss as a further difficulty of self-reported language information that individuals may have different scales of evaluation. In a crosssection, these individual-specific scales cannot be distinguished from measurement error. However, with panel data, and if differences in scales across individuals are constant over time, such a distinction is possible. Dustmann and van Soest (2001) develop an estimator that separates time-varying from time-persistent misclassification. Further, to address the 
endogeneity problem, they use parental education as an instrument for language proficiency conditional on individuals' education, noting that this is less problematic than instrumenting individuals' education with parental education. The findings show that over-reporting language ability is more frequent than under-reporting, and that there is substantial timepersistent misclassification. According to their results, the return to a one standard deviation increase in true German language fluency decreases from 2.8 percentage points to 0.9 percentage points once unobserved heterogeneity is taken into account. However, controlling subsequently for both time-varying measurement error and time-persistent misclassification, the return to German language fluency increases to approximately 7.3 percentage points. Thus, measurement error may lead to a large downward bias of the estimated return to language proficiency that over-compensates any upward bias due to unobserved ability. ${ }^{38}$

If repeated information on language ability is available, an alternative way to address the endogeneity problem is by conditioning on individual-specific effects (or estimating difference equations). However, the downward bias through measurement error in the language variable will be greatly enhanced by such techniques. In most panel data sets that contain repeated information on language ability, immigrant populations have been resident for a large number of years, so that the noise-to-signal ratio is too large to allow estimation. ${ }^{39}$ Berman et al. (2003) use repeated information on the language proficiency of male immigrants from the former Soviet Union that moved to Israel after 1989, focusing on the first few years after arrival in which typically the largest improvements in language skills take place. They find large wage gains of language proficiency for workers in high-skilled,

\footnotetext{
${ }^{38}$ Dustmann and Fabbri (2003) find a similarly large downward bias due to measurement error for the UK, while Dustmann and van Soest (2004) compare parametric and semi-parametric estimators to address measurement error in language variables.

${ }^{39}$ See Dustmann and van Soest (2002) for a discussion.
} 
but not low-skilled professions as well as evidence for an upward ability bias in crosssectional estimates, particularly for workers in low-skilled professions.

Bleakley and Chin (2004) present a further strategy to address the endogeneity problem of language proficiency. Based on census cross-sections, they devise an IV strategy that exploits the psychobiological phenomenon that young children tend to learn languages more easily than adolescents and adults. Focussing on childhood immigrants, an immigrant's age at arrival in the host country is therefore a strong predictor of his or her language proficiency later in life. It can be used as a valid instrument once its effect on earnings through other channels than language, is controlled for. Bleakley and Chin (2004) use immigrants from English-speaking countries as a control group to net out the effects of age at arrival that are not associated with language. Their findings show that OLS estimates of the returns to English language fluency in the U.S. are severely downward biased - which is unexpected if selection is the only problem. They explain this by the IV estimator possibly revealing a local average treatment effect, and by measurement error. Using data on language test results, they estimate that attenuation bias through measurement error may lead to a reduction of the estimated coefficient by one-half - which is similar in magnitude to the effects found by Dustmann and van Soest (2001).

One particular feature of language capital is that it is in most cases not transferable to the country of origin. For instance, German language proficiency is unlikely to be of much use in the Italian or Turkish labour markets. Thus, in the formulation of our model in Section 3.2, language capital should be sensitive to the duration individual immigrants would like to spend in the country of destination. This hypothesis is analysed by Dustmann (1999), who investigates the impact of immigrants' intended duration of stay on their language skills. As migration durations are endogenous in a language equation, he uses an indicator for whether parents who are residing in the home country are still alive as an instrument for the planned 
migration duration. The findings show that an increase in the total intended duration in Germany by 10 years is associated with a 5-percentage point higher probability of being fluent in German.

\subsubsection{Downgrading and Ethnic Networks}

The low wages immigrants often receive upon arrival may be partly explained by initial "downgrading", possibly due to a lack of important complementary skills that allow individuals to fully utilise their human capital in the host country's labour market. The stereotypical cab-driving physician vividly captures this phenomenon. Friedberg (2001) and Eckstein and Weiss (2004) study directly the type of jobs immigrant workers perform after arrival, using data for Israel. They find substantial occupational downgrading of Russian immigrants who arrived in Israel in the 1990s. While these immigrants worked in Russia predominantly as engineers, managers, physicians and teachers, their most important occupations in Israel turned out to be occupations such as service workers, locksmiths/welders, and housemaids. However, over time, particularly highly educated immigrants climb up the occupational ladder. Eckstein and Weiss (2004) show that the proportion of highly-educated immigrants working in high-paid professional occupations rises from about 30 percent at arrival to about 70 percent twenty years later, compared to an increase from 60 percent to 80 percent for equally-educated natives over the same time interval. Overall, around 17 percent of immigrants' wage growth in the first 10 years after arrival in Israel can be attributed to occupational transitions. Mattoo et al. (2008) provide similar evidence of "underplacement" of immigrants in the U.S. labour market, where in particular skilled immigrants from countries with lower expenditures on tertiary education 
and non-English languages of instruction, such as Latin American or Eastern European countries, tend to end up in unskilled jobs.

An important consequence of this occupational downgrading is that an allocation of immigrants to particular skill groups based on observed measurable skills such as their education - for example in order to assess with which subgroup of the native workforce they are most likely to compete in the labour market - is likely to be highly inaccurate and not reflecting the true section of the labour market in which the immigrants are active. Dustmann et al. (2008) illustrate how, due to downgrading, an allocation of immigrants in the UK based on their observed education levels misrepresents their true position in the native wage distribution: while these immigrants are on average significantly better educated than natives, they earn wages at the lower end of the native wage distribution in the UK.

Not only complementary skills (such as language) may be important for immigrants to being able to fully utilise their human capital, but also the reduction in informational deficiencies with respect to the host country's labour market. Here ethnic networks may play an important role. Bartel (1989) and Jaeger (2007) demonstrate the tendency of immigrants to settle in areas where there are already established communities of their ethnic group. Chiswick and Miller (2005) show that living in a region of the U.S. with a high linguistic concentration of the immigrant's mother tongue has a negative effect on the immigrant's own English language skills which in turn tends to reduce her earnings potential. This would speak against ethnic networks operating to the advantage of immigrants. However, straightforward correlations of ethnic segregation and economic outcomes may be affected by a sorting problem. In two papers, Edin et al. (2003) and Piil Damm (2009) use random dispersal policies of refugee immigrants in Sweden and Denmark to investigate the effects of living in enclaves on labour market outcomes. By using the ethnic concentration in the initial 
assignment area (Edin et al.) and the past inflow of assigned co-nationals (Piil Damm) as an instrument, these authors convincingly address the sorting problem. They find that living in an ethnic enclave has positive effects on wages and employment, in particular for workers who have low skill levels. Dustmann et al. (2010d) find similar evidence of a positive effect of obtaining a job through an ethnicity-based network on wages and job stability in the German context. This speaks in favour of networks as a mechanism to reduce informational uncertainties.

\subsubsection{Observed Post-Migration Schooling Investment and Learning Centres}

Most of the assimilation literature discussed so far draws conclusions about the human capital investment of immigrants after arrival in the host country indirectly from the observed earnings patterns. A more direct approach, given suitable data, is to look at the actual acquisition of additional education by immigrants, and the factors that determine it. Using data from the 1976 Survey of Income and Education (SIE) and the 1980 U.S. Census, and focusing on the years of schooling obtained after migration and enrolment status as dependent variables, Khan (1997) finds that the acquisition of human capital of foreign-born adult men decreases with age at migration, and is higher for refugee immigrants and those who are naturalised, and in states with low tuition fees and better quality of schooling. In the SIE data, she also finds that pre-immigration schooling up to the post-bachelor professional level is a substitute for schooling in the U.S., a finding in support of an earlier study by Borjas (1982) of male Hispanic immigrants. In contrast, Chiswick and Miller (1994), who study adult immigrants in Australia, find a positive effect of pre-immigration schooling and occupational status on post-immigration schooling, concluding that these are complementary. 
As briefly pointed out in Section 3, one reason for immigration can be the acquisition of human capital in a host country. This was a particular aspect of our model, which encompasses migration situations where the sole purpose of a migration is the acquisition of human capital that has a high value upon return to the home country (see Section 3.3.4 for details). This phenomenon is particularly pronounced in higher education and in countries like Australia, the U.S. and the UK (compare Table 5), which receive large numbers of foreign students to study at their universities. ${ }^{40}$ In the U.S., for example, foreign-born students (mostly from India, Taiwan, South Korea and China) accounted for 31 percent of all $\mathrm{PhD}$ recipients in 2006, with even higher shares in specific fields such as physical science (44 percent), engineering (59 percent), and economics (59 percent). ${ }^{41}$ Bound et al. (2009) provide an excellent overview of the latest developments in the U.S. context. In the U.K., foreign students account for 42 percent of all $\mathrm{PhD}$ recipients and 55 percent of all recipients of a Master's degree in 2007/2008. ${ }^{42}$ Many students that acquire doctoral degrees stay on after completing their studies. Finn (2007), for example, estimates that about 58 (71) percent of foreign citizens that received a $\mathrm{PhD}$ in science or engineering from a U.S. university in 1991 (1999) are still living in the U.S. in 2001.

\footnotetext{
${ }^{40}$ This type of immigration is institutionalized in many host countries by issuing specific visas created explicitly to permit temporary study (for example the F-1 visa in the U.S. or the Student Visas in the UK).

${ }^{41}$ Source: National Science Foundation: Science and Engineering Doctorate Awards 2006. Own calculations. Foreign students are defined as non-U.S. citizens with temporary visa.

${ }^{42}$ Source: Higher Education Statistics Agency. Foreign students are identified as those with non-UK domicile.
} 


\section{The Effect of Migration on the Skill Base and Educational Attainment of Non-Migrants}

In the previous section, we discuss the relationship between education and migration from the perspective of the migrant. In this section, we address the issue from the perspective of those who have chosen not to migrate - both in the origin- and in the destination country. Our focus will be on the consequences of migration for the skill base and the acquisition of education in the two countries. Migration can affect the skill base of the origin country directly, by changing the skill composition and the talent base. Here the question of selection - who migrates - becomes important. Migration can also affect the skill base of the origin country indirectly through generating incentives to invest into learning and skill acquisition. In the destination country, besides the direct effect because of the inflow of immigrants, migration may change the skill base through responses of the native population, by creating incentives for additional skill accumulation, or for specialising in particular skills where natives have a comparative advantage. Migration can also create spillover effects, for example through complementarity of the migrant population with the existing populations. In this section, we will discuss some of these aspects.

We start with re-investigating one of the key questions in the literature on migration, which has important consequences for the issues we raise here: Who migrates? In an early paper, George Borjas (1987) uses the Roy (1951) model to relate the skills and abilities of immigrants to the distribution of wages and earnings in the host and home country. His analysis provides deep insights, and has been empirically tested in a number of subsequent papers. However, many of these papers have focussed on a particular case of Roy's model, where skills are one-dimensional. Here we will re-examine the original Roy model, and 
explore more closely the implications of multi-dimensionality in skills. We believe that in the context of migration this will provide much additional insight.

\subsection{The Selection of Migrants}

We will start with addressing the question of who migrates. In Section 3, we discuss the incentives to emigrate from the perspective of the potential migrant, and show that these depend - among others - on the capacity of the individual to produce knowledge, which we termed "ability". The optimal migration plan - in the simplest setting where the return to human capital is higher in the host country - usually provides higher migration incentives to those who have a lower cost of human capital production: those with higher ability. In those considerations, we only looked at the migration decision of a single individual, the "average" individual. We did not compare this individual to other individuals in the origin- or destination country, by characterising a distribution of skills. Further, we thought about "skills" as a one-dimensional concept - an individual that has more skills is more productive in both countries.

In this section, we give up this assumption, by introducing multiple skills, which added up and weighted by skill prices that may differ across the two countries - determine the productive capacity, or human capital, of an individual in a particular country. We argue that considering skills as a multi-dimensional concept, with different prices in different countries, is particularly sensible in the context of migration. We investigate the selection of individuals along the distribution of these skills, and state the conditions for positive and negative selection. 
Our considerations are based on the Roy (1951) model which we will formalise as a multiple skill model (concentrating on the special case of two skills), and in which we allow for the possibility that one skill has a higher price in one country, while the other skill has a higher price in the other country. ${ }^{43}$ This generates the possibility of "non-hierarchical sorting" (to use the terminology of Willis, 1987), where those who are most productive in the host country migrate and those who are most productive in the home country do not migrate. ${ }^{44} \mathrm{We}$ will develop this aspect of the Roy model which, as we believe, has not received sufficient attention in the migration context. In our view, thinking about migration as a decision that considers the prices for multiple skills is appropriate in a world where diversely structured national economies trade their comparative and absolute advantages on globalised markets. We show that some of the observed migration patterns that seem not compatible with the one-dimensional skill version of the Roy model can be accommodated by a multidimensional skill model. Drawing on Dustmann et al. (2010a), we then show how the basic static Roy model can be extended to a dynamic Roy model by allowing for learning of skills in the two countries, so that each country is not only characterised by prices for skills, but also by learning opportunities.

\footnotetext{
${ }^{43}$ The Roy model goes back to a paper by Andrew D. Roy published in the Oxford Economic Papers in 1951. In this paper, Roy develops the implications of multi-dimensional abilities for occupational choice, the structure of wages, and earnings distributions. The model has in later years been formalised and developed further (see, for example, Heckman and Honoré, 1990, Willis and Rosen, 1979, and Willis, 1987).

${ }^{44}$ Borjas does, in principle, consider this case, which he terms "refugee sorting", but does not develop its implications in much detail. Most of the literature (e.g. Chiquiar and Hanson, 2005, Orrenius and Zavodny, 2005, McKenzie and Rapoport, 2007, Ibarrarán and Lubotsky, 2007, Belot and Hatton, 2008, FernándezHuertas Moraga, 2010, Kaestner and Malamud, 2010) considers a special case of the Roy model, where skills are one-dimensional, which leads to hierarchical sorting. A very interesting and insightful extension is provided by Gould and Moav (2010) who consider observable skills (such as education) and unobservable skills.
} 


\subsubsection{A Multiple Skill Model of Migrant Selection}

Consider two countries, an origin country $(O)$ and a destination country $(D)$. Further, suppose individuals have two latent skills, $S_{1}$ and $S_{2}$ (this can be easily generalised to more skills). We will here refer to these skills as "analytical skills" $\left(S_{1}\right)$ and "manual" or "trade" skills $\left(S_{2}\right)$. Suppose the two countries have different technologies and industry structures. Thus, we can think about the two countries rewarding the two skills differently, according to the two equations

$$
\begin{gathered}
Y_{D i}=\ln y_{D i}=\mu_{D}+b_{D 1} S_{1 i}+b_{D 2} S_{2 i}=\mu_{D}+u_{D i} \\
Y_{O i}=\ln y_{O i}=\mu_{O}+b_{O 1} S_{1 i}+b_{O 2} S_{2 i}=\mu_{O}+u_{O i} .
\end{gathered}
$$

In (9-a) and (9-b), $b_{j 1}$ and $b_{j 2}$ represent the prices for the two skills in country $j$, $j=O, D$. Notice that this set-up allows for many interesting combinations. For instance, if countries specialise in particular industries and exchange goods in global markets, then in one country the price for skill 1 may be high and the price for skill 2 low, whereas in the other country the price for skill 2 may be high and that of skill 1 low. If both countries are equipped with the same distribution of skills, migration in both directions may create a more efficient skill allocation.

To compare this with the notation used in much of the literature (e.g. Borjas, 1987), we combine the weighted skills to two measures $u_{D}=\ln K_{D}=b_{D 1} S_{1 i}+b_{D 2} S_{2 i}$ and $u_{O}=\ln K_{O}=b_{O 1} S_{1 i}+b_{O 2} S_{2 i}$, where $K_{j}$ is the productive capacity of a person if she works in 
country $j$. Therefore, we can characterise every worker by either a pair of latent skills $\left(S_{1}\right.$ and $\left.S_{2}\right)$ or a pair of productive capacities in the two countries $\left(K_{D}\right.$ and $\left.K_{O}\right)$.

We can think about $\mu_{j}$ as the log of the rental rate to human capital in country $j$ so that $y_{j}=e^{Y_{j}}=R_{j} K_{j}$, with $\mu_{j}=\ln R_{j}$. The rental rate of human capital in the country of destination, $D$, for example, could be persistently higher if it had a superior technology and if it regulated the inflow of immigrants so that only some of those who wish to enter are allowed in.

We assume that both countries have identical distributions of the two skills $S_{1}$ and $S_{2}$ before migration, and that these distributions are normal and independent with mean zero and variance $1: S_{k} \sim \mathrm{N}(0,1) .{ }^{45}$ It then follows that the random variables $Y_{D}$ and $Y_{O}$ are likewise normally distributed, with means $\mu_{D}$ and $\mu_{O}$ and variances and covariance ${ }^{46}$

$$
\begin{aligned}
& \operatorname{Var}\left(Y_{D}\right)=b_{D 1}^{2}+b_{D 2}^{2}=\sigma_{D}^{2}=\operatorname{Var}\left(u_{D}\right) ; \operatorname{Var}\left(Y_{O}\right)=b_{O 1}^{2}+b_{O 2}^{2}=\sigma_{O}^{2}=\operatorname{Var}\left(u_{O}\right) \\
& \operatorname{Cov}\left(Y_{D}, Y_{O}\right)=\operatorname{Cov}\left(u_{D}, u_{O}\right)=\sigma_{D O}=b_{D 1} b_{O 1}+b_{D 2} b_{O 2} .
\end{aligned}
$$

We define

$$
\sigma^{2}=\operatorname{Var}\left(u_{D}-u_{O}\right)=\sigma_{D}^{2}+\sigma_{O}^{2}-2 \sigma_{D O}=b_{D 1}^{2}+b_{D 2}^{2}+b_{O 1}^{2}+b_{O 2}^{2}-2 b_{D 1} b_{O 1}-2 b_{D 2} b_{O 2},
$$

which is the variance of the difference in the log of productive capacity between country $D$ and country $O$. Further, let $u=\left(u_{D}-u_{O}\right) / \sigma$ and $z=\left(\mu_{O}+k-\mu_{D}\right) / \sigma$, where $k$ are migration costs (in time-equivalent units). Also, let

\footnotetext{
${ }^{45}$ The latter assumption simplifies notation, but can easily be relaxed.

${ }^{46}$ Notice that productive capacities are correlated although we assume that the skills $S_{1}$ and $S_{2}$ are independent.
} 


$$
\sigma_{D U}=\operatorname{Cov}\left(u_{D}, u\right)=\left(\sigma_{D}^{2}-\sigma_{D O}\right) / \sigma=\left[b_{D 1}\left(b_{D 1}-b_{O 1}\right)+b_{D 2}\left(b_{D 2}-b_{O 2}\right)\right] / \sigma
$$

and

$$
\sigma_{O U}=\operatorname{Cov}\left(u_{O}, u\right)=\left(\sigma_{D O}-\sigma_{O}^{2}\right) / \sigma=\left[b_{O 1}\left(b_{D 1}-b_{O 1}\right)+b_{O 2}\left(b_{D 2}-b_{O 2}\right)\right] / \sigma .
$$

These covariances are the weighted sums of the differences in skill prices between host and home country, where the weights are the skill prices for the host and home country, normalised by $\sigma$. Notice that $\sigma_{D U}=\sigma_{O U}+\sigma$ so that $\sigma_{D U}-\sigma_{O U}>0$.

Finally, define the correlation between the log of productive capacities in the home and host country as

$$
\rho=\operatorname{Cor}\left(u_{D}, u_{O}\right)=\sigma_{D O} /\left(\sigma_{D} \sigma_{O}\right)=\left(b_{D 1} b_{O 1}+b_{D 2} b_{O 2}\right) /\left[\left(b_{D 1}^{2}+b_{D 2}^{2}\right)\left(b_{O 1}^{2}+b_{O 2}^{2}\right)\right]^{1 / 2} .
$$

We are now ready to establish the different migration scenarios, and to compare the wages of those who decide to migrate, and those who decide not to migrate. It follows from (9-a) and (9-b) that an individual will migrate from country $O$ to country $D$ if $Y_{D i}-k>Y_{O i}$, or

$$
\begin{aligned}
& \mu_{D}-\mu_{O}+\left(b_{D 1}-b_{O 1}\right) S_{1 i}+\left(b_{D 2}-b_{O 2}\right) S_{2 i}>k \\
\Leftrightarrow & \left(u_{D}-u_{O}\right) / \sigma>\left(\mu_{O}+k-\mu_{D}\right) / \sigma \\
\Leftrightarrow & u>z
\end{aligned}
$$

Denoting the density function and the cumulative distribution function of the standard normal distribution by $\phi(\cdot)$ and $\Phi(\cdot)$, the expected earnings of individuals who decide to emigrate are given by ${ }^{47}$

$$
E\left(Y_{D} \mid Y_{D}-k>Y_{O}\right)=\mu_{D}+\sigma_{D U}[\phi(z) /(1-\Phi(z))]
$$

${ }^{47}$ See Johnson and Kotz (1972), Heckman (1979) and Heckman and Honoré (1990) for details. 
Likewise, the expected earnings of those in the home country who decide not to migrate are given by

$$
E\left(Y_{O} \mid Y_{O}>Y_{D}-k\right)=\mu_{O}-\sigma_{O U}[\phi(z) / \Phi(z)]
$$

How much would those who decide to migrate earn in the home country, and how much would those who decide not to migrate earn in the host country? These two counterfactuals are given by

$$
E\left(Y_{O} \mid Y_{D}-k>Y_{O}\right)=\mu_{O}+\sigma_{O U}[\phi(z) /(1-\Phi(z))]
$$

(IV) $\quad E\left(Y_{D} \mid Y_{O}>Y_{D}-k\right)=\mu_{D}-\sigma_{D U}[\phi(z) / \Phi(z)]$

It follows from (I)-(IV) that the selection of migrants depends on the size and the relative magnitude of the covariances $\sigma_{D U}$ and $\sigma_{O U}$. We can distinguish 3 regimes.

Regime 1: $\sigma_{D U}>0$ and $\sigma_{O U}>0$. It follows that the mean earnings of those who decide to emigrate are higher than the mean earnings in the host country (I), and higher than the mean earnings in the home country (III). On the other hand, the mean earnings of those who decide not to migrate are lower than the mean earnings in the host country (IV), and lower than the mean earnings in the home country (II). This case is one of positive selection of immigrants: those who migrate have higher than average earnings in both countries, those who do not migrate have lower than average earnings in both countries. ${ }^{48} \mathrm{~A}$ necessary condition for regime 1 is a higher variance of the earnings distribution in the destination country compared to the origin country and a sufficiently high correlation between the productive capacities in both countries, $\frac{\sigma_{D}}{\sigma_{O}}>1$ and $\rho>\frac{\sigma_{O}}{\sigma_{D}}$ (see Borjas, 1987, 1999).

\footnotetext{
${ }^{48}$ Note that mean earnings always refer to the pre-migration period.
} 
In terms of the underlying skill distribution, regime 1 states that the return to both skills must be sufficiently large in the host country. It follows from (11-a) and (11-b) that the sum of the price differentials for the two skills between host and home countries, weighted by the host country prices, is larger than the sum of the price differentials weighted by home country prices. This is certainly the case if the returns to both skills are higher in the host country.

One special case, which is frequently assumed in the literature on the selection of immigrants (see for example Chiquiar and Hanson, 2005, Belot and Hatton, 2008), is that $u_{D}=c u_{O}$, where $c$ is some constant. This occurs if either the return to one skill equals zero in both countries (for instance $b_{D 2}=b_{O 2}=0$ ), or if the ratios of skill prices are equal in the two countries $\left(b_{D 2} / b_{D 1}=b_{O 2} / b_{O 1}=c\right)$. In both cases, the correlation between $u_{D}$ and $u_{O}$, $\rho$, is equal to one. Notice that the two cases have different interpretations. In the first case, the skill distribution reduces to one dimension. In the second case, the skill distribution is still two-dimensional (both "analytical" and "manual/trade" skills are needed in the two countries), and individuals may still have different endowments of the two skills; however, the production technologies in the two countries are such that the skill price proportions are exactly equal. A particular case is the one where $c=1$, which implies identical skill prices in both economies.

Regime 2: $\sigma_{D U}<0$ and $\sigma_{O U}<0$. This case leads to opposite conclusions to regime 1 .

Regime 1 and 2 are the two cases that are usually considered in the migration literature. They correspond to the "positive selection" and "negative selection" scenarios in Borjas (1987). 
Regime 3: $\sigma_{D U}>0$ and $\sigma_{O U}<0$. In this case, the mean earnings of those who decide to migrate are higher than the mean earnings in the host country (I), but they are lower than the mean earnings in the home country (III). On the other hand, the mean earnings of those who do not migrate are lower than the mean earnings in the host country (IV), but higher than the mean earnings in the home country (II). Thus, those who migrate have a below-average productive capacity in their origin country, but an above-average productive capacity in the destination country. Their departure increases the average productivity level in the home country (as individuals below average productive capacity leave the country), and increases the average productivity level in the host country. Thus, if the initial skill distribution is the same in the two countries, this situation may lead to a "brain gain" in both countries. ${ }^{49}$

Borjas (1987) refers to regime 3 as "refugee sorting", the underlying idea being that highly skilled individuals are discriminated against in dictatorial systems, receiving a return for their skills that is below average, while being rewarded according to market prices in countries that accommodate refugees. However, this case has many more interesting implications for the study of modern migrations. As we discuss above, global trade has led national economies to focus on particular industries, like manufacturing, or financial services. These industries may have different skill requirements across more than one dimension, and many migrations we observe today may be a response to these processes. The idea that migration is a response to skill demands along more than one skill dimension is compatible with the literature on task usage and polarisation, which argues that jobs can be characterised by multiple tasks, such as cognitive, routine and manual tasks (see, for instance, Autor et al. 2003, Goos and Manning, 2007, and Acemoglu and Autor, 2010).

\footnotetext{
${ }^{49}$ It is important to define brain drain / brain gain. We think about brain gain as an event that increases per capita productivity in either country, and a brain drain as an event that decreases per capita productivity in either country.
} 
Regime 3 is "non-hierarchical", in the sense that both those who migrate and those who do not migrate have above average earnings in the country of their choice: individuals are sorted based on their comparative advantage. Note that the case $\sigma_{D U}<0$ and $\sigma_{O U}>0$ is not possible if we allow for regime 3 , as it would contradict $\sigma_{D U}-\sigma_{O U}>0$. Notice further that the assumption $u_{D}=c u_{O}$, which is made in many papers that study the selection of immigrants, rules out regime 3 .

A special case of regime 3 occurs when each skill is only priced in one of the two countries; for example, $b_{D 1}=b_{O 2}=0$. Now the correlation between productive capacities in the two countries is zero: the productive capacity of an individual in one country does not give any insight about her productive capacity in another country. An individual who possesses skill $S_{1}$ will only be able to obtain a return in the home country, while an individual with skill $S_{2}$ will only obtain a return in the host country.

\subsubsection{Skill Prices, Productive Capacity and Selection}

It follows from (11-a) and (11-b) that whether migration is selective in terms of productive capacity depends on the underlying skill prices. Changes in these prices will change the type of migration that occurs, and the nature of selection. Which regime characterises a particular migration situation depends on the two expressions

$$
\sigma_{D U}=\left(\sigma_{D}^{2}-\sigma_{D O}\right) / \sigma=\left[b_{D 1}\left(b_{D 1}-b_{O 1}\right)+b_{D 2}\left(b_{D 2}-b_{O 2}\right)\right] / \sigma
$$

and

$$
\sigma_{O U}=\left(\sigma_{D O}-\sigma_{O}^{2}\right) / \sigma=\left[b_{O 1}\left(b_{D 1}-b_{O 1}\right)+b_{O 2}\left(b_{D 2}-b_{O 2}\right)\right] / \sigma
$$


where $\sigma_{D U}=\sigma_{O U}+\sigma$. To illustrate how the different regimes depend on skill prices, consider the top left graph in Figure 5, where we have fixed $b_{D 1}=1, b_{D 2}=2, b_{O 2}=1$, and we allow $b_{O 1}$ to vary between 0 and 5. The dashed and dotted lines in the figure are $\sigma_{D U}$ and $\sigma_{O U}$, respectively. For $b_{O 1}$ in the range between 0 and 1.62, $\sigma_{D U}>0$ and $\sigma_{O U}>0$; thus we are in regime 1 , with migration being positively selective. In the range where $b_{O 1}$ is between 1.62 and $3, \sigma_{D U}>0$ and $\sigma_{O U}<0$, and we are in the non-hierarchical regime 3, where those who would do best in the host country migrate and those who would do best in the home country do not migrate. Finally, above $b_{O 1}=3$, both $\sigma_{D U}$ and $\sigma_{O U}$ are negative; we are in regime 2 where migration is negatively selective. This demonstrates that the selection of immigrants in terms of their productive capacity depends on relative skill prices, which may change over time.

In the remaining two graphs in Figure 5, we plot the respective variances and the covariance (right top), and the correlation coefficient (left bottom). In the range where positive selection occurs, the variance of productive capacity is higher in the destination country, and the correlation between skills is high. In the range where negative selection occurs, the variance of productive capacity is higher in the country of origin, and the correlation between skills is lower. Notice that there is a range where the variance of productive capacity is higher in the destination country; yet, we are in regime 3, where we cannot hierarchically sort immigrants in terms of their average productive capacity. The migration decision of an individual migrant is based on a comparison of individual earnings in the home and host country. Using (9-a), (9-b) and (13), an individual will emigrate if $Y_{D}-k>Y_{O}$, or

$$
S_{2}>\frac{\mu_{O}-\mu_{D}+k}{b_{D 2}-b_{O 2}}-\frac{b_{D 1}-b_{O 1}}{b_{D 2}-b_{O 2}} S_{1} .
$$




\section{[ Figure 5: Selection Scenarios ]}

\subsubsection{Explaining Different Selection Patterns}

There is by now a large empirical literature that attempts to assess the direction of migrant selection. Most of the papers in this literature draw on Borjas (1987) as an underlying theoretical framework, but consider the special case where $u_{D}=c u_{O}$. The evidence these papers establish is mixed. Some papers (including Borjas' 1987 original analysis) find evidence that is compatible with the predictions of the simple one-dimensional skill model, namely that selection is positive from country $O$ to country $D$ if skill prices are higher in country $D$, and that selection is negative if skill prices are lower in country $D$. Examples are Cobb-Clark (1993) or Ramos (1992), who finds that, consistent with negative selection, nonmigrants in Puerto Rico are more educated than individuals migrating from Puerto Rico to the United States and that those individuals migrating back from the United States to Puerto Rico are more educated than those who remain in the United States. Others (for example Feliciano, 2005, Orrenius and Zavodny, 2005, McKenzie and Rapoport, 2007, Belot and Hatton, 2008) find limited, or no evidence that is compatible with this simple model.

In an influential paper, Chiquiar and Hanson (2005) investigate migration from Mexico to the United States. They argue that as the return to schooling is higher in Mexico, individuals with high levels of schooling are less likely to migrate. They compare actual wage densities for residents of Mexico with counterfactual wage densities that would be obtained were Mexican immigrants paid according to skill prices in Mexico - thus comparing the conditional distributions whose means are given by (I) and (III). The findings suggest that, were Mexican immigrants in the United States paid according to Mexican skill prices, 
they would fall disproportionately in the middle and upper middle of Mexico's wage distribution. As Chiquiar and Hanson (2005) point out, this does not support negative selection, but rather suggests intermediate or moderate positive selection of Mexican immigrants. This empirical finding is not compatible with the original model they started off with, which is our model above, but restricted to the special case where $u_{D}=c u_{O}$. To reconcile the empirical evidence with the model, they introduce non-linear migration costs. They assume that costs are large, but decrease in schooling at a decreasing rate, so that the net advantage of migration is highest for those in the middle of the distribution of skills. We re-produce their explanatory graph in Figure 6, which illustrates the case of constant migration costs $\left(Y_{D}\right)$ and varying migration costs that are non-linear in schooling $\left(Y_{D}^{*}\right) .{ }^{50}$ The way we have drawn the figure, skills are one-dimensional and migration costs $k$ are equal to $k=\exp \left(\mu_{\pi}-\delta_{\pi} S\right)$. The way the figure is drawn for the constant migration cost case ( $\delta_{\pi}=0$ ), the rent on human capital is higher in the destination country (U.S.), $\mu_{D}>\mu_{O}$, but the return to skill $S$ is higher in the origin country (Mexico). Thus, those with levels of skill $S$ below $S^{*}$ will emigrate, but those with levels of skill $S$ above $S^{*}$ will remain in Mexico - which is what Chiquiar and Hanson expected to find in the data. If $\delta_{\pi}>0$, and for sufficiently high fixed costs of migration, those at the low end of the skill distribution, below level $S^{L}$, may now find it too costly to emigrate, while migration is advantageous for those in the middle of the wage distribution, between level $S^{L}$ and level $S^{U}$. Chiquiar and Hanson

\footnotetext{
${ }^{50}$ The case of migration costs that are linear in schooling is straightforward in that it either leaves the overall selection pattern unchanged or it reverses it entirely, depending on the pace at which migration costs decrease with educational attainment.
} 
conclude that such cost schedules may provide a possible explanation for the observed migration pattern from Mexico to the United States. ${ }^{51}$

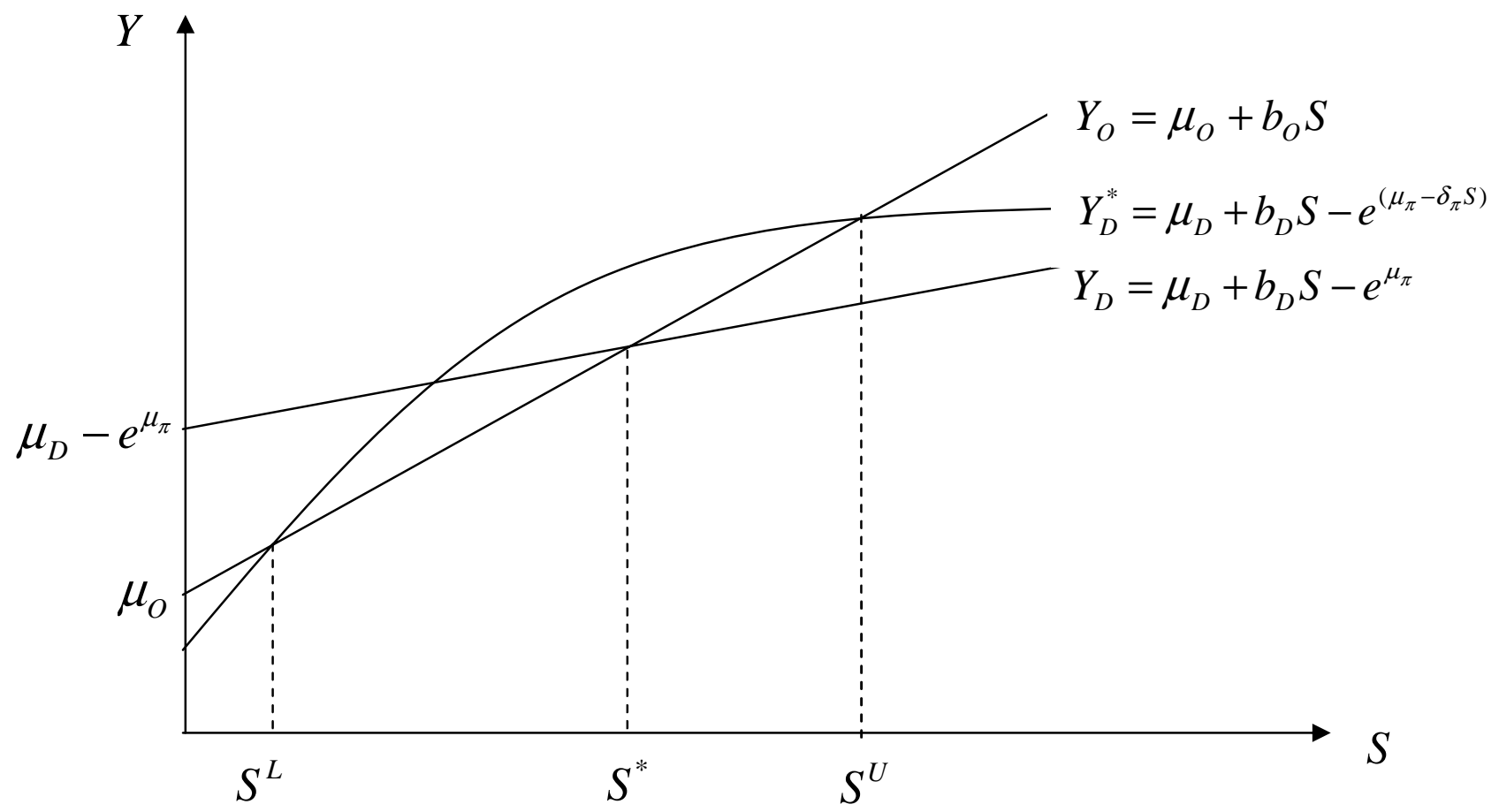

Figure 6: Non-linear Migration Costs

Non-linear migration costs are one reason why the one-dimensional model may not fit the data. Another reason may be that the one-dimensional model is overly restrictive, and omits an important aspect of migration decisions. Our discussion in the previous section has illustrated that migration decisions may be taken by considering the prices of multiple skills in the home- and potential host country. Clearly, education is a one-dimensional measure of

\footnotetext{
${ }^{51}$ For a further discussion of how different assumptions regarding the migration costs affect predicted selection patterns - for example whether or not migration costs are assumed to be fixed in time-equivalent units or in monetary units - see Rosenzweig (2007) and Hanson (2010).
} 
skills, which may for instance reflect well the academic skills of individuals, but may measure less well trade- and manual skills. If the latter are highly valued in the destination country, and are more prevalent for individuals in the middle of the education distribution, then migration patterns like those illustrated by Chiquiar and Hanson (2005) can be explained without making assumptions about migration costs, as the following example illustrates.

Consider the case where the skill distribution is two-dimensional. Suppose further that the first skill (which we termed "analytical" skill) is strongly correlated with education, but the second skill (which we termed "manual" or "trade" skill) is more strongly present in individuals with intermediate years of education. A multi-dimensional education system like the German apprenticeship system could produce such patterns, with individuals with intermediate levels of education having often gone through vocational training in crafts and trades. In countries without well-developed vocational training schemes, those with intermediate years of education may still have specialised in manual- or trade-related skills, as development of many of these skills requires some basic level of schooling. Measured education may reflect mainly skill $S_{1}$ but not necessarily skill $S_{2}$.

For the case of Mexican-U.S. migration, the manual/trade related skill dimension, although probably not highly valued in Mexico (as these skills are in plentiful supply), may command a relatively high price in the United States. This seems to be compatible with the occupational distribution of Mexicans immigrant workers in the United States, with the three main occupations falling exactly into this category of skills: cooks (6.1 percent of workers), construction labourers (5.8 percent), and grounds maintenance workers (4.9 percent). ${ }^{52}$

In Table 11, we give a numerical example. We distinguish between three education groups, "low", "medium", and "high". We have chosen the skill prices such that skill 1 has a higher

\footnotetext{
${ }^{52}$ Figures calculated from the 2009 IPUMS CPS sample using all Mexican-born individuals in the U.S. who are currently at work and aged above 16.
} 
return in the origin country, and skill 2 has a higher return in the destination country. Skill 1 increases with education but skill 2 is particularly high for those in the middle of the education distribution, and less developed for those who are either low educated or highly educated.

\section{[Table 11: Example Intermediate Selection]}

For simplicity, suppose migration costs are zero and the rental rate of human capital is identical in both countries and normalized to zero. The differentials between wages that can be obtained in the destination- and the origin country are reported in the last column of Table 11. Those who are low educated will not migrate and are better off in their country of origin, while those with intermediate levels of education will gain from migration, and those with high levels of education will again lose. Thus, this scenario creates a migration situation where only those in the middle of the education distribution will want to emigrate.

The scenario corresponds to the empirical evidence of intermediate selection provided by Chiquiar and Hanson (2005) without introducing non-linear migration cost. This illustrates the capacity of the multi-dimensional Roy model to accommodate different migration patterns that remain unexplained in a simple one-dimensional skill model.

To conclude, we believe that the full potential of the Roy model has not been explored in the migration context. The situation where individuals are characterised by multiple skills, and where these skills are priced differently in different countries, is, in our view, important in an ever more globalised world economy where individual countries specialise in particular industries. 


\subsection{Selection and Return Migration}

The framework above explains selection of immigrants, but does not address return migration. Borjas and Bratsberg (1996) use the one-dimensional Roy model to explore the selection of emigrants as well as those who return. We will briefly introduce the main features of their model, and extend it below to a multi-dimensional skill model.

Using our notation, log earnings in the origin- and destination country in their model are given by $Y_{O}=\mu_{O}+u_{O}$ and $Y_{D}=\mu_{D}+u_{D}$, respectively. They further assume that $u_{O}=c u_{D}$. Thus, $\operatorname{Var}\left(u_{D}\right)=1, \operatorname{Var}\left(u_{O}\right)=c^{2}$, and $\operatorname{Corr}\left(u_{D}, u_{O}\right)=1$, so that the variance of earnings is higher in the host country when $c<1$. They allow workers to have three options: to stay at home, to migrate temporarily, or to migrate permanently. A return migration may be optimal for the same reason we discuss in Section 3.3.4: staying abroad for a period $t$ increases human capital that is valuable at home by an amount $\kappa$. Thus, earnings when emigrating and returning are given by $Y_{D O}=t\left(\mu_{D}+u_{D}\right)+(1-t)\left(\mu_{O}+u_{O}+\kappa\right)$. No migration will take place if $Y_{O}>Y_{D}$ and $Y_{O}>Y_{D O}$; a permanent migration will take place when $Y_{D}>Y_{O}$ and $Y_{D}>Y_{D O}$; and migration and return migration will take place when $Y_{D O}>Y_{D}$ and $Y_{D O}>Y_{O}$. We illustrate the ensuing regimes in Figure 7 for the case where $c<1$ (which is the case where the variance of earnings - and the price of skills - is higher in the destination country). 


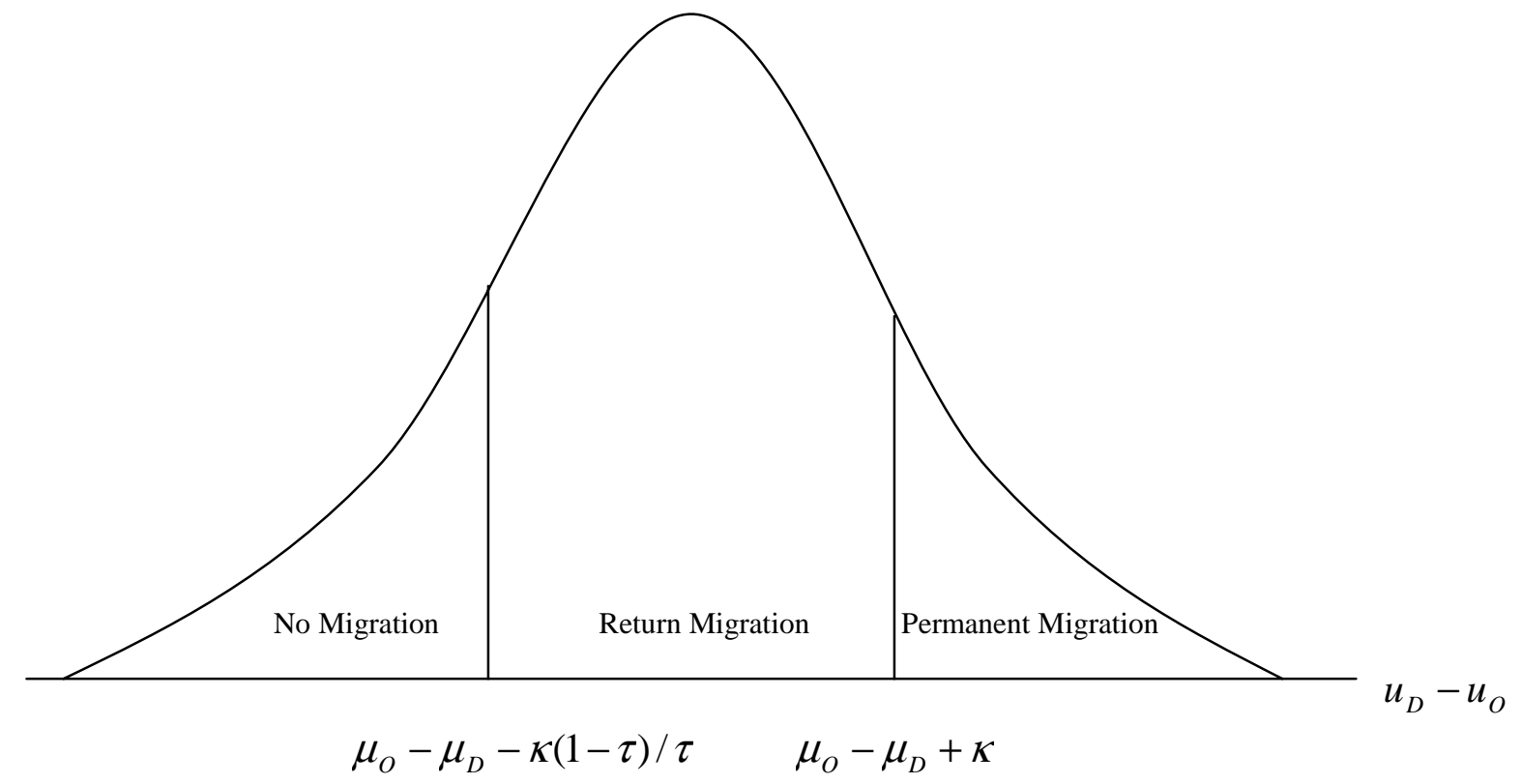

\section{Figure 7: Selection with Return Migration}

The figure shows the distribution of skills, where those with the lowest skills (below the threshold $\left.\mu_{O}-\mu_{D}-\kappa(1-\tau) / \tau\right)$ will decide not to emigrate, those with the highest skills (above the threshold $\left.\mu_{O}-\mu_{D}+\kappa\right)$ will decide to emigrate and remain permanently, and those between the two thresholds will decide to emigrate, but return home after spending time $t$ abroad. Thus, those who return have higher skills than those who have not emigrated, but lower skills than those who decide to remain permanently. Further, an increase in the rent on human capital in the country of destination $\mu_{D}$ will lead to a shift in the thresholds to the left, while an increase in the value of human capital acquired abroad back in the home country, $\kappa$, leads to a widening of the distance between the two thresholds and thus to increased return migration. It is easy to show that selection of emigrants and return migrants will be exactly 
the opposite when the price of skills is higher in the country of origin. We will now extend this model to a multi-dimensional setting.

\subsection{Learning, Multi-Dimensional Skills, and Return Migration}

The multi-dimensional model described in Section 4.1 is a static model, in the sense that it assumes that the skills individuals have cannot be augmented. In Section 3, we illustrate within a one-dimensional skill framework - that many migrations take place for the purpose of skill accumulation. Student migrations, for example, have increased by more than 80 percent between 1999 and 2008, constituting an increasingly important component of international migration as illustrated in Figure 1.

In a recent paper, Dustmann et al. (2010a) extend the two-dimensional framework, and develop a dynamic Roy model with learning, where migration- and return migration decisions do not only depend (for given skill prices) on the skills individuals possess, but also on learning opportunities in the origin- and destination countries, i.e. where skills can be acquired more efficiently. As before, they allow skills to command different prices in different countries, but, in addition, add the possibility that individuals can accumulate skills in different countries at different rates.

We will briefly sketch their model, using the same notation as before. Human capital is again an aggregate that summarises individual skills:

$$
Y_{j}=\ln y_{j}=\mu_{j}+\ln K_{j}(t)=\mu_{j}+b_{j 1} S_{1}(t)+b_{j 2} S_{2}(t),
$$


where $j=O, D$, and where the skills $S$ now carry a time index as they can be augmented in a "learning by doing" way. Dustmann et al. (2010a) concentrate on the case where $b_{D 1}>b_{O 1}, b_{O 2}>b_{D 2}$, which implies non-hierarchical sorting.

Individuals accumulate skills $S_{1}$ and $S_{2}$ while working. However, the extent of human capital accumulation differs between the two countries, due to different learning rates, and due to different prices for the two skills. Denoting the rate of accumulation of skill $S$ in country $j$ by $\gamma_{j S}$, and assuming that skill $S_{1}$ can be accumulated at a faster rate in country $D$, while skill $S_{2}$ can be accumulated at a faster rate in country $O$, one obtains $\gamma_{D 1}>\gamma_{D 2}, \gamma_{O 2}>\gamma_{O 1}$. Assuming continuous time, a person who works in country $D$ accumulates local productive capacity $\left(K_{D, D}\right)$ and productive capacity applicable in the country of origin $\left(K_{O, D}\right)$ at rates

$$
\frac{\dot{K}_{D, D}}{K_{D, D}}=b_{D 1} \gamma_{D 1}+b_{D 2} \gamma_{D 2} \equiv g_{D D} ; \quad \frac{\dot{K}_{O, D}}{K_{O, D}}=b_{O 1} \gamma_{D 1}+b_{O 2} \gamma_{D 2} \equiv g_{O D}
$$

Further, human capital is accumulated in country $O$ at rates

$$
\frac{\dot{K}_{O, O}}{K_{O, O}}=b_{O 1} \gamma_{O 1}+b_{O 2} \gamma_{O 2} \equiv g_{O O} ; \quad \frac{\dot{K}_{D, O}}{K_{D, O}}=b_{D 1} \gamma_{O 1}+b_{D 2} \gamma_{O 2} \equiv g_{D O}
$$

The parameters $g$ measure the rates at which productive capacity for either country can be augmented in each country. For example, the parameter $g_{O D}$ measures the rate at which productive capacity for the origin country can be acquired in the destination country $D$. This depends on the rate at which the two skills $S_{1}$ and $S_{2}$ are acquired in country $D\left(\gamma_{D 1}\right.$ and $\left.\gamma_{D 2}\right)$, and the prices these skills command in country $O\left(b_{O 1}\right.$ and $\left.b_{O 2}\right)$. 
The model is analysed under certainty, with infinitely long-lived agents, and a fixed interest rate. There is a fixed learning period: learning can take place only until age $T$, and remains constant thereafter, so that substitution between learning abroad and at home occurs. The time line is given in Figure 8. Individuals are born at 0 , emigrate at $\tau$, and have the possibility to return at $\varepsilon$. The length of the learning period is given by $T$, and the return time $\varepsilon$ may be before or after $T$.

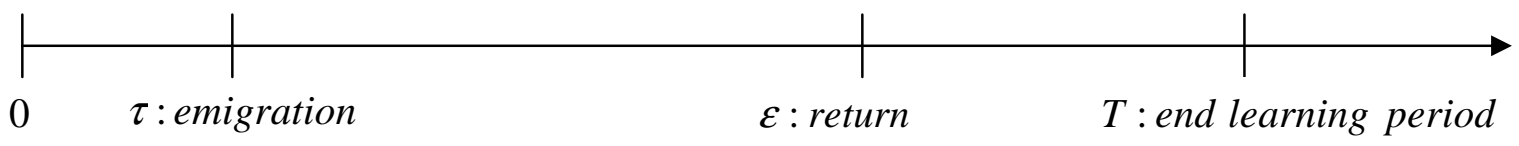

Figure 8: Timeline Return Migration

Three cases are distinguished that relate to the intensity to which staying in the host country affects human capital in the two countries, referred to as partial transferability, strong transferability, and super transferability. We will here briefly consider the first two cases.

Partial transferability characterises a situation where $g_{D D}>g_{O O}>g_{O D}$, while strong transferability characterises a situation where $g_{O D}>g_{D D}>g_{O O}$. Thus, with partial transferability, experience in the host country leads to less accumulation of human capital that is applicable to the home country than experience in the home country. Furthermore, experience in the home country leads to less accumulation of human capital that is applicable to the home country than experience in the host country leads to accumulation of human capital applicable in the host country. Thus, those who have a high endowment of $K_{D}$ will emigrate (and they will do so at the first possible opportunity, $\tau=0$, as this maximises the amount of human capital that can be accumulated). Furthermore, as experience in the host 
country enhances human capital in the host country by more than human capital in the home country, those who have decided to emigrate will never return.

With strong transferability, time in the host country will enhance human capital applicable in the home country by more than human capital in the host country and by more than time in the home country. Country $D$ is a "learning centre". Again, those who decide to emigrate will do so at $\tau=0$, and some of those who decide to emigrate will return prior to $T$.

In Figure 9, we display the marginal gain and marginal cost schedules from delaying the return back home for the case of strong transferability. ${ }^{53}$ The intersection of these two curves presents the optimal return time. The cost of a delayed return rises with the time in the host country, as the migrant's home country human capital $K_{O}$ increases at a faster rate than her host country human capital $K_{D}\left(g_{O D}>g_{D D}\right)$. A return will occur if the two schedules cross at $\varepsilon<T$. If the schedules cross at $\varepsilon>T$, Dustmann et al. (2010a) show that return will occur either at $T$, or the migration will be permanent.

\footnotetext{
${ }^{53}$ Notice that this situation is similar to the one-dimensional model we discuss in Section 3.3.4, where a return is triggered by an increase in human capital that is valuable in the home country. The reason for the increasing marginal gain schedule is that Dustmann et al. (2010a) allow for imperfect transferability of productive capacity. They assume that the rent on human capital in the destination country is initially the same as in the origin country $\left(R_{O}\right)$, but converges to the rent on human capital in the destination country $\left(R_{D}\right)$. The discontinuity in the marginal cost schedule at $T$ results from the assumption that learning can only take place until $T$.
} 


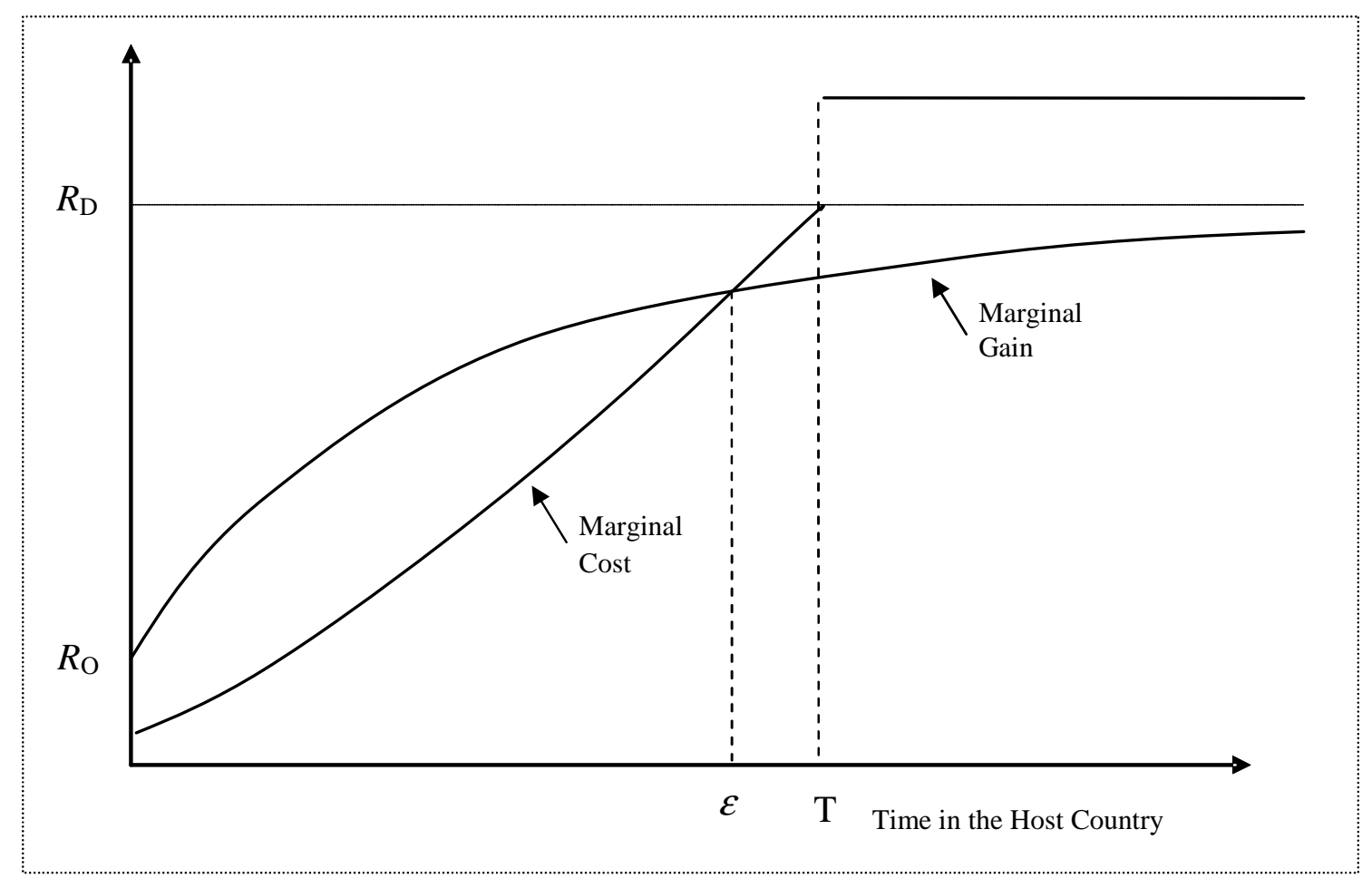

Figure 9: Return Migration in 2-Dimensional Skill Framework with Learning

Consider now the question who leaves, and who will return. In the case of partial transferability, migrations will either not occur, or they will be permanent, as the gap between home and host country human capital will increase with the migration duration. This situation is not dissimilar to the two-dimensional Roy model we have discussed in Section 4.1. The migration decision is based on $S_{2}(0)>\frac{\Omega}{b_{D 2}-b_{O 2}}-\frac{b_{D 1}-b_{O 1}}{b_{D 2}-b_{O 2}} S_{1}(0)$, where now the skills $S_{1}$ and $S_{2}$ are evaluated at $\tau=0$, and $\Omega$ depends on the present value of lifetime earnings, and is endogenously determined. As before, who migrates (and the type of selection) depends on the skill prices.

More interesting is the case of strong transferability. In this case, return migration occurs, given the assumptions on skill prices and their accumulation rates in the host and home country $\left(b_{D 1}>b_{O 1}, b_{O 2}>b_{D 2}\right.$, and $\left.\gamma_{D 1}>\gamma_{D 2}, \gamma_{O 2}>\gamma_{O 1}\right)$. Figure 10 illustrates the migration 
and re-migration choices in the $S_{1}(0)$ and $S_{2}(0)$ space. Those with relatively more $S_{1}(0)$ (which commands a higher price in the country of destination) will emigrate and, among them, those with relatively more $S_{2}(0)$ will return home.

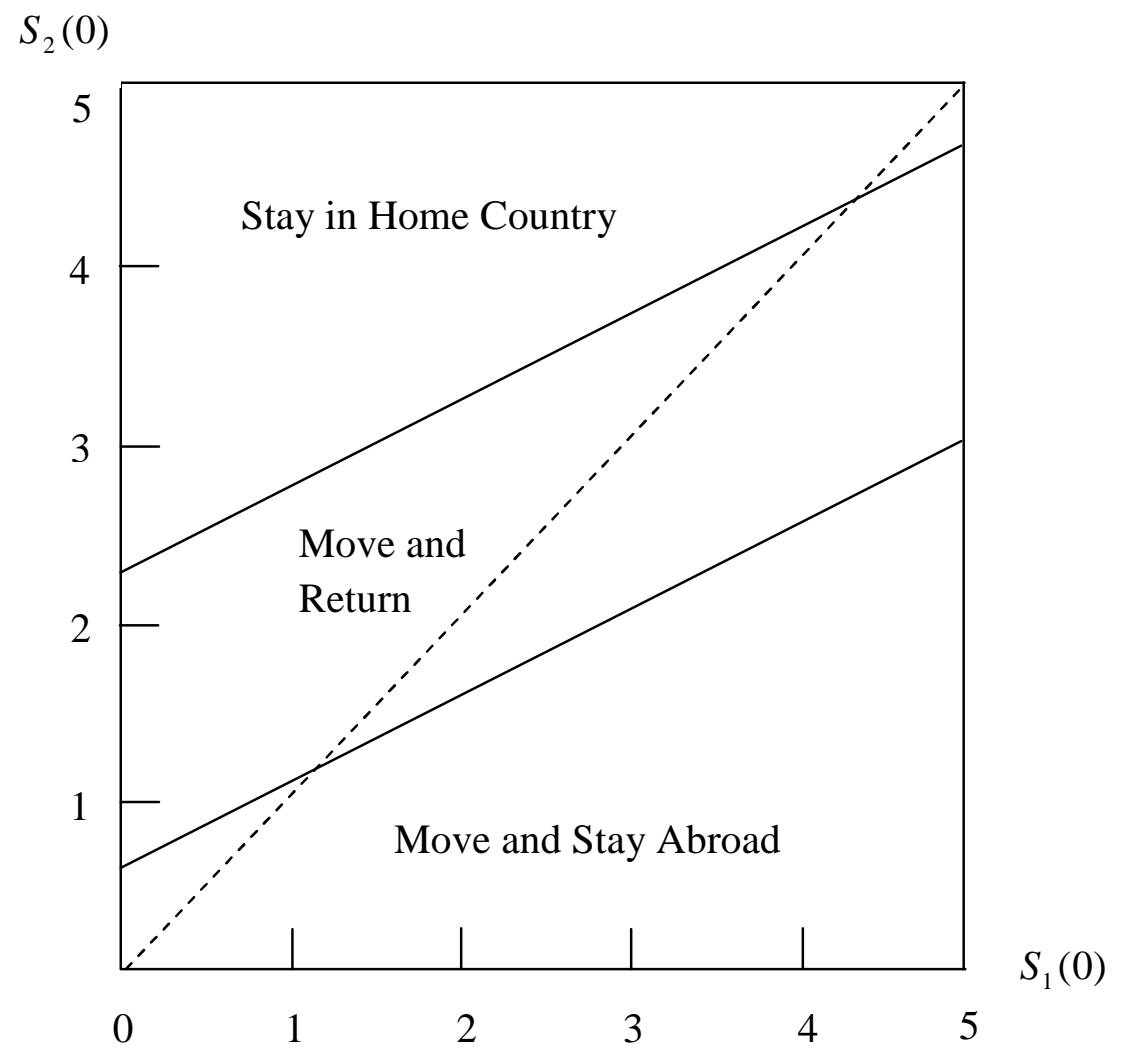

Figure 10: Selection in 2-Dimensional Skill Space with Learning.

In Borjas and Bratsberg (1996) the motive for a return is the same as the one we discuss here: the time in the host country may increase immigrants' home country human capital by more than their host country human capital. However, they do not consider learning (which in our case affects both emigration- and re-migration decisions), and they consider the return decision in the one-dimensional case. The model collapses to the onedimensional case by assuming that $S_{1}=S_{2}$ (or, alternatively, by assuming $b_{D 1}=b_{O 1}=0$ ). In 
that case, the two-dimensional distribution of $S_{1}$ and $S_{2}$ collapses to a one-dimensional distribution along the 45 degree line (or along the $S_{2}(0)$ axis if $b_{D 1}=b_{O 1}=0$ ). It is obvious that in that case, selection will be either positively or negatively selective, according to the relative skill prices - similar to Figure 7 in Section 4.2. For the way Figure 10 is drawn, emigration and re-migration will be negatively selective.

\subsection{Empirical Studies}

The selection of immigrants and return migrants, and the effect of migration on the skill base of the origin- and destination country, are important to understand the consequences of migration for those who do not migrate. The last sections have developed a framework within which these processes can be understood and analysed. We have also discussed some empirical papers that try to assess the direction of selection, and we have suggested some possibilities of how to think about selection in a multi-dimensional skill world.

In this section, we will discuss some of the empirical papers that study additional ways in which migrations affect non-migrants and their skills and skill accumulation. Much of this work can be directly related to the theoretical models we discussed in the previous sections.

\subsubsection{Emigration and Human Capital Investment in the Sending Country}

Emigration - or the possibility of emigration - may have important consequences for the skill accumulation in the origin country through several channels. First, emigrants may re- 
distribute some of the migration surplus they capture to family members back home by means of remittances which may then be used for educational investments that would otherwise not have been possible due to a lack of available funds and credit constraints (for a formal model describing this mechanism, see Rapoport and Docquier, 2006). A number of studies suggest that this is happening. Yang (2008), for instance, studies how sudden shocks in exchange rates due to the Asian financial crisis in 1997 affected child schooling and educational expenditures in the Philippines through their effect on remittances, taking advantage of the diverse set of host countries Filipino emigrants are located in. He finds positive effects on human capital accumulation in the origin households. Similarly, Cox Edwards and Ureta (2003) and Acosta (2006) provide evidence that remittances increase educational attainment of children in El Salvador, and López-Córdoba (2005) shows that municipalities in Mexico that receive more remittances have higher literacy and school attendance rates among their 6 to 14 year-old children.

Secondly, the possibility of a future migration may increase the incentives to invest in further education. This point has first been made by Mountford (1997), and we have illustrated the basic idea in Section 3.3.5: if the return to education is higher in a potential destination country, and if there is a positive probability of a future migration, then this will lead to a higher incentive to invest in human capital. While higher returns to education in the host country have a negative direct effect on the home country's skill base by inducing skilled emigration, it encourages human-capital formation in the longer-run. Mountford shows that this can potentially be beneficial for the country of origin ("beneficial brain drain"), as long as the probability of an actual future emigration is smaller than 1 (see also Stark et al., 1997, Vidal, 1998, and Beine et al., 2001). Such uncertainty of migration could 
result, for example, from the unpredictability and restrictiveness of migration policies in potential destination countries.

In a series of empirical studies, Beine et al. (2001, 2008, and 2010) assess the possibility of a beneficial brain drain using both cross-sectional and panel data for a large set of developing countries. Their findings provide some evidence that higher emigration rates may indeed have a positive effect on average human capital levels. For example, their work shows that in those countries that are characterised by low levels of human capital, low income and relatively low emigration rates of skilled workers (not exceeding 20 to 30 percent), the net effect on the average human capital level of the remaining population is positive, implying a beneficial brain drain effect. Such a positive incentive effect of emigration on human capital accumulation may be further reinforced in the presence of positive externalities of human capital in production (Stark and Wang, 2002) and perpetuated through the intergenerational transmission of human capital from one generation to the next. Schiff (2005) takes a more sceptical view regarding the likelihood and magnitude of a beneficial brain drain through the incentive effect of skilled emigration, a view supported by empirical evidence provided by Lucas (2005) and Checchi et al. (2007). These studies suggest that in many countries that experience emigration of their skilled workers, the net effect on the average educational attainment of those remaining in the country is likely to be negative. $^{54}$

Thirdly, selective emigration, as discussed in the previous section, may affect skill acquisition in the origin country by changing the existing skill base, which in turn affects the return to education. For example, if emigrants are predominantly high-skilled, then the

\footnotetext{
${ }^{54}$ This is more likely for those countries where skilled emigration rates are excessively high, such as many subSaharan African and Central American countries where they often exceed 40 percent. See also Marchiori et al. (2009), who come to this conclusion based on an overlapping-generations general equilibrium model.
} 
reduction in the relative supply of high-skilled workers in the home country should lead to an increase in skilled workers' wage rates. Mishra (2007) analyses this relationship for the Mexican case. Following an empirical strategy first suggested by Borjas (2003), she finds that Mexican emigration to the United States has had a significant positive effect on Mexican wages, a conclusion supported by evidence provided by Hanson (2007) and Aydemir and Borjas (2007). According to Mishra's results, a 10 percent decrease of Mexican workers in a skill group (measured by education and experience) due to emigration increases average wages in that group by 4 percent. Since emigrants are disproportionately drawn from the middle of the Mexican skill distribution (high school graduates and those with some college education) wages of medium-educated workers in Mexico have risen the most as a result of emigration. The resulting increase in the return to education may induce more individuals to invest in additional schooling.

Lastly, as discussed in Dustmann et al. (2010a), emigration and return migration may lead to an increase in the productive human capital stock in the sending country if a sufficiently large fraction of the migrations are temporary and the returning migrants accumulate valuable human capital while being abroad. The empirical evidence suggests that return migration of high-skilled workers - in particular the highest-skilled ones such as $\mathrm{PhD}$ recipients - is comparatively limited. One channel through which human capital of return migrants may lead to economic growth in their home countries is through facilitating knowledge and technology spillovers from the typically more advanced host countries. Domingues Dos Santos and Postel-Vinay (2004) derive the theoretical conditions required for such an overall positive effect to occur.

While each of the four channels presented may individually lead to a positive effect of migration on educational attainment in the origin country, there are also counteracting 
factors, likely to depend on the particularities of the considered migration situation, that tend to reduce educational attainment. For example, while the positive income effect through remittances may well alleviate credit constraints and lead to higher investments in education, the absence of a parent, and in particular of a mother, is likely to negatively affect overall parental inputs into the children's development. It may also force children to undertake additional household chores or other work to help maintaining the household. Cortés (2010), for instance, provides evidence that children of migrant mothers in the Philippines are approximately 10 percentage points more likely to be lagging behind in school compared to children with migrant fathers.

Also, the possibility of a future migration may create opposite incentive effects if the return to education in occupations potential emigrants consider as attainable is lower in the destination country than in the origin country (this could be due to a high return to trade (manual) skills and low returns to academic skills), or if migration is seen as an alternative to the acquisition of education. Due to these counteracting factors, the overall effect of migration on human capital acquisition in the home country is a priori ambiguous. McKenzie and Rapoport (2010) empirically assess this net effect of migration for the Mexican case based on data from the National Survey of Demographic Dynamics, using historical migration rates to instrument for current migration. Their findings show a significant negative effect of migration on school attendance and attainment of 12 to 18 year-old boys and 16 to 18 year-old girls: living in a migrant household is estimated to lower the probability of completing high school by 13 percent for males and 14 percent for females. These effects are somewhat mitigated for children from a poorer background which is consistent with a more prominent role of credit constraints in these households. Overall, most of the negative effect of migration on educational attainment is due to young males migrating themselves rather 
than attending school, and young females dropping out of school to work at home. ${ }^{55}$ For a detailed discussion of this literature, including earlier work, see Commander et al. (2004) and Docquier and Rapoport (2009).

\subsubsection{Immigration and Human Capital Investment in the Receiving Country}

In the last section, we considered the possible channels by which emigration can affect skill accumulation and education of those in the country of origin who do not emigrate. We now turn to the destination country. Again, there are various channels by which immigration may affect the accumulation of skills and education. First - and similar to what we discussed in the previous section - immigration may affect the price of skills by changing the relative factor supplies in the host country's economy. For example, a large inflow of low-skilled immigrants could lead to a decrease in the relative wages of low-skilled workers and to an increase in the relative wages of high-skilled workers. Most of the existing papers do not find large wage effects of immigration, although there is still a lot of controversy in the literature investigating this issue, which includes studies by Card (1990), Altonji and Card (1991), Butcher and Card (1991), Borjas et al. (1997), Card (2001), Friedberg (2001), Borjas (2003), Dustmann et al. (2005), Manacorda et al. (2006), Ottaviano and Peri (2008), Dustmann et al. (2008), and Glitz (2011). ${ }^{56}$

In the simplest model of an economy with one sector and unskilled and skilled labour, the effect of immigration depends on assumptions about the elasticity of capital supply as well as the share of skilled immigrants relative to the share of skilled workers in the

\footnotetext{
${ }^{55}$ See also De Brauw and Giles (2006) and Antman (2009), who similarly find a negative overall effect of migration on investments in education in China and Mexico, respectively, and Hanson and Woodruff (2003) who find a positive effect on the schooling of less-educated mothers' teenage daughters in Mexico.

${ }^{56}$ For a comprehensive overview of this literature, see Okkerse (2008).
} 
native population. We have seen in Table 1a in Section 2 that this share differs substantially across countries, so that we cannot expect immigration to have the same effects in different countries. If immigration is unskilled and affects skill prices by, for example, generating higher returns to education, then this may create incentives to invest into education. Findings for the U.S. by Jackson (2010) show that a 1 percent increase in relatively unskilled immigrant labour raises the rate of native college enrolment by 0.33 percent. This crowd-in effect is driven primarily by natives aged 18 to 24 due to their higher sensitivity to the returns to college education relative to older natives. In a more specific case, if immigrants are complementing labour supply of highly skilled women by providing domestic services that are otherwise not available or considerably more costly, then this is likely to increase the return to higher education for women. Such immigration should then not only lead to higher female labour supply (as shown by Cortés and Tessada, 2009, Cortés and Pan, 2009, and Farré et al., 2009) but also more human capital investment.

Secondly, immigration may create incentives for native-born workers to specialise in areas where they have a comparative advantage, for instance through their knowledge of the host country language or of existing networks. Such specialisation may well imply the accumulation of additional skills. More generally, if immigrants and natives have different comparative advantages in the labour market, then immigration will lead to shifts in the skill distribution of the native workforce. For example, Peri and Sparber (2009) show that natives reallocate their task supply towards occupations that are more communication and language intensive when faced with an inflow of immigrants that increases the supply of manual and physical labour intensive occupations. Task specialisation also extends to the highly educated segment of the labour market, where immigrants with a graduate degree tend to specialize in occupations demanding quantitative and analytical skills whereas native-born graduates 
specialize in occupations requiring interactive and communicative skills (Peri and Sparber, 2008).

Thirdly, immigrants may affect the human capital acquisition of natives through their presence in the educational system, both on the tertiary and prior levels. Borjas (2006a) finds that admitting foreign students to doctoral programs has a negative effect on the earnings of native doctoral recipients in the corresponding field. According to his results, a 10 percent increase in the supply of doctorates in a specific field reduces earnings of competing workers by 3 to 4 percent, half of which is due to a shift towards lower-paid postdoctoral appointments. He also finds some evidence of foreign students crowding out white native men (Borjas, 2007) which, although in line with earlier evidence provided by Hoxby (1998), stands somewhat in contrast to other findings showing no significant crowd-out effect of native students (Jackson, 2010). Crowding-out of native students has also been found at the secondary school level. Betts and Fairlie (2003) found evidence that for every four immigrants who arrive in public high schools, one native student switches to a private school, and that this "native flight" is particularly pronounced among white native students and in response to the arrival of non-English speaking immigrant children. Gould et al. (2009) show that the presence of immigrants during elementary school has a negative long-term effect on the probability of passing the high school matriculation exam in Israel, which enables students to attend college. Neymotin (2009), on the other hand, provides evidence that immigration did not negatively affect the SAT-scores of native high school students in California and Texas.

Finally, in a wider context, immigration may affect the stock of human capital in the host country by its contribution to new innovations. For instance, Hunt and Gauthier-Loiselle (2010), using the 2003 National Survey of College Graduates, show that the large number of 
immigrants with science and engineering degrees in the U.S. adds significantly to the number of patents granted: a 1 percentage point increase in the immigrant college graduates' population accordingly leads to an increase in patents per capita by 9 to 18 percent. Hunt (2010) and Kerr and Lincoln (2010) find complementary evidence regarding immigrants' contribution to general productivity-increasing activities such as patenting, publishing and company start-ups.

\section{The Children of Immigrants}

In the previous sections, we have considered the relationship between education, skill accumulation, and migration. We focussed on the way education interacts with migration decisions, and how migration affects skill accumulation and the skill base of those populations that do not migrate. In this context, we have touched on the educational achievements of the children of emigrants in the home countries, and on the incentives to invest in education for young people in the host countries as a result of immigration. In this section, we will focus explicitly on the children of immigrants in the countries of destination. We will study their educational achievements and ensuing labour market outcomes, and relate these to their parent generation and their peers born to native parents.

The educational achievement of the children of immigrants is one of the key issues in the immigration debate in many countries. Under-achievement of immigrant children is often seen as a major factor for the long-term segregation of immigrant communities, and educational achievements of immigrant children in comparison to their native-born peers are considered an important indicator of successful immigration policy (see, for example, OECD, 2006). As Table 8 in Section 2 shows, the test score results for children with a migration 
background, based on the PISA data, are indeed on average below those of children of nativeborn parents, although there is quite some variation across countries. This is in line with the limited set of findings for individual countries that are based on alternative standardized performance measures. For instance, Rampney et al. (2009) show that the reading (mathematics) score gap in the National Assessment of Educational Progress (NAEP) between White and Hispanic students in the U.S. in 2008 was 9.2 (6.4) percent for the 9 yearolds, 9.7 (7.9) percent for the 13 year-olds, and 8.8 (6.7) percent for the 17 year-olds.

As Figure 2 shows, educational achievement of immigrant children is related to the educational achievement of their parents. This suggests that the relatively low achievement of immigrant children in some countries is at least partly due to the lower educational background of their parent generation, and does not necessarily reflect the failure of the host society to educate second-generation immigrants. However, in the public debate the comparison between children born to immigrants and native parents is often unconditional on parental characteristics - a comparison that seems not very meaningful. If the first generation of immigrants is less educated than the native population (which is the case for a number of countries, see Section 2), then even a strong educational progress of immigrant children may still result in educational outcomes that are lower than those of natives. We will discuss this issue below.

How should we then think about the dynastic assimilation of immigrant communities? What is it exactly that determines the educational outcomes of immigrant children? There are at least three factors that matter. First, as just argued, the educational achievements of immigrant children are linked to their parental background. There is a large literature on the intergenerational transmission of human capital, for example Behrman and Taubman (1985), Solon (1992), Zimmermann (1992), Björklund and Jäntti (1997), Corak and 
Heisz (1999), or Blanden et al. (2004), which shows that there is considerable intergenerational immobility across generations in a large number of outcomes.

Second, immigrant children may be differently affected by the institutional setting and support structures of the host countries' education systems. Another large literature in economics studies the different features of educational production, and how it relates to resources, institutions, and parental input (see, for example, Todd and Wolpin, 2003, Cunha et al., 2006, or Hanushek and Woessmann, 2008, 2010). Even without differential access to these educational institutions across populations in the same country, the same resources may affect immigrant children's educational outcomes in a different way than those of children born to native-born parents - for example due to complementary forms of knowledge that are not sufficiently available in immigrant communities ${ }^{57}$ - and prevent immigrants' children from making full use of existing educational support structures.

Third, the social context in which immigrant children grow up is an important determinant of their educational outcomes. Borjas (1992, 1995a) was among the first to emphasise what he calls the effect of "ethnic capital" on the educational achievements of immigrant children. The ethnic context of immigrants shapes their own, and their parents' values and incentives. For instance, immigrant children who grow up in an ethnic environment that is characterised by particular educational- and occupational choices are likely to make similar choices. Ethnic capital summarises things like peer effects, role models, and community ambitions, which may all be strongly related to immigrants' educational outcomes. This may reduce the overall educational attainment of secondgeneration immigrants, but it may also enhance it. A good example is the success of South-

\footnotetext{
${ }^{57}$ On of those is, for instance, language. Dustmann et al. (2010f) illustrate that language is the key factor that holds children of ethnic minority background back in the first years of full-time education.
} 
and South-East Asian immigrant children that may be partly due to the high value attached to education within their communities (which in turn may be related to the Confucian tradition, which emphasises the importance of study). In the UK, for example, Chinese students, who at the beginning of their compulsory schooling at age 6/7 start off with a 7.6 percent of a standard deviation lower English test score than White British students, outperform their native counterparts by more than 50 percent of a standard deviation by the time they reach age 15/16 (Dustmann et al., 2010f).

There are other important factors that relate to the educational achievement of immigrant children. Parental considerations that affect their own investment in learning may also influence decisions about their children. For instance, we have seen that in the case of temporary migrations, and if skills acquired in the host country are only partially transferable to the home country labour market, immigrants will invest less in their human capital than they would in case of a permanent migration. In the same way, it is not unlikely that parental decisions about the educational attainment of their children are affected by where parents see their children's future. For instance, if a migrant household intends to return to the home country, and if this planned return migration is including the children, then this may induce parents to invest less into their children's education than they would do in the case of a permanent migration. Dustmann (2008) has made this point, and provides empirical evidence that supports this hypothesis.

As before, we will commence with a formal discussion, laying out some of the key issues. We will then review and interpret the empirical evidence that exists to date.

\subsection{Immigrants and Intergenerational Mobility}


The empirical approach to study the relationship between outcomes of parents and outcomes of children is to regress a permanent outcome measure (for example earnings) of the child on a permanent outcome measure of the parent, by applying a Least Squares estimator to the regression equation

$$
\log y_{i t}^{j}=\alpha^{j}+\rho^{j} \log y_{i t-1}^{j}+\varepsilon_{i t}^{j},
$$

where $\log y_{i t}^{j}$ and $\log y_{i t-1}^{j}$ are some permanent measures for outcomes (such as education, wealth or earnings) of a child and parent, respectively, belonging to group $j$ (which could be immigrants and their children, or natives and their children). For simplification, in what follows, we will refer to the outcome as "earnings". According to Equation (14), the earnings of family i's child is determined by family i's parental earnings and other influences $\varepsilon$ (which we will discuss further below). The parameter $\alpha^{j}$ can be thought of as the average effect on earnings of these other influences, which can differ between groups. Assuming that the variances of $\log y_{i t}^{j}$ and $\log y_{i t-1}^{j}$ are the same, $\rho^{j}$ is the population correlation coefficient between $\log y_{i t}^{j}$ and $\log y_{i t-1}^{j}$. Assume that the $\varepsilon_{i t}^{j}$ are iid distributed with mean zero and $\operatorname{Var}\left(\log y_{i t}^{j}\right)=\operatorname{Var}\left(\log y_{i t-1}^{j}\right)=\sigma_{y}^{2, j}$, so that estimation of Equation (14) gives a consistent estimate of $\rho^{j}, \hat{\rho}^{j} .^{58}$ The coefficient $\rho^{j}$ represents the fraction of economic advantage (in terms of earnings, education, or wealth) that is on average transmitted across the generations. It is called the intergenerational correlation coefficient or transmission parameter. A coefficient close to zero suggests high intergenerational mobility, while a coefficient close to one indicates low mobility. The coefficient $\left(1-\rho^{j}\right)$ is often referred to as the degree of regression to the mean.

\footnotetext{
${ }^{58}$ If the variance of log wages differs across the two generations, the OLS estimator $\hat{\rho}$ measures $\rho \sigma_{y t} / \sigma_{y t-1}$.
} 
For immigrants, the study of intergenerational mobility has a particular significance. If first-generation immigrants are disadvantaged, in the sense that they are less well educated or have lower earnings than the native population, then immigrant and native populations may differ for many generations, depending on the magnitude of $\rho$.

To illustrate this point, consider Equation (14), and index outcomes of immigrants and natives by $I$ and $N$, respectively. Further, allow the intergenerational transmission parameter to differ between the two groups, so that $\rho^{N}=\rho^{I}+\zeta$. Then the wage differential between the two populations in generation $t$ is given by

$$
E\left(\log y_{t}^{N}\right)-E\left(\log y_{t}^{I}\right)=\alpha^{N}-\alpha^{I}+\rho^{N}\left(E\left(\log y_{t-1}^{N}\right)-E\left(\log y_{t-1}^{I}\right)\right)+\zeta E\left(\log y_{t-1}^{I}\right) .
$$

Consider the case where $\zeta=0$ (intergenerational transmission $\rho$ is the same in the two populations) and assume for simplicity that $\alpha^{N}=\alpha^{I}$. In this case, the native-immigrant gap in outcomes disappears from one generation to the next only if $\rho=\rho^{N}=\rho^{I}=0$. If $\rho=1$, the initial outcome differential will be fully transmitted to the next generation. If $\rho$ is smaller than 1, inequality between the two groups will fall and assimilation across groups will take place, but not within one generation. The magnitude of $\rho$ determines the speed of convergence. For example, for $\rho=0.4$, a 20 percent average earnings disadvantage for immigrants in the parent generation translates into an 8 percent earnings disadvantage in their children's generation. Now suppose "other influences" determining outcomes as captured by the parameter $\alpha$ differ across the two groups. If $\alpha^{N}-\alpha^{I}>0$, the difference in outcomes in the next generation may even be larger than in the parent generation, despite regression to the mean, as indicated by $\rho<1$. In the next section, we develop a simple model of 
intergenerational mobility, and we will show that one reason for differences in the mean influence of other factors could be discrimination.

Now consider the case where $\zeta \neq 0$ : the intergenerational transmission parameter differs between the two groups. It follows from Equation (15) that if $\zeta>0$ (i.e. intergenerational mobility in the advantaged groups - natives - is smaller than in the disadvantaged group), outcome differentials in the next generation may even be larger than those in the previous generation despite regression to the mean in both groups. The degree of assimilation between the two groups across generations depends on the parameters $\zeta, \rho^{N}$, and $\alpha^{N}-\alpha^{I}$.

In general, earnings of immigrants in the next generation will converge to the earnings of natives (in the sense of $\left.E\left(\log y_{t}^{N}\right)-E\left(\log y_{t}^{I}\right)<E\left(\log y_{t-1}^{N}\right)-E\left(\log y_{t-1}^{I}\right)\right)$ if

$$
\frac{\alpha^{N}-\alpha^{I}}{\left(1-\rho^{N}\right) E\left(\log y_{t-1}^{I}\right)}+\frac{1-\rho^{N}+\zeta}{\left(1-\rho^{N}\right)}<\frac{E\left(\log y_{t-1}^{N}\right)}{E\left(\log y_{t-1}^{I}\right)}
$$

Thus, if mean log earnings of natives are larger than those of immigrants in generation $t-1$, there will always be convergence as long as $\alpha^{N}-\alpha^{I}=0, \zeta=0$ and $\rho^{N}=\rho^{I}=\rho<1$. On the other hand, both a higher $\zeta$ (less intergenerational mobility of natives) and a higher $\alpha^{N}-\alpha^{I}$ (stronger effect of other influences on native earnings than on immigrant earnings) lead to slower convergence. For sufficiently high values of either of these parameters, the difference in expected earnings between immigrants and natives in the next generation could be larger than in the previous generation.

What is the interpretation of the parameters $\rho$ and $\alpha$, and how do they relate to an underlying structural model and its parameters? This is what we will explore next. We will 
show why these parameters are likely to differ between immigrants and natives and generate different intergenerational correlation coefficients and intercepts and hence different intergenerational persistence of outcomes for these groups. We will also demonstrate why the assumption that $\varepsilon_{i t}$ is iid is unlikely to hold in reality, which may affect the actual estimation of the parameter $\rho$.

\subsection{A Model of Intergenerational Mobility of Immigrants}

Becker and Tomes (1979) develop a theoretical model for the intergenerational transmission of wealth and human capital, and Solon (2004) provides a parameterisation that derives an intergenerational transmission function of the type illustrated above. In the following, we will draw on Solon's formulation, and simplify and adjust it to emphasise what we believe are some key insights for the study of educational attainments of the children of immigrants in comparison with natives. The model is a permanent income model of intergenerational mobility with parental investments in the child's earnings potential. ${ }^{59}$ Consider a one-person household with one child, situated in the host country. There are two periods. In the first period (period $t-1$ ) the parent has earnings equal to $y_{t-1}$ and the child is in full-time education. In the second period (period $t$ ) the parent retires while the child participates in the labour market and has earnings $y_{t}$, which depend in magnitude on investments in education in the first period. The parent is altruistic and maximises an intertemporal utility function by choosing first period savings $S_{t-1}$, and investment in the child's human capital in the first period, $I_{t-1}:$

\footnotetext{
${ }^{59}$ See Dustmann (2008) for an extension that takes account of the way the probability of a permanent migration as opposed to a future return - may affect the decision of the parent to invest in their offspring's human capital.
} 


$$
V=u\left(c_{t-1}\right)+\delta\left[u\left(c_{t}\right)+\gamma \log y_{t}\right]
$$

where $u($.$) is the parent's utility from consuming c_{t}$ and $c_{t-1}$ in periods $t$ and $t-1$, respectively, and $\delta$ is a discount factor. The parameter $\gamma$ is an altruistic weight. If $\gamma=0$, the parent does not consider the child's earnings in period $t$. Assume that parental investments $I_{t-1}$ translate into human capital of the child $\left(H_{t}\right)$ according to the following production technology:

$$
\log H_{t}=h_{t}=\theta \log I_{t-1}+e_{t}
$$

The parameter $\theta$ is a technology parameter measuring the productivity of investments. This parameter can be viewed as the "talent" or the "ability" of the child, but may also be related to institutional settings and school quality. The term $e_{t}$ is the human capital the child receives without any direct parental investments. This term represents the attributes endowed upon the child, depending on characteristics of the parents, the child's upbringing, genetic factors, environment, and luck. It may also depend on existing networks, as well as the lack of opportunity to move out of social and economic structures from one generation to the next. Becker and Tomes (1979) refer to this term as endowments of capital that "are determined by the reputation and 'connections' of their families, the contribution to the ability, race, and other characteristics of children from the genetic constitutions of their families, and the learning, skills, goals, and other 'family commodities' acquired through belonging to a particular family culture. Obviously, endowments depend on many characteristics of parents, grandparents, and other family members and may also be culturally influenced by other families". The influence of cultural factors and family background may be particularly important for immigrants and we will discuss the implications in Section 5.2.3. These factors include what Borjas (1992) calls "ethnic capital" the quality of the environment in which parental investments are made. 
Human capital translates into earnings of parents and children according to the following relationship:

$$
\begin{aligned}
& \log y_{t-1}=\mu_{t-1}+r_{t-1} h_{t-1}, \\
& \log y_{t}=\mu_{t}+r_{t} h_{t} .
\end{aligned}
$$

Our formulation allows for different "rental rates" on human capital in the different periods, $\mu$, as well as different returns to human capital, $r$. It follows from (17) and (18-b) that the child's earnings in the second period are related to parental investments by:

$$
\log y_{t}=\mu_{t}+r_{t} \theta \log I_{t-1}+r_{t} e_{t} \text {. }
$$

The parent's consumption in period $t-1$ equals $c_{t-1}=y_{t-1}-I_{t-1}-S_{t-1}$, where $y_{t-1}$ are earnings in period $t-1$. For simplicity, we assume that the parent cannot borrow against the child's future earnings and does not bequeath financial assets to the child. As the parent retires in period $t$, period $t$ consumption is thus equal to period $t-1$ savings, $c_{t}=S_{t-1}$.

Choosing a simple logarithmic utility function for consumption, and substituting (19) for the child's earnings into (16), the optimisation problem of the parent can be expressed as

$$
\max _{S, I} V=\log \left(y_{t-1}-I_{t-1}-S_{t-1}\right)+\delta\left[\log S_{t-1}+\gamma\left(\mu_{t}+r_{t} \theta \log I_{t-1}+r_{t} e_{t}\right)\right]
$$

Maximising (20) with respect to savings and investment, and solving the first order conditions for the optimal investment $I_{t-1}$ yields:

(21) $\quad I_{t-1}=\frac{\delta \gamma \theta r_{t}}{(1+\delta)+\delta \gamma \theta r_{t}} y_{t-1}$.

The term in the numerator (which is the same as the second term in the denominator) 
is the expected discounted utility gain to one log unit of parental investment in the child's human capital. The first term in the denominator is the expected lifetime utility gain from one $\log$ unit of additional lifetime consumption. Thus, investments into the child as a fraction of income equal the expected fraction of utility resulting from this investment. Simple comparative statics show that investment in the child's human capital increases with altruism $\gamma$, the productivity of investment $\theta$, the return to human capital $r_{t}$, and the discount rate $\delta$.

Human capital and earnings of the child are related to human capital and earnings of the parent as follows:

$$
\begin{aligned}
& h_{t}=\theta \log \left[\frac{\delta \gamma \theta r_{t}}{(1+\delta)+\delta \gamma \theta r_{t}}\right]+\theta \mu_{t-1}+\theta r_{t-1} h_{t-1}+e_{t} \\
& \log y_{t}=\mu_{t}+r_{t} \theta \log \left[\frac{\delta \gamma \theta r_{t}}{(1+\delta)+\delta \gamma \theta r_{t}}\right]+\theta r_{t} \log y_{t-1}+r_{t} e_{t} .
\end{aligned}
$$

Equations like (22-a) and (22-b) are usually estimated in the literature when regressing education (or earnings) of children on those of their parents. Consider first Equation (22-a). The level of education obtained by the child depends on all the parameters that affect investment. These may differ between immigrants and natives. If, for instance, the rate of return to skills $r_{t}$, is perceived to be lower for immigrants, the level of human capital acquired by immigrant children will also be lower as will be their earnings. Neal (2006), for example, discusses statistical discrimination as one reason that has frequently been brought forward to explain the low attainment levels of black youth in the U.S., in the sense that employers are not likely to view them as skilled no matter what their level of education is. Also, a lower price for human capital, $\mu_{t-1}$, in the parent generation of immigrants relative to natives, due to, for instance, a lack of important complementary skills such as language, leads to a lower level of education 
of their children. Finally, education of children depends on "inherited" traits as well as institutional features such as access to schooling and school quality, which are all captured in the term $e_{t}$. If these differ between the immigrant and native population, both their education and earnings may differ due to this channel, too (see, for example, Parent, 2009).

Suppose now that we regress log earnings (or education) of immigrant children on log earnings (or education) of their parents, following much of the literature that we will discuss below. What does the OLS coefficient we estimate measure? Following Becker and Tomes (1979) and Solon (2004), assume that $e_{t}$ follows an AR(1) process, reflecting a serial correlation in the parent's and the child's human capital endowments so that $e_{t}=\lambda_{0}+\lambda_{1} e_{t-1}+v_{t}$, where $v_{t}$ is a white noise error term and $\lambda_{1} \in(0,1)$. As discussed above, these endowments may include ability, but may also be related to networks, ethnic reference groups, or other "ethnic capital". Then, in steady state, the probability limit of the OLS estimate of the coefficients on $h_{t-1}$ and $y_{t-1}$ are given by $\frac{\theta r_{t-1}+\lambda_{1}}{1+\theta r_{t-1} \lambda_{1}}$ and $\frac{\theta r_{t}+\lambda_{1}}{1+\theta r_{t} \lambda_{1}}$, respectively. Thus, the coefficient estimate of $\rho$ in the simple model we discussed at the beginning of Section 5.1 is larger the larger the return to human capital and the productivity of human capital production, $r_{t}$ and $\theta$, and it also increases in the correlation in heritable traits, $\lambda_{1}$. All these parameters can differ between populations. For instance, if the heritability parameter is larger in the immigrant population because family structures are tighter, the intergenerational correlation coefficient will also be larger for this population, implying less mobility from one generation to the next.

\subsection{Empirical Evidence}




\subsubsection{Schooling Outcomes of Immigrant Children}

We start in this section with the first important period in an immigrant's life, his or her childhood. To this end, we return to the data from the PISA study that we already introduced in Section 2. As we have seen in Table 8, with the exception of Australia and Canada, the student population with immigrant background tends to score significantly lower than the native population in both mathematics and reading. One of the main explanations for these differences could be the lack of fluency in the host country language. The last two columns of Table 8 indeed show that students who speak a different language at home than the language of instruction at school fare particularly badly. In addition to language, the general skill level of the parents is likely to play a major role in the ability of their children to acquire human capital and, given that in most host countries the immigrant population is less educated than the native population, may contribute significantly to any observed differences in the raw test scores.

\section{[Table 12: PISA Summary Statistics]}

Table 12 shows a number of descriptive statistics for our 10 most important immigrant receiving OECD countries. For the sake of brevity, the immigrant student populations we consider include all children whose parents are both foreign-born, no matter whether the children themselves were born in the host country or not. ${ }^{60}$ As Column (4) shows, except for Australia and Spain, the majority of immigrant students speak a foreign language at home that is different from the language of instruction at school. ${ }^{61}$ This pattern is particularly pronounced in Italy and the United States, where the share of those speaking a foreign

\footnotetext{
${ }^{60}$ The results we present in this section draw on work by Dustmann et al. (2010c).

${ }^{61}$ Whether or not a student speaks a foreign language at home is obviously only an imperfect measure of language skills as it may very well be that a student is proficient in the language of instruction but still speaks another language at home with his or her parents.
} 
language at home exceeds 60 percent. Given the complementarity between language and human capital accumulation, this is bound to affect the performance of these children in the different proficiency tests. Columns (5) and (6) show that relative to the native student population, immigrant students have parents with, on average, significantly lower educational attainment. With the exception of Italy and Spain, the share of native students whose both parents have low educational attainment (measured as not exceeding lower secondary education), is fairly low, ranging between about 2 and 15 percent, whereas it ranges between 10 and 40 percent for immigrant students (not considering Australia and Canada). The differences in parental educational attainment are particularly large in France, Switzerland and the United States. These results also hold when looking at alternative measures of economic status, such as the Highest International Socio-Economic Index of Occupational Status (HISEI) of the parents (not reported), which is designed to capture those features of occupations that convert education into income (Ganzeboom et al., 1992).

So how do these differences in language and family background contribute to the measured raw test score gaps between natives and immigrants? Column (7) shows again the raw proficiency gaps in mathematics between immigrant students and native students. As we already discussed in Section 2, immigrant students do substantially worse in all destination countries except Australia and Canada, with the largest gaps arising in Germany, the Netherlands, and Switzerland. However, controlling for language reduces these gaps significantly as shown in Column (8). The reduction is particularly large in Germany, Italy, Switzerland, the UK and the United States. In the latter two countries, including an indicator for language spoken at home actually closes the test score gap entirely, with none of the remaining small differences being statistically significant. Adding control variables for the educational attainment of the parents in Column (9) has a further mitigating effect on the test 
score gaps between natives and immigrants, in particular in France, the Netherlands and the United States. The only major exception is Spain where the test score gap actually widens once controls for parental education are included, owing to the, on average, better educational background of immigrant children's parents (compare Columns (5) and (6)). Very similar patterns hold for immigrant and native students' reading proficiency (not reported) where, naturally, the impact of language spoken at home is an even stronger determinant of performance. Both language and the educational attainment of the parents thus go a long way in explaining the large gap in mathematics and reading skills between native and immigrant students (for additional evidence, see for example Entorf and Minoiu, 2005, and Schnepf, 2007).

The significance of language spoken at home for the - at least initial - achievements of immigrant children at school is also documented in other work. In a recent paper based on the British school census, Dustmann et al. (2010f) investigate the school curriculum of children from ethnic minority backgrounds and compare it to children from non-minority families, from the age of 5 until the age of 16. Their findings show that just before they start school, ethnic minority children significantly underperform in early cognitive tests compared with white British-born children. However, by the end of compulsory schooling at age 15/16, most ethnic minority groups catch up with (Bangladeshi, Pakistani and black non-Caribbean pupils) or even overtake (Indian and Chinese pupils) their white British counterparts (in key stage 4 tests). The analysis shows that improvements in their proficiency of the English language is the single most important contributor to the catch-up of ethnic minority pupils relative to white British pupils, accounting for up to two thirds of their relative progress. The importance of language proficiency, in particular, for school performance and integration more generally has been recognized by many host countries by implementing a variety of 
policies and practices to support immigrant students' acquisition of the language of instruction. For a detailed overview of these policies across OECD countries, see OECD (2006).

\section{[Table 13: PISA Regression Results]}

\subsubsection{Intergenerational Transmission of Human Capital}

The results presented in Table 12 demonstrate that parental background and language spoken at home matter importantly for the educational success of the children of immigrants. We now briefly review the empirical evidence regarding the intergenerational transmission of human capital and the long-term assimilation of second-generation immigrants. ${ }^{62}$

Chiswick (1977) and Carliner (1980) were the first to look at the intergenerational aspect of immigrant earnings in the United States. These studies do not relate one generation's earnings to the earnings of its parent generation in the spirit of Equation (14) but compare directly the earnings of different generations of immigrants using cross-sectional data from the 1970 U.S. Census. They distinguish male first- and second-generation immigrant workers and native workers, with the latter defined as individuals who have two native-born parents. Both studies' key finding is that the earnings of second-generation immigrant workers are higher than those of natives. ${ }^{63}$ In addition, Carliner (1980) finds that second-generation immigrant men also earn more than first-generation immigrant men from the same ethnic group. Pointing again to the substantial changes in cohort quality over the

\footnotetext{
${ }^{62}$ For an overview of the literature on intergenerational mobility, see Solon $(1999,2002)$, Corak $(2004,2006)$ and D'Addio (2007).

${ }^{63}$ Note that Chiswick only looks at white second-generation immigrant men who, at the time of the study, had predominantly a European background.
} 
course of the $20^{\text {th }}$ century and the bias this can induce in cross-sectional analyses, Borjas (1993) employs grouped data from the 1940-1970 Censuses to isolate cohort effects from intergenerational earnings mobility. He compares the relative earnings of foreign-born men in 1940 with the relative earnings of their potential offspring 30 years later, in 1970. His findings show that the earnings of second-generation immigrants are strongly correlated with the earnings of the corresponding first generation, with an estimate of the intergenerational correlation coefficient of around 0.45 . Hence about half of the differences in relative economic status across different ethnic groups in one generation persist into the next generation. Using more recent data reaching up to the year 2000, but based on a similar methodology of grouping immigrants and their potential offspring, Card et al. (2000) and Borjas (2006b) show that the intergenerational correlation of earnings has remained relatively unchanged over the last decades: native-born children of immigrants can expect to close 50 to 60 percent of the gap in relative earnings experienced by their father's generation. Card et al. (2000) also estimate the intergenerational correlation in the years of education obtained and find a very stable estimate over time for both sons and daughters in the range of 0.41 to 0.47 . These estimates are comparable with those we report in Figure 2 for the pooled sample of immigrant groups in France, Germany and the UK, where the slopes of the regression lines with respect to education and $\log$ wages are 0.53 and 0.36 , respectively. ${ }^{64}$ Overall, the empirical evidence suggests that most of the strong intergenerational linkages between immigrant fathers and their native-born children work through education.

With increasing data availability and the passing of time, it has become possible in some cases to analyse the correlation between first and third generation immigrants. Using

\footnotetext{
${ }^{64}$ Dustmann and Theodoropoulos (2010) analyse the educational attainment and economic behaviour of ethnic minority immigrants and their children in Britain and compare it to that of their white British born peers, showing that Britain's ethnic minority immigrants and their children are on average better educated than their white native-born peers, and that groups with better educated parents have higher levels of education.
} 
data from the 1910 U.S. Census as well as the General Social Surveys to link a sample of American-born workers to their grandparents who arrived in the U.S. during the first Great Migration at the beginning of the twentieth century, Borjas (1994, 2006b) estimates an intergenerational correlation in relative wages between the first and the third generation of about 0.22 , which implies that 22 percent of the wage gap between any two groups in the immigrant generation persisted into the third generation. Note that this is compatible with a correlation coefficient across subsequent generations of about 0.5 - similar to the one estimated in the studies discussed above. Current differences in economic status among firstgeneration immigrants are thus likely to shape the labour market experience of their offspring for generations to come. ${ }^{65}$ Table 13 summarises the existing literature on the intergenerational mobility in earnings and educational attainment of immigrants across a variety of different countries. Column (7) reports estimated intergenerational correlation coefficients based on specifications such as the one in Equation (14). Overall, the evidence suggests that intergenerational mobility is lower for immigrants than for natives, higher for immigrant women than for immigrant men, relatively high in Scandinavian countries (with an estimated correlation coefficient for men of around 0.1-0.2), relatively low in the U.S. (with estimates of around 0.5-0.6), and somewhere in the middle in Canada and Germany (with estimates of around 0.2-0.4).

[Table 13: intergenerational correlation coefficients with respect to earnings and educational attainment]

\footnotetext{
${ }^{65}$ Deutsch et al. (2006) and Hammarstedt (2009) provide evidence on the relative outcomes of first- second- and third-generation immigrants in Israel and Sweden, respectively.
} 
As we discussed above, the investment decisions of immigrants into their own education, and that of their children, may be shaped by their return intentions. Dustmann (2008) extends the standard permanent income model of intergenerational mobility as sketched in Section 5.2 by allowing for the possibility of return migration. As we have already alluded to on various occasions throughout this chapter, the prospect of returning home has important consequences for an immigrants' human capital investment in the host country. In an intergenerational context with altruistic parents, such considerations also affect the parents' investment into the human capital of their children (under the assumption that the child's perceived return probability increases with the return probability of the parent) and thus the measured intergenerational earnings mobility. More specifically, Dustmann (2008) shows that as long as the return to human capital is higher and the preference for consumption lower in the host- than in the home country, investments into the children's human capital will increase with the probability of a permanent migration. This is because the latter increases the expected monetary gain from an additional unit of human capital for the child, and because it decreases the expected utility gain from consuming in the home country, leading to a reduction in parents' savings for future consumption and an increase of their investments into their children. Using German panel data on father-son pairs that include information on parental return intentions, Dustmann (2008) shows, first, that parental investment in children's education increases with the permanent migration probability of the parent and, second, that the son's permanent earnings increase with the father's permanent migration probability, conditional on father's permanent earnings and education. Accounting for measurement error in parental earnings by using repeated wage observations reveals substantial downward bias in a standard estimation of the intergenerational earnings correlation, increasing the parameter estimate from about 0.140 to 0.344 . The corresponding 
estimates for native father-son pairs are 0.177 and 0.251 , which, although not statistically different, suggest less intergenerational mobility for immigrants than for natives.

\subsubsection{Intergenerational Transmission and Language}

In Section 3.4.4, we discussed language as one of the key human capital characteristics determining the economic outcomes of immigrants in their host country. Since the language skills of parents are likely to at least partly determine the language skills of their children, they could be an important factor underlying the observed persistence in economic status between first- and second-generation immigrants. A number of studies have investigated the link between the language proficiency of children and their parents. For Australia, Chiswick et al. (2005) find strong links between parents' measured and unmeasured determinants of language proficiency and the language skills of their children, in particular between mothers and their children. Bleakley and Chin (2008) show that parental language skills have a significant positive causal effect on U.S.-born children's ability to speak English. Interestingly, this positive effect is only present while the children are young but fades out by the time they reach middle school. However, the poorer language skills when young turn out to have detrimental long-term consequences for the children's educational outcomes in terms of drop-out rates, attendance of age-appropriate grades and attendance of preschool. ${ }^{66}$ Unlike Bleakley and Chin (2008), who use data from the 2000 U.S. Census, and Chiswick et al. (2005), who use data from the 1996 Australian Census, Casey and Dustmann (2008) use repeated information on both parents and their children from the German Socio-

\footnotetext{
${ }^{66}$ As in Bleakley and Chin (2004), the authors use the parents' age at arrival interacted with a dummy for nonEnglish-speaking country of origin as an instrument for their English language skills, making this the probably most convincing strategy to deal with the endogeneity of parental language skills.
} 
Economic Panel. This allows them, first, to address the problem of measurement error that is widespread in self-reported data on language proficiency (see Dustmann and van Soest, 2001), second, to avoid sample selection due to children leaving the parental household, and third, to analyse the association between parental language proficiency and children's later economic outcomes. The results from this study show a significant and sizeable effect of parental language fluency on that of their children. While for males, language proficiency does not significantly affect any of the labour market outcomes considered (wages, labour market participation, employment, and unemployment), it has a beneficial effect for the labour market outcomes of women, in particular those who were born abroad but arrived in Germany before the age of ten. This differential pattern could be due to women's higher propensity to work in occupations where language fluency is important, such as white-collar jobs in the service sector. Overall, the empirical evidence so far suggests a strong intergenerational transmission of language skills, in particular at younger ages of the secondgeneration immigrants, which may contribute to the relatively low intergenerational mobility in educational attainment and earnings that characterises many immigrant groups in the host countries studied.

\subsubsection{Intergenerational Transmission and Ethnic Networks}

In an important contribution, Borjas (1992) extends the standard framework for analysing the intergenerational transmission of human capital by assuming that ethnicity acts as an externality in the human capital accumulation process. In the model outlined in Section 5.2, such an externality would be captured in the term $e_{t}$. This implies that a correctly specified economic model of intergenerational mobility should not only include parental 
inputs as a determinant of the children's skills, but also the average quality of the ethnic environment in which the child is raised, the so-called "ethnic capital". As long as ethnic capital plays an important role in the intergenerational transmission of skills, ignoring it in a regression based on individual level data may lead to a severe underestimation of the true persistence in earnings across generations. Using data from the General Social Surveys and the National Longitudinal Surveys of Youth that include information on both the respondents' and their parents' educational attainment and occupation, as well as the respondents' wages (NLSY only), Borjas (1992) finds overall intergenerational correlations of educational attainment, occupations and log wages of around 0.35-0.40, 0.57, and 0.60, respectively, where all of these estimates reflect the sum of the effects due to parental variables on the one hand, and ethnic capital on the other hand. The latter, measured by the mean of the characteristic in the corresponding ethnic group, has a positive and significant effect of roughly similar (for education and wages) or greater (occupations) magnitude as the corresponding parental variable, suggesting an important role in the intergenerational transmission process. Neglecting ethnic capital will thus lead to an underestimation of the intergenerational correlation coefficient and hence to an overestimation of the speed of economic convergence of ethnic groups across generations. ${ }^{67}$ Aydemir et al. (2009) work with a somewhat broader interpretation of what the average group characteristics may capture, including social factors such as discrimination or lack of access to good schools and credit markets. Using grouped data from the 2001 Canadian Census, they employ quantile regression methods to separate the influence of social capital from the influence of broader social institutions. Their findings suggest that social institutions limit intergenerational

\footnotetext{
${ }^{67}$ In later work, Borjas (1995b) shows that segregation into particular neighbourhoods could be one reason for the external effects of ethnicity, a point that has been reemphasized by Nielsen et al. (2001) and Rooth and Ekberg (2003). See also Cutler et al. (2005).
} 
earnings mobility and that parental education is the key ingredient necessary to circumvent the restrictions imposed by such social institutions.

\section{Conclusion}

This chapter addresses the relationship between migration and education. What seems at first view a small and rather specific area in the research on the Economics of Migration turns out to be at its front and centre. The chapter attempts to provide a first overview of the issues we consider important when studying migration in relation to education.

Overall, this is a rapidly growing field, illustrated by the rising number of papers over the last decades, ${ }^{68}$ and there are exciting new research avenues at its frontier. It is also an area that reflects the challenge to single economies to develop competitive structures that prevail on increasingly globalised markets, and that are based on a flexible and highly responsive skill base. Both education and migration are key ingredients to achieve this.

Our first reference is to Sjaastad (1962), who viewed migration - as education - as an investment in the human agent. As the various sections of this chapter show, migration decisions and decisions about learning and human capital investments are indeed closely related. Migration is not only intertwined with human capital investment decisions of those who move, but has also important consequences for education and knowledge acquisition of those who do not move, both in the home- and in the host countries. Migrations are dynamic and dynastic processes, forming countries for generations to come, and one of the key

\footnotetext{
${ }^{68}$ Searching on Google for papers written in Economics, Business or Finance with migration, immigration or emigration and education, human capital, or skill in the title gives 36 papers between 1991 and 1999, 40 papers between 2000 and 2004, and 65 papers between 2005 and 2009.
} 
determinants of the success of the children of immigrants is their educational attainment. We decided to focus in this chapter on three aspects that we believe are the cornerstones of the connection between migration and education: the economic aspects of the individual migration decisions and how they relate to the acquisition of education, the connection between the acquisition of education and the skill selection of immigrants, and the nature of intergenerational spillovers. Although we attempted to be exhaustive in our coverage, we have almost certainly missed out important additional contributions that investigate these subjects.

The chapter commences with a section (Section 2) that provides an overview of the stylised facts that connect immigration and education. The following three sections (Sections 3-5) each start off with a discussion of a simple theoretical framework, which helps to structure the large empirical literature that exists in each of the areas considered. In Section 3, where we focus on the migrant, we show that educational choices and the accumulation of skills are inherently connected to migration- and re-migration decisions. We emphasise that decisions about non-permanent forms of migration are key to understand educational choices and decisions about skill acquisition, and we demonstrate the challenges for obtaining estimates of immigrant career paths that are generated if migrations are non-permanent and if migration decisions are taken in conjunction with decisions on human capital investment. In our view, this is an area where many research questions are still unexplored. For instance, as we show in Section 2, in many cases the acquisition of education rather than the pursuit of higher wages may be the main motive of migration - a hypothesis that is supported by the growing fraction of student migrations in the overall migration flows. Also, the forms of migration and implied career paths of immigrants have been changing, with temporary migrations today being the rule rather than the exception. Yet, most papers that study career paths of immigrants are still assuming permanent forms of migration. 
In Section 4, we discuss the way in which migration affects educational choices and skill accumulation of individuals who do not migrate, both in the home- and in the potential host countries. This area overlaps with many issues in development economics. We argue that while, as in the quote of Sjaastad, the return to education has been the main motive for migration, it is the acquisition of education itself that is becoming an important trigger for migration movements, and we explore the consequences for the destination- and the origin countries. Another important aspect - from the perspective of both sets of countries - is who migrates. The answer to this question has important implications for the effect of immigration on the economies of both countries, through mechanisms such as the brain gain and the brain drain. We argue that additional insights can be gained when considering an application of the Roy (1951) model to the migration context that takes account of the multi-dimensionality of skills, in order to be able to explain recent migration patterns. Modern economies have specialised in different industries to gain competitiveness in international markets. As a consequence, the return to different skills may differ across countries, changing the incentives underlying individual migration decisions. Yet, most of the literature that studies the selection of immigrants focuses on a special case of the Roy model where skills are one-dimensional.

In the final section, we take a more dynastic view of immigration. Here we focus on the children of immigrants, their educational achievements, and their human capital accumulation and ensuing career paths. This long-term aspect of immigrant integration and assimilation is likely to be a particular focus of research over the next decade due to the increasing number of countries that have recently experienced significant increases in their foreign-born populations. The existing evidence we discuss suggests that education is the key factor determining both the degree and the pace of the economic integration of immigrants and their descendants. 


\section{References}

Acemoglu, D. and D. Autor (2010), "Skills, Tasks and Technologies: Implications for Employment and Earnings" in O. Ashenfelter and D. Card (Eds.), Handbook of Labor Economics, Volume 4, Amsterdam: Elsevier-North Holland, forthcoming.

Acosta, P. (2006), "Labor Supply, School Attendance, and Remittances from International Migration: the case of El Salvador", World Bank Policy Research Working Paper No. 3903.

Algan, Y., C. Dustmann, A. Glitz and A. Manning (2010), "The Economic Situation of Firstand Second-Generation Immigrants in France, Germany, and the UK", Economic Journal, Vol. 120 (542), F4-F30.

Altonji, J. G. and D. Card (1991), "The Effects of Immigration on the Labor Market Outcomes of Less-skilled Natives", in J. M. Abowd and R. B. Freeman (Eds.), Immigration, Trade, and the Labor Market, Chapter 7, pp. 201-234, Chicago: University of Chicago Press.

Antman, F. (2009), “The Intergenerational Effects of Paternal Migration on Schooling: What Can We Learn from Children's Time Allocations?", Department of Economics, University of Colorado at Boulder Working Paper No. 08-03.

Aydemir, A. and G. J. Borjas (2007), "Cross-Country Variation in the Impact of International Migration: Canada, Mexico, and the United States", Journal of the European Economic Association, Vol. 5 (4), 663-708.

Aydemir, A., W.-H. Chen and M. Corak (2009), "Intergenerational Earnings Mobility Among the Children of Canadian Immigrants", Review of Economics and Statistics, Vol. 91 (2), 377-397.

Aydemir, A. and C. Robinson (2008), "Global Labour Markets, Return and Onward Migration", Canadian Journal of Economics, Vol. 41 (4), 1285-1311.

Autor, D. H., F. Levy and R. J. Murnane (2003), “The Skill Content of Recent Technological Change: An Empirical Exploration”, Quarterly Journal of Economics, Vol. 118 (4), 12791334. 
Baker, M. and D. Benjamin (1994), "The Performance of Immigrants in the Canadian Labor Market", Journal of Labor Economics, Vol. 12 (3), 369-405.

Barrett, A. and P. J. O'Connell (2001), "Is There a Wage Premium for Returning Irish Migrants?", The Economic and Social Review", Vol. 32 (1), 1-21.

Bartel, A. (1989), “Where Do the New U.S. Immigrants Live?”, Journal of Labor Economics, Vol. 7 (4), 371-391.

Barth, E., B. Bratsberg and O. Raaum (2004), "Identifying Earnings Assimilation of Immigrants under Changing Macroeconomic Conditions", Scandinavian Journal of Economics, Vol. 106 (1), 1-22.

Barth, E., B. Bratsberg and O. Raaum (2006), "Local Unemployment and the Relative Wages of Immigrants: Evidence from the Current Population Surveys", Review of Economics and Statistics, Vol. 88 (2), 243-263.

Basilio, L. and T. Bauer (2010). "Transferability of Human Capital and Immigrant Assimilation: An Analysis for Germany”, IZA Discussion Paper No. 4716.

Becker, G. S. and N. Tomes (1979), "An Equilibrium Theory of the Distribution of Income and Intergenerational Mobility”, Journal of Political Economy, Vol. 87 (6), 1153-1189.

Beggs, J. J. and B. J. Chapman (1988a), “The International Transferability of Human Capital: Immigrant Labour Market Outcomes in Australia", in (Eds.) L. Baker and P. Miller (Eds.), The Economics of Immigration, Australian Government Publishing Service, Canberra.

Beggs, J. J. and B. J. Chapman (1988b), "Immigrant Wage Adjustment in Australia: Cross Section and Time-Series Estimates”, Economic Record, Vol. 64 (186), 161-167.

Beine, M., C. Defoort and F. Docquier (2010), "A Panel Data Analysis of the Brain Gain", World Development, forthcoming.

Beine, M., F. Docquier and H. Rapoport (2001), "Brain Drain and Economic Growth: Theory and Evidence", Journal of Development Economics, Vol. 64 (1), 275-289. 
Beine, M., F. Docquier and H. Rapoport (2008), "Brain Drain and Human Capital Formation in Developing Countries: Winners and Losers”, Economic Journal, Vol. 118 (528), 631-652.

Bell, B. D. (1997), “The Performance of Immigrants in the United Kingdom: Evidence from the GHS”, Economic Journal, Vol. 107 (441), 333-344.

Belot, M. V. K. and T. J. Hatton (2008), "Immigrant Selection in the OECD”, CEPR Discussion Paper No. 6675.

Ben-Porath, Y. (1967), “The Production of Human Capital and the Life Cycle of Earnings", Journal of Political Economy, Vol. 75 (4), 352-365.

Berman, E., K. Lang and E. Siniver (2003), "Language-skill Complementarity: Returns to Immigrant Language Acquisition", Labour Economics, Vol. 10, 265-290.

Behrman, J. and P. Taubman (1985), "Intergenerational Earnings Mobility in the United States: Some Estimates and a Test of Becker's Intergenerational Endowment's Model", Review of Economics and Statistics, Vol. 67 (1), 141-151.

Betts, J. and R. Fairlie (2003), "Does Immigration Induce `Native Flight' from Public Schools into Private Schools?", Journal of Public Economics, Vol. 87 (5-6), 987-1012.

Bijwaard, G. E. (2004), "Dynamic Economic Aspects of Migration”, Medium Econometrische Toepassingen, Vol. 12 (3), 26-30.

Bishop, K. C. (2008). “A Dynamic Model of Location Choice and Hedonic Valuation", Unpublished Working Paper.

Björklund, A. and M. Jäntti (1997), "Intergenerational Income Mobility in Sweden Compared to the United States", American Economic Review, Vol. 87 (5), 1009-1018.

Blanden, J., A. Goodman, P. Gregg and S. Machin (2004), "Changes in Intergenerational Mobility in Britain", in M. Corak (Ed.), Generational Income Mobility in North America and Europe, Cambridge: Cambridge University Press.

Bleakley, H. and A. Chin (2004), "Language Skills and Earnings: Evidence from Childhood Immigrants", Review of Economics and Statistics, Vol. 86 (2), 481-496. 
Bleakley, H. and A. Chin (2008), "What Holds Back the Second Generation? The Intergenerational Transmission of Language Human Capital among Immigrants", Journal of Human Resources, Vol. 43 (2), 267-298.

Borjas, G. J. (1982), "The Earnings of Male Hispanic Immigrants in the United States", Industrial and Labor Relations Review, Vol. 35, 343-353.

Borjas, G. J. (1985), "Assimilation, Changes in Cohort Quality, and the Earnings of Immigrants", Journal of Labor Economics, Vol. 3 (4), 463-489.

Borjas, G. J. (1987), "Self-Selection and the Earnings of Immigrants", American Economic Review, Vol. 77 (4), 531-553.

Borjas, G. J. (1992), "Ethnic Capital and Intergenerational Mobility”, Quarterly Journal of Economics, Vol. 107 (1), 123-150.

Borjas, G. J. (1993), “The Intergenerational Mobility of Immigrants", Journal of Labor Economics, Vol. 11 (1), 113-135.

Borjas, G. J. (1994), "Long-Run Convergence of Ethnic Skill Differentials: The Children and Grandchildren of the Great Migration", Industrial and Labor Relations Review, Vol. 47 (4), 553-573.

Borjas, G. J. (1995a), “Assimilation and Changes in Cohort Quality Revisited: What Happened to Immigrant Earnings in the 1980s?", Journal of Labor Economics, Vol. 13 (2), 201-245.

Borjas, G. J. (1995b), "Ethnicity, Neighborhoods, and Human-Capital Externalities", American Economic Review, Vol. 85 (3), 365-390.

Borjas, G. J. (1999), "The Economic Analysis of Immigration”, in O. Ashenfelter and D. Card (Eds.), Handbook of Labor Economics, Vol. 3 (3), Chapter 28, 1697-1760.

Borjas, G. J. (2000), “The Economic Progress of Immigrants”, in G. J. Borjas (Ed.), Issues in the Economics of Immigration, NBER Books, Chapter 1, 15-50. 
Borjas, G. J. (2003), "The Labor Demand Curve is Downward Sloping: Reexamining the Impact of Immigration on the Labor Market”, Quarterly Journal of Economics, Vol. 118 (4), $1335-1374$.

Borjas, G. J. (2006a), "Immigration in High-Skill Labor Markets: The Impact of Foreign Students on the Earnings of Doctorates", NBER Working Paper 12085.

Borjas, G. J. (2006b), "Making It in America: Social Mobility in the Immigrant Population", The Future of Children, Vol. 16 (2), 55-71.

Borjas, G. J. (2007), "Do Foreign Students Crowd Out Native Students from Graduate Programs?" in P. E. Stephan and R. G. Ehrenberg (Eds.), Science and the University (Science and Technology in Society), University of Wisconsin Press.

Borjas, G. J. and B. Bratsberg (1996), "Who Leaves? The Outmigration of the ForeignBorn", Review of Economics and Statistics, Vol. 78 (1), 165-176.

Borjas, G. J., Freeman, R. B. and L. F. Katz (1997). "How Much Do Immigration and Trade Affect Labor Market Outcomes?", Brookings Papers on Economic Activity, Vol. 1, 1-67.

Bound, J., S. Turner and P. Walsh (2009), "Internationalization of U.S. Doctorate Education”, Population Studies Center Research Report 09-675, University of Michigan.

Bratsberg, B., O. Raaum and K. Sorlie (2007), "Foreign-Born Migration to and from Norway", in Ç. Özden and M. Schiff (Eds.), International Migration, Economic Development and Policy, Palgrave Macmillan, New York.

Bratsberg, B. and J. F. Ragan Jr. (2002), "The Impact of Host-Country Schooling on Earnings: A Study of Male Immigrants in the United States", Journal of Human Resources, Vol. 37 (1), 63-105.

Butcher, K. F. and D. Card (1991), "Immigration and Wages: Evidence from the 1980s", American Economic Review, Vol. 81 (2), 292-296.

Card, D. (1990), "The Impact of the Mariel Boatlift on the Miami Labor Market", Industrial and Labor Relations Review, Vol. 43 (2), 245-257. 
Card, D. (2001). "Immigrant Inflows, Native Outflows, and the Local Labor Market Impacts of Higher Immigration", Journal of Labor Economics, Vol. 19 (1), 22-64.

Card, D., J. DiNardo and E. Estes (2000), "The More Things Change: Immigrants and the Children of Immigrants in the 1940s, the 1970s, and the 1990s", in G. J. Borjas (Ed.), Issues in the Economics of Immigration, Chicago: NBER and University of Chicago Press.

Carliner, G. (1980), "Wages, Earnings, and Hours of First, Second and Third Generation American Males”, Economic Inquiry, Vol. 18 (1), 87-102.

Carliner, G. (1981), "Wage Differences by Language Group and the Market for Language Skills in Canada”, Journal of Human Resources, Vol. 16 (3), 384-399.

Casey, T. and C. Dustmann (2008), "Intergenerational Transmission of Language Capital and Economic Outcomes", Journal of Human Resources, Vol. 43 (3), 660-687.

Checchi, D., G. De Simone and R. Faini (2007), "Skilled Migration, FDI and Human Capital Investment", IZA Discussion Paper No. 2795.

Chiquiar, D. and G. H. Hanson (2005), "International Migration, Self-Selection and the Distribution of Wages: Evidence from Mexico and the United States", Journal of Political Economy, Vol. 113 (2), 239-281.

Chiswick, B. R. (1977). "Sons of Immigrants: Are They at an Earnings Disadvantage?", American Economic Review Papers and Proceedings, Vol. 67, 376-380.

Chiswick, B. R. (1978), “The Effect of Americanization on the Earnings of Foreign-born Men”, Journal of Political Economy, Vol. 86 (5), 897-921.

Chiswick, B. R. (1991), “Speaking, Reading, and Earnings among Low-Skilled Immigrants”, Journal of Labor Economics, Vol. 9 (2), pp. 149-170.

Chiswick, B. R. (1998), "Hebrew Language Usage: Determinants and Effects on Earnings among Immigrants in Israel”, Journal of Population Economics, Vol. 11 (2), 253-271.

Chiswick, B. R. and N. DebBurman (2004), "Educational Attainment: Analysis by Immigrant Generation", Economics of Education Review, Vol. 23 (4), 361-379. 
Chiswick, B. R., Y. L. Lee and P. W. Miller (2005), "Parents and Children Talk: English Language Proficiency within Immigrant Families", Review of Economics of the Household, Vol. 3 (3), 243-268.

Chiswick, B. R. and P. W. Miller (1992), "Language in the Immigrant Labor Market: The Immigrant Experience in Canada and the United States", in B. R. Chiswick (Ed.), Immigration, Language and Ethnicity: Canada and the United States, pp. 229-296, American Enterprise Institute, Washington, DC.

Chiswick, B. R. and P. W. Miller (1994), "The Determinants of Post-Immigration Investments in Education”, Economics of Education Review, Vol. 13 (2), 163-177.

Chiswick, B. R. and P. W. Miller (1995), "The Endogeneity between Language and Earnings: International Analyses”, Journal of Labor Economics, Vol. 13 (2), 246-288.

Chiswick, B. R. and P. W. Miller (2002), "Immigrant Earnings: Language Skills, Linguistic Concentration and the Business Cycle”, Journal of Population Economics, Vol. 15 (1), 3157.

Chiswick, B. R. and P. W. Miller (2003), “The Complementarity of Language and Other Human Capital: Immigrant Earnings in Canada”, Economics of Education Review, Vol. 22 (5), 469-480.

Chiswick, B. R. and P. W. Miller (2005), “Do Enclaves Matter in Immigrant Adjustment?”, City and Community, Vol. 4 (1), 5-35.

Chiswick, B. R. and P. W. Miller (2007), “The International Transferability of Immigrants' Human Capital Skills", IZA Discussion Paper No. 2670.

Chiswick, B. R. and P. W. Miller (2008), "Why is the Payoff to Schooling Smaller For Immigrants?", Labour Economics, Vol. 15 (6), 1317-1340.

Chiswick, B. R. and G. Repetto (2001), "Immigrant Adjustment in Israel: The Determinants of Literacy and Fluency in Hebrew and Their Effects on Earnings", in S. Djajic (Ed.), International Migration: Trends, Policies and Economic Impact, pp. 204-228, Routledge, London. 
Clark, K. and J. K. Lindley (2009), "Immigrant Assimilation Pre and Post Labour Market Entry: Evidence from the UK Labour Force Survey", Journal of Population Economics, Vol. 22 (1), 175-198.

Co, C. Y., I. Gang and M.-S. Yun (2000), "Returns to Returning", Journal of Population Economics, Vol. 13 (1), 57-79.

Cobb-Clark, D. A. (1993), "Immigrant Selectivity and Wages - The Evidence for Women", American Economic Review, Vol. 83 (4), 986-993.

Cohen-Goldner, S. and Z. Eckstein (2008), "Labor Mobility of Immigrants: Training, Experience, Language, and Opportunities", International Economic Review, Vol. 49 (3), 837 872.

Commander, S., M. Kangasniemi and L. A. Winters (2004), "The Brain Drain: Curse or Boon? A Survey of the Literature", in R. Baldwin and L. A. Winters (Eds.), Challenges to Globalization, pp. 235-72, Chicago: University of Chicago Press.

Constant, A. F. and K. F. Zimmermann (2008), "Measuring Ethnic Identity and Its Impact on Economic Behavior", Journal of the European Economic Association, Vol. 6 (2-3), 424-433.

Corak, M. (2004) (Editor), Generational Income Mobility in North America and Europe, Cambridge: Cambridge University Press.

Corak, M. (2006), "Do Poor Children Become Poor Adults? Lessons for Public Policy from a Cross Country Comparison of Generational Earnings Mobility", in J. Creedy and G. Kalb (Eds.), Research on Economic Inequality, Vol. 13, Dynamics of Inequality and Poverty, Amsterdam: Elsevier Press.

Corak, M. and A. Heisz (1999), "The Intergenerational Earnings and Income Mobility of Canadian Men: Evidence from Longitudinal Income Tax Data", Journal of Human Resources, Vol. 34 (3), 504-533.

Cortés, P. (2010), "The Feminization of International Migration and its Effects on the Families Left Behind: Evidence from the Philippines”, unpublished manuscript. 
Cortés, P. and J. Pan (2009), "Outsourcing Household Production: The Demand for Foreign Domestic Helpers and Native Labor Supply in Hong Kong”, Working Paper, University of Chicago, Booth School of Business.

Cortés, P. and J. Tessada (2009), "Low-Skilled Immigration and the Labor Supply of Highly Educated Women", unpublished manuscript.

Cortes, K. E. (2004), “Are Refugees Different from Economic Immigrants? Some Empirical Evidence on the Heterogeneity of Immigrant Groups in the United States", Review of Economics and Statistics, Vol. 86 (2), 465-480.

Cortes, K. E. (2006), "The Effects of Age at Arrival and Enclave Schools on the Academic Performance of Immigrant Children”, Economics of Education Review, Vol. 25 (2), 121-132.

Cox Edwards, A. and M. Ureta (2003), "International Migration, Remittances and Schooling: Evidence from El Salvador", Journal of Development Economics, Vol. 72 (2), 429-461.

Cunha, F., J. J. Heckman, L. Lochner, and D. V. Masterov (2006), "Interpreting the Evidence on Life Cycle Skill Formation”, in E. A. Hanushek and F. Welch (Eds.), Handbook of the Economics of Education, Chapter 12, pp. 697-812, Amsterdam: North-Holland.

Cutler, D. M., E. L. Glaeser and J. L. Vigdor (2005), "Ghettos and the Transmission of Ethnic Capital", in G. Loury, T. Modood and S. M. Teles (Eds.), Ethnicity, Social Mobility and Public Policy: Comparing the US and UK, pp. 204-222, Cambridge University Press.

D’Addio, A. C. (2007), "Intergenerational Transmission of Disadvantage: Mobility or Immobility across Generations? A Review of the Evidence for OECD Countries", OECD Social, Employment and Migration Working Paper No. 52.

Dahl, G. (2002), "Mobility and the Return to Education: Testing a Roy Model with Multiple Markets”, Econometrica, Vol. 70 (6), 2367-2420.

DeFreitas, G. (1980), “The Earnings of Immigrants in the American Labor Market”, PhD dissertation, Columbia University.

De Brauw, A. and J. Giles (2006), "Migrant Opportunity and the Educational Attainment of Youth in Rural China”, IZA Discussion Paper No. 2326. 
Deutsch, J., G. S. Epstein and T. Lecker (2006), "Multi-Generation Model of Immigrant Earnings: Theory and Application”, in S. W. Polachek, C. Chiswick and H. Rapoport (Eds.), Research in Labor Economics, Vol. 24, pp. 217-234, Elsevier: Amsterdam.

Domingues Dos Santos, M. and F. Postel-Vinay (2003), "Migration as a Source of Growth: the Perspective of a Developing Country", Journal of Population Economics, Vol. 16 (1), 161-175.

Domingues Dos Santos, M. and F. Postel-Vinay (2004), "The Impact of Temporary Migration on Human Capital Accumulation and Economic Development", Brussels Economic Review, Vol. 47 (1), 77-88.

Docquier, F. and A. Marfouk (2006), "International Migration by Educational Attainment (1990-2000)", in Ç. Özden and M. Schiff (Eds.), International Migration, Remittances and Development, Palgrave Macmillan: New York.

Docquier, F. and Rapoport, H. (2009), "Skilled Migration: The Perspective of Developing Countries", in J. Baghwati and G. Hanson (eds.) Skilled Immigration Today: Prospects, Problems and Policies, Chapter 9, pp. 247-284, New York: Russell Sage Foundation.

Duleep, H. O. and M. C. Regets (1999), "Immigrants and Human-Capital Investment", American Economic Review Papers and Proceedings, Vol. 89 (2), 186-191.

Duleep, H. O. and M. C. Regets (2002), “The Elusive Concept of Immigrant Quality”, IZA Discussion Paper No. 631.

Dustmann, C. (1993), "Earnings Adjustment of Temporary Migrants", Journal of Population Economics, Vol. 6 (2), 153-168.

Dustmann, C. (1994a), "Return Intentions of Migrants: Theory and Evidence", CEPR Discussion Paper No. 906.

Dustmann, C. (1994b), "Speaking Fluency, Writing Fluency and Earnings of Migrants", Journal of Population Economics, Vol. 7 (2), 133-156.

Dustmann, C. (1995), "Savings Behavior of Migrant Workers - a Life Cycle Analysis", Zeitschrift fuer Wirtschafts-und Sozialwissenschaften, Vol. 4, 511-533. 
Dustmann, C. (1997), "Differences in the Labour Market Behaviour between Temporary and Permanent Migrant Women”, Labour Economics, Vol. 4 (1), 29-46.

Dustmann, C. (1999), “Temporary Migration, Human Capital, and Language Fluency of Migrants", Scandinavian Journal of Economics, Vol. 101 (2), 297-314.

Dustmann, C. (2000), “Temporary Migration and Economic Assimilation”, Swedish Economic Policy Review, Vol. 7, 213-244.

Dustmann, C. (2003), "Return Migration, Wage Differentials and the Optimal Migration Duration", European Economic Review, Vol. 47 (2), 353-369.

Dustmann, C. (2008), "Return Migration, Investment in Children, and Intergenerational Mobility: Comparing Sons of Foreign- and Native-Born Fathers", Journal of Human Resources, Vol. 43 (2), 299-324.

Dustmann, C. and F. Fabbri (2003), "Language Proficiency and Labour Market Performance of Immigrants in the UK", Economic Journal, Vol. 113 (489), 695-717.

Dustmann, C., F. Fabbri and I. Preston (2005), “The Impact of Immigration on the British Labour Market”, Economic Journal, Vol. 115 (507), F324-F341.

Dustmann, C., I. Fadlon and Y. Weiss (2010a), "Return Migration, Human Capital Accumulation and the Brain Drain", Journal of Development Economics, forthcoming.

Dustmann, C., T. Frattini and C. Halls (2010b), "Assessing the Fiscal Costs and Benefits of A8 Migration to the UK", Fiscal Studies, Vol. 31 (1), 1-41.

Dustmann, C., T. Frattini and I. Preston (2008), "The Effect of Immigration along the Distribution of Wages", CReAM Discussion Paper No. 03/08.

Dustmann, C., T. Frattini and G. Lanzara (2010c), "Educational Achievements and Ambitions of Second Generation Immigrants - An International Comparison”, mimeo, UCL.

Dustmann, C., A. Glitz and U. Schönberg (2010d), "Referral-based Job Search Networks", unpublished manuscript. 
Dustmann, C., A. Glitz and T. Vogel (2010e), "Employment, Wages, and the Economic Cycle: Differences between Immigrants and Natives", European Economic Review, Vol. 54 (1), 1-17.

Dustmann, C., S. Machin and U. Schönberg (2010f), "Ethnicity and Educational Achievement in Compulsory Schooling”, Economic Journal, Vol. 120 (546), F272-297.

Dustmann, C. and N. Theodoropoulos (2010), "Ethnic Minority Immigrants and Their Children in Britain", Oxford Economic Papers, Vol. 62 (2), 209-233.

Dustmann, C. and A. van Soest (2001), "Language Fluency and Earnings: Estimation with Misclassified Language Indicators", Review of Economics and Statistics, Vol. 83 (4), 663674.

Dustmann, C. and A. van Soest (2002), "Language and the Earnings of Immigrants", Industrial and Labor Relations Review, Vol. 55 (3), 473-492.

Dustmann, C. and A. van Soest (2004), “An Analysis of Speaking Fluency of Immigrants Using Ordered Response Models With Classification Errors", Journal of Business and Economic Statistics, Vol. 22 (3), 312-321.

Dustmann, C. and Y. Weiss (2007), "Return migration: Theory and Empirical Evidence from the UK", British Journal of Industrial Relations, Vol. 45, pp. 236-256.

Eckstein, Z. and Y. Weiss (2004), “On the Wage Growth of Immigrants: Israel 1990-2000”, Journal of the European Economic Association, Vol. 2 (4), 665-695.

Edin, P.-A., P. Fredriksson and O. Åslund (2003), "Ethnic Enclaves and the Economic Success of Immigrants - Evidence from a Natural Experiment", Quarterly Journal of Economics, Vol. 118 (1), 329-357.

Edin, P.-A., R. J. LaLonde and O. Åslund (2000), "Emigration of Immigrants and Measures of Immigrant Assimilation: Evidence from Sweden", Swedish Economic Policy Review, Vol. (7), 163-204.

Entorf, H. and N. Minoiu (2005), "What a Difference Immigration Policy Makes: A Comparison of PISA Scores in Europe and Traditional Countries of Immigration", German 
Economic Review, Vol. 6 (2), 355-376.

Farré, L., L. González and F. Ortega (2009), "Immigration, Family Responsibilities and the Labor Supply of Skilled Native Women”, CReAM Discussion Paper No. 16/09.

Feliciano, C. (2005), "Educational Selectivity in U.S. Immigration: How Do Immigrants Compare to Those Left Behind?” Demography, Vol. 42 (1), 131-152.

Fernández-Huertas Moraga, J. (2010), “New Evidence on Emigrant Selection”, Review of Economics and Statistics, forthcoming.

Finn, M.G. (2007), Stay Rates of Foreign Doctorate Recipients from US Universities, 2005, Oak Ridge Institute for Science and Education, Oak Ridge.

Friedberg, R. M. (1992). "The Labor Market Assimilation of Immigrants in the United States: The Role of Age at Arrival”, Unpublished Manuscript, Providence, RI: Brown University.

Friedberg, R. M. (2000), “You Can't Take It with You? Immigrant Assimilation and the Portability of Human Capital”, Journal of Labor Economics, Vol. 18 (2), 221-251.

Friedberg, R. M. (2001), "The Impact of Mass Migration on the Israeli Labor Market", Quarterly Journal of Economics, Vol. 116 (4), 1373-1408.

Funkhouser, E. and S. J. Trejo (1995), “The Labor Market Skills of Recent Male Immigrants: Evidence from the Current Population Survey", Industrial anad Labor Relations Review, Vol. 48 (4), 792-811.

Gang, I. N. and K. F. Zimmermann (2000), "Is Child Like Parent? Educational Attainment and Ethnic Origin”, Journal of Human Resources, Vol. 35 (3), 550-569.

Ganzeboom, H. B. G., P. M. De Graaf, J. de Leeuw and D. J. Treiman (1992), “A Standard Internacional Socio-Economic Index of Occupational Status", Social Science Research, Vol. $21(1), 1-56$.

Glitz, A (2011), “The Labor Market Impact of Immigration: A Quasi-Experiment Exploiting Immigrant Location Rules in Germany", Journal of Labor Economics, forthcoming. 
Gonzalez, A. (2003), “The Education and Wages of Immigrant Children: The Impact of Age at Arrival", Economics of Education Review, Vol. 22 (2), 203-212.

Goos, M. and A. Manning (2007), "Lousy and Lovely Jobs: The Rising Polarization of Work in Britain”, Review of Economics and Statistics, Vol. 89 (1), 118-133.

Gould, E. D., V. Lavy and M. D. Paserman (2009), "Does Immigration Affect the Long-term Educational Outcomes of Natives? Quasi-Experimental Evidence", Economic Journal, Vol. 119 (540), 1243-1269.

Gould, E. D. and O. Moav (2010), "When is 'Too Much' Inequality Not Enough? The Selection of Israeli Emigrants", CReAM Discussion Paper No. 14/10.

Green, C., P. Kler and G. Leeves (2007), "Immigrant Overeducation: Evidence from Recent Arrivals to Australia", Economics of Education Review, Vol. 26 (4), 420-432.

Green, D. A. and C. Worswick (2004), "Immigrant Earnings Profiles in the Presence of Human Capital Investment: Measuring Cohort and Macro Effects", IFS Working Paper $04 / 13$.

Grenier, G. (1984), "The Effect of Language Characteristics on the Wages of Hispanic American Males", Journal of Human Resources, Vol. 19 (1), 35-52.

Grogger, J. and G. Hanson (2008). "Income Maximization and the Selection and Sorting of International Migrants”, NBER Working Paper No. 13821, Cambridge, MA.

Hanson, G. (2007), "Emigration, Labor Supply, and Earnings in Mexico", in (Ed.) G. J. Borjas, Mexican Immigration, University of Chicago Press.

Hanson, G. (2010), “International Migration and the Developing World”, in (Eds.) D. Rodrik and M. Rosenzweig, Handbook of Development Economics, Vol. 5, Chapter 66, pp. 43634414, Amsterdam: North Holland.

Hanson, G. and C. Woodruff (2003), "Emigration and Educational Attainment in Mexico", Mimeo, University of California at San Diego. 
Hanushek, E. A. and L. Woessmann (2008), "The Role of Cognitive Skills in Economic Development”, Journal of Economic Literature, Vol. 46 (3), 607-668.

Hanushek, E. A. and L. Woessmann (2010), "The Economics of International Differences in Educational Achievement", in (Eds.) E. A. Hanushek, S. Machin, and L. Woessmann, Handbook of the Economics of Education, Vol. 3. Amsterdam: North Holland, forthcoming.

Hanushek, E. A. and L. Zhang (2009), "Quality-Consistent Estimates of International Schooling and Skill Gradients", Journal of Human Capital, Vol. 3 (2), 107-143.

Hammarstedt, M. (2009), "Intergenerational Mobility and the Earnings Position of First-, Second-, and Third-Generation Immigrants", Kyklos, Vol. 62 (2), 275-292.

Hayfron, J. E. (1998), “The Performance of Immigrants in the Norwegian Labor Market", Journal of Population Economics, Vol. 11 (2), 293-303.

Heckman, J. J. (1979), "Sample Selection Bias as a Specification Error”, Econometrica, Vol. 47 (1), 153-161.

Heckman, J. J. and B. Honoré (1990), "The Empirical Content of the Roy Model", Econometrica, Vol. 58 (5), 1121-1149.

Hicks, J. (1932), The Theory of Wages, New York: MacMillan.

Hirschman, C. (2001), "The Educational Enrollment of Immigrant Youth: A Test of the Segmented-Assimilation Hypothesis”, Demography, Vol. 39 (3), 317-336.

Hoxby, C.M. (1998), “Do Immigrants Crowd Disadvantaged American Natives out of Higher Education?", in D.S. Hamermesh and F.D. Bean (eds.), Help or Hindrance? The Economic Implications of Immigration for African Americans, pp. 282-321, New York: Russell Sage Foundation.

Hunt, J. (2010), "Which Immigrants Are Most Innovative and Entrepreneurial? Distinctions by Entry Visa”, IZA Discussion Paper No. 4745.

Hunt, J. and M. Gauthier-Loiselle (2010), "How Much Does Immigration Boost Innovation?", American Economic Journal: Macroeconomics, Vol. 2 (2), 31-56. 
Husted, L., H. S. Nielsen, M. Rosholm and N. Smith (2001), "Employment and Wage Assimilation of Male First Generation Immigrants in Denmark", International Journal of Manpower, Vol. 22, 39-68.

Iara, A. (2006), "Skill Diffusion by Temporary Migration? Returns to Western European Working Experience in the EU Accession Countries", A Global Development Network Working Paper.

Ibarrarán, P. and D. Lubotsky (2007), "Immigration and Self-Selection: New Evidence from the 2000 Mexican Census", in (Ed.) G. J. Borjas, Mexican Immigration to the United States, Chapter 5, pp. 159-192, University of Chicago Press.

ICMPD (2006), Comparative Study on Policies towards Foreign Graduates. Study on Retention Policies towards Foreign Students in Industrialised Countries, ICMPD, Vienna.

Jackson, O. (2010), "Does Immigration Crowd Natives Into or Out of Higher Education?", University of Michigan Working Paper.

Jaeger, D. A. (2007), "Green Cards and the Location Choices of Immigrants in the United States, 1971-2000", Research in Labor Economics, Vol. 27, 131-183.

Jensen, P. and P. J. Pedersen (2007), “To Stay or Not To Stay? Out-Migration of Immigrants from Denmark", International Migration, Vol. 45 (5), 87-113.

Johnson, N. and S. Kotz, (1972), Distribution in Statistics: Continuous Multivariate Distributions, New York: John Wiley \& Sons.

Kaestner, R. and O. Malamud (2010), "Self-selection and International Migration: New Evidence from Mexico", NBER Working Paper No. 15765.

Kato, T. and C. Sparber (2010), "Quotas and Quality: The Effect of H-1B Visa Restrictions on the Pool of Prospective Undergraduate Students from Abroad", CReAM Discussion Paper No. $10 / 10$.

Khan, A. (1997), "Post-migration Investment in Education by Immigrants in the United States," Quarterly Review of Economics and Finance, Vol. 37, Supplement 1, 285-313. 
Kossoudji, S. A. (1988), "English Language Ability and the Labor Market Opportunities of Hispanic and East Asian Immigrant Men”, Journal of Labor Economics, Vol. 6 (2), 205-228.

Kossoudji, S. A. (1989), “Immigrant Worker Assimilation: Is It a Labor Market Phenomenon?”, Journal of Human Resources, Vol. 24 (3), 494-527.

Kee, P. (1995), “Native-Immigrant Wage Differentials in the Netherlands: Discrimination?”, Oxford Economic Papers, Vol. 47 (2), 302-317.

Kennan, J. (2010), "Higher Education Subsidies and Human Capital Mobility", Working Paper.

Kennan, J. and J. R. Walker (2010) "The Effect of Expected Income on Individual Migration Decisions", Econometrica, forthcoming.

Kerr, W. R. and W. Lincoln (2010), “The Supply Side of Innovation: H-1B Visa Reforms and U.S. Ethnic Invention”, NBER Working Paper No. 15768.

LaLonde, R. J. and R. H. Topel (1991), "Immigrants in the American Labor Market: Quality, Assimilation, and Distributional Effects", American Economic Review Papers and Proceedings, Vol. 81 (2), 297-302.

LaLonde, R. J. and R. H. Topel (1992), "The Assimilation of Immigrants in the U.S. Labor Market", in (Eds.) G. J. Borjas and R. B. Freeman, Immigration and the Work Force: Economic Consequences for the United States and Source Areas, pp. 67-92, Chicago: University of Chicago Press.

Lazear, E. P. (1979), “Why Is There Mandatory Retirement?”, Journal of Political Economy, Vol. 87 (6), 1261-1284.

Lindley, J. and P. Lenton (2006), The Over-Education of UK Immigrants: Evidence from the Labour Force Survey, Sheffield Economic Research Paper Series No. 2006001.

Longva, P. and O. Raaum, (2003), "Earnings Assimilation of Immigrants in Norway - A Reappraisal”, Journal of Population Economics, Vol. 16 (1), 177-193. 
López-Córdova, J. E. (2005), "Globalization, Migration, and Development: The Role of Mexican Migrant Remittances”, Economía, Vol. 6 (1), 217-256.

Lubotsky, D. (2007), "Chutes or Ladders? A Longitudinal Analysis of Immigrant Earnings", Journal of Political Economy, Vol. 115 (5), 820-867.

Lucas, R. E. B. (2005), "International Migration: Lessons from Recent Data", Presentation in the Migration Seminar Series, World Bank. Washington, D.C.

Manacorda, M., A. Manning and J. Wadsworth (2006), "The Impact of Immigration on the Structure of Male Wages: Theory and Evidence from Britain”, CReAM Discussion Paper No. 08/06.

Marchiori, L., I.-L. Shen and F. Docquier (2009), "Brain Drain in Globalization: A General Equilibrium Analysis from the Sending Countries' Perspective”, IZA Discussion Paper No. 4207.

Mattoo, A., I. C. Neagu and C. Özden (2008), "Brain Waste? Educated Immigrants in the US Labor Market", Journal of Development Economics, Vol. 87 (2), 255-269.

McKenzie, D. J. and H. Rapoport (2007), "Self-selection Patterns in Mexico-U.S. Migration: The Role of Migration Networks", CReAM Discussion Paper No. 01/07.

McKenzie, D. and H. Rapoport (2010), "Can Migration Reduce Educational Attainment? Evidence from Mexico", Journal of Population Economics, forthcoming.

McManus, W., W. Gould and F. Welch (1983), "Earnings of Hispanic Men: The Role of English Language Proficiency”, Journal of Labor Economics, Vol. 1 (2), 101-130.

Mishra, P. (2007), "Emigration and Wages in Source Countries: Evidence from Mexico", Journal of Development Economics, Vol. 82 (1), 180-199.

Mountford, A. (1997), "Can A Brain Drain Be Good for Growth in the Economy?", Journal of Development Economics, Vol. 53 (2), 287-303.

Neal, D. (2006), “Why Has Black-White Skill Convergence Stopped?”, in E. Hanushek and F. Welch (Eds.), Handbook of the Economics of Education, Vol. 1, Chapter 9, 511-576. Elsevier. 
Nekby, L. (2004). “The Emigration of Immigrants, Return vs. Onward Migration: Evidence from Sweden". Research Papers in Economics No. 2004:7, Stockholm University, Department of Economics.

Neymotin, F. (2009), "Immigration and its Effect on the College-Going Outcomes of Natives", Economics of Education Review, Vol. 28 (5), 538-550.

Nielsen, C. P. (2007), Immigrant Overeducation: Evidence from Denmark, World Bank Policy Research Working Paper 4234.

Nielsen, H. S., M. Rosholm, N. Smith and L. Husted (2003), “The School-to-Work Transition of 2nd Generation Immigrants in Denmark," Journal of Population Economics, Vol. 16 (4), $755-786$.

Palifka, B. (2003), "Study Abroad and the Transition from School to Work for Mexican College Graduates", Working Paper.

Parent, D. (2009), "Intergenerational Progress in Educational Attainment When Institutional Change Really Matters: A Case Study of Franco-Americans vs. French-Speaking Quebecers", CLSRN Working Paper No. 2009-36.

OECD (2006), Where Immigrant Students Succeed - A Comparative Review of Performance and Engagement in PISA 2003, OECD Publishing, Paris.

OECD (2007), PISA 2006 - Science Competencies for Tomorrow's World, OECD Publishing, Paris.

OECD (2008), International Migration Outlook, OECD Publishing, Paris.

OECD (2009), PISA 2006 Technical Report, OECD Publishing, Paris.

OECD (2010), International Migration Outlook, OECD Publishing, Paris.

Okkerse, L. (2008), "How to Measure Labour Market Effects of Immigration: A Review”, Journal of Economic Surveys, Vol. 22 (1), 1-30.

Oosterbeek, H. and D. Webbink (2006), “Assessing the Returns to Studying Abroad”, CPB Working Paper No. 64. 
Orrenius, P. M. and M. Zavodny (2005), "Self-selection Among Undocumented Immigrants from Mexico", Journal of Development Economics, Vol. 78 (1), 215-240.

Ortega, F. and G. Peri (2009), "The Causes and Effects of International Migrations: Evidence from OECD Countries 1980-2005”, NBER Working Paper No. 14833.

Osterberg, T. (2000), "Economic Perspectives on Immigrants and Intergenerational Transmissions", Ekonomiska Studier, Vol. 102, 115-149.

Ottaviano, G. I. P. and G. Peri (2008), "Immigration and National Wages: Clarifying the Theory and the Empirics", NBER Working Paper No. 14188.

Peri, G. and C. Sparber (2008), "Highly Educated Immigrants and Occupational Choice”, CReAM Discussion Paper No 13/08.

Peri, G. and C. Sparber (2009), “Task Specialization, Immigration, and Wages”, American Economic Journal: Applied Economics, Vol. 1 (3), 135-169.

Perreira, K. M., K. M. Harris and D. Lee, (2006), "Making it in America: High School Completion by Immigrant and Native Youth", Demography, Vol. 43 (3), 511-536.

Piil Damm, A. (2009), "Ethnic Enclaves and Immigrant Labor Market Outcomes: QuasiExperimental Evidence”, Journal of Labor Economics, Vol. 27 (2), 281-314.

Ramos, F. A. (1992), “Out-Migration and Return Migration of Puerto Ricans”, in G. J. Borjas and R. B. Freeman (Eds.), Immigration and the Work Force: Economic Consequences for the United States and Source Areas, Chapter 2, pp. 49-66, Chicago: University of Chicago Press.

Rampney, B. D., G. S. Dion and P. L. Donahue (2009), NAEP 2008 Trends in Academic Progress (NCES-2009-479), National Center for Education Statistics, Institute of Education Sciences, U.S. Department of Education, Washington, D.C.

Rapoport, H. and F. Docquier (2006), “The Economics of Migrants' Remittances”, in (Eds.) S.-C. Kolm and J. M. Ythier, Handbook on the Economics of Giving, Reciprocity and Altruism, Vol. 2, Chapter 17, pp. 1135-1198, Amsterdam: North Holland. 
Reinhold, S. and K. Thom (2009), “Temporary Migration and Skill Upgrading: Evidence from Mexican Migrants”, MEA Discussion Paper No. 09182.

Riphahn, R. T. (2003), "Cohort Effects in the Educational Attainment of Second Generation Immigrants in Germany: An Analysis of Census Data", Journal of Population Economics, Vol. 16 (4), 711-737.

Rivera-Batiz, Francisco (1990), "English Language Proficiency and the Economic Progress of Immigrants”, Economics Letters, Vol. 34 (3), pp. 295-300.

Rivera-Batiz, Francisco (1992), "English Language Proficiency and the Earnings of Young Immigrants in U.S. Labor Markets”, Review of Policy Research, Vol. 11 (2), pp. 165-175.

Rooth, D.-O. and J. Ekberg (2003), "Unemployment and Earnings for Second Generation Immigrants in Sweden. Ethnic Background and Parent Composition", Journal of Population Economics, Vol. 16 (4), 787-814.

Rosenzweig, M. (2007), Education and Migration: A Global Perspective, Yale University, Mimeo.

Roy, A. D. (1951), "Some Thoughts on the Distribution of Earnings", Oxford Economic Papers, Vol. 3 (2), 135-146.

Sanromá, E., R. Ramos and H. Simón (2008), “The Portability of Human Capital Immigrant Assimilation: Evidence for Spain”, IZA Discussion Paper No. 3649.

Sanromá, E., R. Ramos and H. Simón, (2009), "Immigrant Wages in the Spanish Labour Market: Does the Origin of Human Capital Matter?”, IZA Discussion Paper No. 4157.

Schaafsma, J. and A. Sweetman (2001). "Immigrant Earnings: Age at Immigration Matters", Canadian Journal of Economics, Vol. 34 (4), 1066-1099.

Schiff, M. (2005), "Brain Gain: Claims about Its Size and Impact on Welfare and Growth Are Greatly Exaggerated”, IZA Discussion Paper No. 1599.

Schnepf, S. V. (2007), “Immigrants’ Educational Disadvantage: An Examination across Ten Countries and Three Surveys", Journal of Population Economics, Vol. 20 (3), 527-545. 
Schoeni, R. (1997), "New Evidence on the Economic Progress of Foreign-Born Men in the 1970s and 1980s", Journal of Human Resources, Vol. 32 (4), 683-740.

Shields, M. A. and S. Wheatley Price (1998), "The Earnings of Male Immigrants in England: Evidence from the Quarterly LFS", Applied Economics, Vol. 30 (9), 1157-1168.

Shortland, P. (2006), People on the Move: A Study of Migrant Movement Patterns to and from New Zealand, New Zealand Department of Labour, Wellington.

Sjaastad, L. A. (1962), "The Costs and Returns of Human Migration”, Journal of Political Economy, Vol. 70 (5), 80-93.

Smith, J. (2003), "Assimilation across the Latino generations", American Economic Review (Papers and Proceedings), Vol. 93 (2), 315-319.

Solon, G. (1992), "Intergenerational Income Mobility in the United States", American Economic Review. Vol. 82 (3), 393-408.

Solon, G. (1999), "Intergenerational Mobility in the Labor Market", in (Eds.) O. C. Ashenfelter and D. Card, Handbook of Labor Economics, Vol. 3A, Chapter 29, pp. 17611800, Amsterdam: North-Holland.

Solon, G. (2002), "Cross-Country Differences in Intergenerational Earnings Mobility", Journal of Economic Perspectives, Vol. 16 (3), 59-66.

Solon, G. (2004), “A Model of Intergenerational Mobility Variation over Time and Place”, in (Ed.) M. Corak, Generational Income Mobility in North America and Europe, Chapter 2, pp. 38-47, Cambridge, England: Cambridge University Press.

Stark, O., C. Helmenstein and A. Prskawetz (1997), “A Brain Drain with a Brain Gain”, Economics Letters, Vol. 55 (2), 227-234.

Stark, O. and Y. Wang (2002), "Inducing Human Capital Formation: Migration as a Substitute for Subsidies", Journal of Public Economics, Vol. 86 (1), 29-46.

Steward, J. B. and T. Hyclak (1984), “An Analysis of the Earnings Profiles of Immigrants”, Review of Economics and Statistics, Vol. 66 (2), 292-296. 
Storesletten, K. (2000), "Sustaining Fiscal Policy through Immigration”, Journal of Political Economy, Vol. 108 (2), 300-323.

Tainer, Evelina (1988), "English Language Proficiency and the Determination of Earnings among Foreign-born Men”, Journal of Human Resources, Vol. 23 (1), 108-122.

Todd, P. E. and K. I. Wolpin (2003), "On the Specification and Estimation of the Production Function for Cognitive Achievement”, Economic Journal, Vol. 113 (485), F3-F33.

Trejo, S. (2003), "Intergenerational Progress of Mexican-Origin Workers in the US Labor Market", Journal of Human Resources, Vol. 38 (3), 467-489.

Venturini, A. and C. Villosio (2008), "Labour-Market Assimilation of Foreign Workers in Italy", Oxford Review of Economic Policy, Vol. 24 (3), 517-541.

Vidal, J.-P. (1998), “The Effect of Emigration on Human Capital Formation", Journal of Population Economics, Vol. 11 (4), 589-600.

Wiers-Jenssen, J. and S. Try (2005), "Labour Market Outcomes of Higher Education Undertaken Abroad", Studies in Higher Education, Vol. 30 (6), 681-705.

Wilkins, R. (2003), "Immigrant Earnings Adjustment: The Impact of Age at Migration", Australian Economic Papers, Vol. 42 (3), 292-315.

Willis, R. J. (1987), "Wage Determinants: A Survey and Reinterpretation of Human Capital Earnings Functions", in (Eds.) O. Ashenfelter and R. Layard, Handbook of Labor Economics, Edition 1, Vol. 1, Chapter 10, pp. 525-602. Elsevier: Amsterdam.

Willis, R. J. and S. Rosen (1979), "Education and Self-Selection", Journal of Political Economy, Vol. 87 (5), S7-S36.

Van Ours, J. C. and J. Veenman (2006), “Age at Immigration and Educational Attainment of Young Immigrants", Economics Letters, Vol. 90, 310-316.

Yang, D. (2008), "International Migration, Remittances, and Household Investment: Evidence from Philippine Migrants' Exchange Rate Shocks”, Economic Journal, Vol. 118 (528), 591-630. 
Zimmerman, D. J. (1992), "Regression Toward Mediocrity in Economic Stature", American Economic Review. Vol. 82 (3), 409-429. 


\begin{tabular}{|c|c|c|c|c|c|c|c|c|c|}
\hline $\begin{array}{l}\text { Destination } \\
\text { Country }\end{array}$ & Number FB & Share FB & $\begin{array}{l}\text { Main Countries of Origin } \\
\text { of FB Population) }\end{array}$ & $\begin{array}{l}\text { Share Low } \\
\text { Education FB }\end{array}$ & $\begin{array}{l}\text { Share Medium } \\
\text { Education FB }\end{array}$ & $\begin{array}{l}\text { Share High } \\
\text { Education FB }\end{array}$ & $\begin{array}{l}\text { Share Low } \\
\text { Education NB }\end{array}$ & $\begin{array}{l}\text { Share Medium } \\
\text { Education NB }\end{array}$ & $\begin{array}{l}\text { Share High } \\
\text { Education NB }\end{array}$ \\
\hline & (1) & (2) & (3) & (4) & (5) & (6) & (7) & (8) & (9) \\
\hline Australia & $3,860,215$ & 26.0 & $\begin{array}{c}\text { United Kingdom (26.1), New Zealand (8.2), } \\
\text { Italy (5.6) }\end{array}$ & 36.8 & 32.6 & 30.6 & 43.8 & 31.2 & 25.1 \\
\hline Canada & $5,355,210$ & 22.4 & $\begin{array}{l}\text { United Kingdom (11.4), China (5.9), Italy } \\
\text { (5.9) }\end{array}$ & 22.1 & 31.8 & 46.1 & 22.9 & 38.3 & 38.8 \\
\hline France & $5,600,198$ & 11.7 & $\begin{array}{c}\text { Algeria (21.6), Marocco (12.3), Portugal } \\
(10.1)\end{array}$ & 48.4 & 29.9 & 21.7 & 33.8 & 44.1 & 22.1 \\
\hline Germany & $7,831,959$ & 11.5 & Turkey (15.2), Poland (13.1), Russia (11.9) & 40.1 & 42.8 & 17.2 & 14.6 & 61.4 & 24.0 \\
\hline Italy & $2,020,934$ & 4.1 & $\begin{array}{c}\text { Switzerland (8.9), Germany (8.3), Marocco } \\
(6.8)\end{array}$ & 50.2 & 35.4 & 14.4 & 57.3 & 31.9 & 10.8 \\
\hline Netherlands & $1,419,940$ & 11.2 & $\begin{array}{l}\text { South and Central America and Carribean } \\
(20.4) \text {, Indonesia (12.5), Turkey (11.2) }\end{array}$ & 45.6 & 32.8 & 21.6 & 32.4 & 43.8 & 23.8 \\
\hline Spain & $1,914,920$ & 5.5 & Marocco (14.5), Ecuador (9.9), France (7.8) & 52.8 & 22.7 & 24.5 & 60.9 & 15.9 & 23.2 \\
\hline Switzerland & $1,454,185$ & 24.1 & $\begin{array}{c}\text { Italy (15.9), Germany (12.1), Serbia and } \\
\text { Montenegro (9.1) }\end{array}$ & 38.8 & 34.6 & 26.6 & 16.3 & 60.8 & 22.9 \\
\hline United Kingdom & $4,503,466$ & 9.4 & Ireland (11.7), India (10.1), Pakistan (6.7) & 39.1 & 21.6 & 39.3 & 51.3 & 25.5 & 23.2 \\
\hline United States & $31,389,926$ & 14.5 & $\begin{array}{c}\text { Mexico (26.3), Philippines (4.3), Puerto Rico } \\
\text { (4.1) }\end{array}$ & 35.3 & 33.9 & 30.9 & 12.5 & 53.2 & 34.3 \\
\hline
\end{tabular}

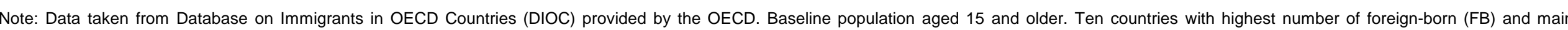

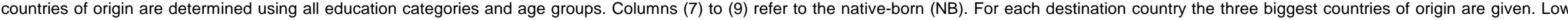

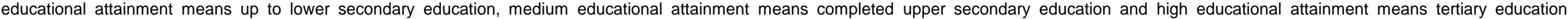

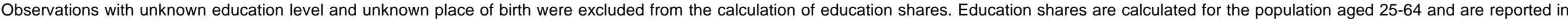
percentages. 
Table 1b: Educational Attainment of Movers and Stayers, around 2000

\begin{tabular}{|c|c|c|c|c|c|c|c|}
\hline Country of Origin & $\begin{array}{l}\text { Share Living in } \\
\text { Other OECD } \\
\text { Countries } \\
\text { (1) }\end{array}$ & $\begin{array}{l}\text { Share Movers Low } \\
\text { Education } \\
\text { (2) }\end{array}$ & $\begin{array}{c}\text { Share Movers } \\
\text { Medium Education } \\
\text { (3) }\end{array}$ & $\begin{array}{c}\text { Share Movers } \\
\text { High Education } \\
\text { (4) }\end{array}$ & $\begin{array}{c}\text { Share Stayers Low } \\
\text { Education } \\
\text { (5) }\end{array}$ & $\begin{array}{c}\text { Share Stayers } \\
\text { Medium Education } \\
\text { (6) }\end{array}$ & $\begin{array}{c}\text { Share Stayers } \\
\text { High Education } \\
\text { (7) }\end{array}$ \\
\hline Mexico & 13.3 & 68.7 & 24.5 & 6.8 & 70.7 & 14.6 & 14.7 \\
\hline United Kingdom & 6.8 & 22.0 & 37.7 & 40.3 & 51.3 & 25.5 & 23.2 \\
\hline Germany & 4.6 & 20.8 & 44.2 & 34.9 & 14.6 & 61.4 & 24.0 \\
\hline Italy & 4.8 & 51.0 & 32.9 & 16.1 & 57.3 & 31.9 & 10.8 \\
\hline Poland & 6.8 & 19.0 & 53.8 & 27.3 & 19.0 & 67.2 & 13.8 \\
\hline Turkey & 4.4 & 69.9 & 22.6 & 7.5 & 77.2 & 14.1 & 8.8 \\
\hline Portugal & 14.5 & 68.4 & 24.8 & 6.8 & 77.7 & 11.9 & 10.4 \\
\hline France & 2.4 & 27.4 & 32.3 & 40.3 & 33.8 & 44.1 & 22.1 \\
\hline Canada & 4.5 & 11.2 & 38.5 & 50.3 & 22.9 & 38.3 & 38.8 \\
\hline South Korea & $\mathrm{n} / \mathrm{a}$ & 10.3 & 37.7 & 52.0 & $\mathrm{n} / \mathrm{a}$ & $\mathrm{n} / \mathrm{a}$ & $\mathrm{n} / \mathrm{a}$ \\
\hline United States & 0.4 & 10.7 & 28.6 & 60.7 & 12.5 & 53.2 & 34.3 \\
\hline
\end{tabular}

Note: Data taken from Database on Immigrants in OECD Countries (DIOC) provided by the OECD. Baseline population aged 15 and older. Eleven OECD-countries with highest number of native-born residing in a foreign OECD country (listed in descending order) are determined using all education categories and age groups (for South Korea data on native-born residing in country of birth are not available). Share living in other OECD countries is relative to overall population currently living in the country of origin. Low educational attainment means up to lower secondary education, medium educational attainment means completed upper secondary education and high educational attainment means tertiary education. Observations with unknown education level and unknown place of birth were excluded from the calculation of education shares. Education shares are calculated for the population aged 25-64-year-old. Shares are given in percentages. 


\begin{tabular}{|c|c|c|c|c|c|c|c|c|c|c|}
\hline \multirow{3}{*}{$\begin{array}{l}\text { Destination } \\
\text { Country }\end{array}$} & \multicolumn{5}{|c|}{ Low Education } & \multicolumn{5}{|c|}{ High Education } \\
\hline & $\begin{array}{l}\text { Minimum Share of } \\
\text { Low Education } \\
\text { across Origin } \\
\text { Countries }\end{array}$ & $\begin{array}{l}\text { Country of Origin with } \\
\text { Minimum Share }\end{array}$ & $\begin{array}{l}\text { Maximum } \\
\text { Share of Low } \\
\text { Education } \\
\text { across Origin } \\
\text { Countries }\end{array}$ & $\begin{array}{l}\text { Country of Origin with } \\
\text { Maximum Share }\end{array}$ & $\begin{array}{l}\text { Standard Deviation of } \\
\text { Low Education } \\
\text { Shares within } \\
\text { Destination Country } \\
\text { across Origin } \\
\text { Countries }\end{array}$ & $\begin{array}{l}\text { Minimum Share } \\
\text { of } \\
\text { HighEducation } \\
\text { across Origin } \\
\text { Countries }\end{array}$ & $\begin{array}{l}\text { Country of Origin with } \\
\text { Minimum Share }\end{array}$ & $\begin{array}{l}\text { Maximum } \\
\text { Share of High } \\
\text { Education } \\
\text { across Origin } \\
\text { Countries }\end{array}$ & $\begin{array}{l}\text { Country of Origin with } \\
\text { Maximum Share }\end{array}$ & $\begin{array}{l}\text { Standard Deviation of } \\
\text { High Education } \\
\text { Shares within } \\
\text { Destination Country } \\
\text { across Origin } \\
\text { Countries }\end{array}$ \\
\hline & (1) & (2) & (3) & (4) & (5) & (6) & (7) & (8) & (9) & (10) \\
\hline Australia & 7.9 & United States (1.2) & 71.6 & Malta (1.2) & 19.4 & 6.5 & Malta (1.2) & 63.3 & United States (1.2) & 19.3 \\
\hline Canada & 6.9 & South Korea (1.4) & 61.7 & Portugal (2.9) & 16.6 & 11.7 & Portugal (2.9) & 66.5 & South Korea (1.4) & 16.2 \\
\hline France & 15.6 & United Kingdom (1.4) & 75.1 & Turkey (3.0) & 18.4 & 4.3 & Portugal (10.1) & 57.0 & United Kingdom (1.4) & 13.7 \\
\hline Germany & 9.8 & France $(0.7)$ & 73.0 & Turkey (15.2) & 19.1 & 4.2 & Turkey (15.2) & 49.7 & France $(0.7)$ & 12.0 \\
\hline Italy & 21.7 & United States (2.2) & 84.0 & Senegal (1.4) & 17.5 & 3.9 & Senegal (1.4) & 37.7 & United States (2.2) & 8.1 \\
\hline Netherlands & 14.9 & France $(0.8)$ & 75.0 & Turkey (11.2) & 17.9 & 6.0 & Turkey (11.2) & 76.4 & United States (0.6) & 16.9 \\
\hline Spain & 28.1 & Cuba (2.4) & 82.4 & Portugal (2.8) & 15.6 & 8.5 & Portugal (2.8) & 40.3 & Cuba (2.4) & 10.6 \\
\hline Switzerland & 7.4 & United States (1.2) & 81.1 & Portugal (6.5) & 25.7 & 2.9 & Portugal (6.5) & 71.9 & United States (1.2) & 20.3 \\
\hline United Kingdom & 10.8 & United States (2.8) & 74.1 & Bangladesh (3.2) & 20.4 & 15.4 & Bangladesh (3.2) & 70.5 & United States (2.8) & 16.9 \\
\hline United States & 4.9 & Japan (1.4) & 69.1 & Mexico (26.3) & 20.4 & 6.5 & Mexico (26.3) & 75.1 & India (3.1) & 19.2 \\
\hline
\end{tabular}

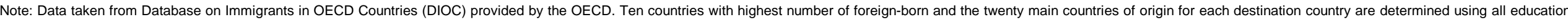

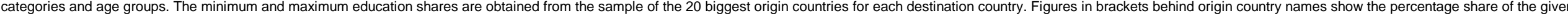

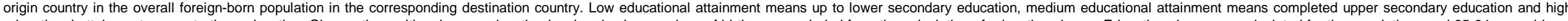

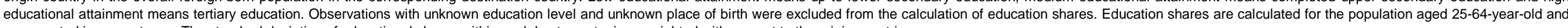
are reported in percentages. The standard deviation of educational shares within each host country is unweighted with respect to the origin countries. 


\begin{tabular}{|c|c|c|c|c|c|c|c|c|c|c|}
\hline \multirow[b]{2}{*}{ Country of Origin } & \multicolumn{5}{|c|}{ Low Education } & \multicolumn{5}{|c|}{ High Education } \\
\hline & $\begin{array}{l}\text { Minimum Share } \\
\text { of Low } \\
\text { Education } \\
\text { across } \\
\text { Destination } \\
\text { Countries } \\
\text { (1) }\end{array}$ & $\begin{array}{l}\text { Destination Country } \\
\text { with Minimum Share } \\
\text { (2) }\end{array}$ & $\begin{array}{l}\text { Maximum Share } \\
\text { of Low } \\
\text { Education } \\
\text { across } \\
\text { Destination } \\
\text { Countries } \\
\text { (3) }\end{array}$ & $\begin{array}{l}\text { Destination Country } \\
\text { with Maximum Share } \\
\text { (4) }\end{array}$ & $\begin{array}{c}\text { Standard } \\
\text { Deviation of Low } \\
\text { Education } \\
\text { Shares within } \\
\text { Source Country } \\
\text { across } \\
\text { Destination } \\
\text { Countries } \\
\text { (5) }\end{array}$ & $\begin{array}{l}\text { Minimum Share } \\
\text { of High } \\
\text { Education } \\
\text { across } \\
\text { Destination } \\
\text { Countries } \\
\text { (6) }\end{array}$ & $\begin{array}{l}\text { Destination Country } \\
\text { with Minimum Share }\end{array}$ & $\begin{array}{l}\text { Maximum Share } \\
\text { of High } \\
\text { Education } \\
\text { across } \\
\text { Destination } \\
\text { Countries }\end{array}$ & $\begin{array}{l}\text { Destination Country } \\
\text { with Maximum Share } \\
\text { (9) }\end{array}$ & $\begin{array}{c}\text { Standard } \\
\text { Deviation of High } \\
\text { Education } \\
\text { Shares within } \\
\text { Source Country } \\
\text { across } \\
\text { Destination } \\
\text { Countries } \\
\text { (10) }\end{array}$ \\
\hline Mexico & 5.0 & Sweden $(0.0)$ & 69.0 & United States (99.1) & 20.4 & 6.5 & United States (99.1) & 77.8 & United Kingdom (0.1) & 20.9 \\
\hline United Kingdom & 5.6 & United States (23.4) & 46.1 & Spain (3.0) & 13.8 & 26.1 & Italy (1.5) & 57.0 & France (2.4) & 11.2 \\
\hline Germany & 8.1 & United States (34.2) & 49.1 & Italy (5.4) & 13.7 & 12.9 & Italy (5.4) & 43.3 & Canada (5.8) & 9.9 \\
\hline Italy & 31.2 & United States (22.0) & 72.3 & Belgium (5.5) & 13.4 & 8.2 & Germany (14.2) & 36.5 & Spain (1.0) & 10.4 \\
\hline Poland & 11.6 & Sweden (1.7) & 31.1 & Czech Republic (1.2) & 6.1 & 7.0 & Czech Republic (1.2) & 48.7 & United Kingdom (2.8) & 14.0 \\
\hline Turkey & 14.2 & United States (4.0) & 81.8 & Austria (5.4) & 20.8 & 2.5 & Austria (5.4) & 52.7 & United States (4.0) & 15.2 \\
\hline Portugal & 51.5 & United States (16.4) & 82.4 & Spain (4.2) & 9.8 & 2.2 & Luxembourg (3.0) & 20.5 & United Kingdom (2.6) & 5.8 \\
\hline France & 6.9 & United States (16.6) & 51.2 & Italy (11.1) & 19.4 & 12.1 & Poland (2.9) & 65.9 & United Kingdom (7.5) & 19.5 \\
\hline Canada & 0.7 & Japan (0.6) & 35.7 & Italy (2.1) & 11.4 & 16.7 & Italy (2.1) & 91.8 & Japan (0.6) & 20.2 \\
\hline South Korea & 3.2 & New Zealand (1.4) & 13.7 & Denmark (0.7) & 3.8 & 27.5 & New Zealand (1.4) & 78.3 & United Kingdom (1.0) & 15.9 \\
\hline United States & 1.8 & Japan (3.9) & 32.7 & Mexico (12.8) & 9.4 & 37.2 & Mexico (12.8) & 82.9 & Japan (3.9) & 16.3 \\
\hline
\end{tabular}

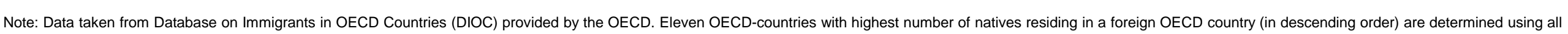

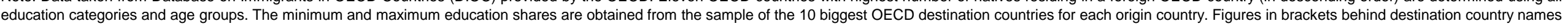

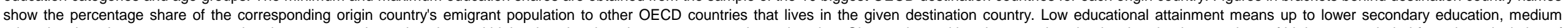

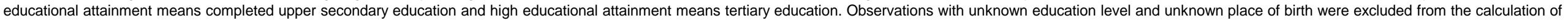

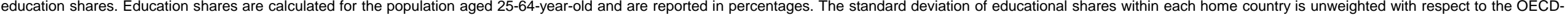
host countries. 
Table 4: Median Wages of Foreign-Born Relative to Native-Born by Broad Educational Categories, 2005/2006

\begin{tabular}{|c|c|c|c|c|c|c|c|c|}
\hline \multirow{3}{*}{$\begin{array}{l}\text { Destination } \\
\text { Country }\end{array}$} & \multirow{3}{*}{$\begin{array}{l}\text { Overall } \\
\text { (1) }\end{array}$} & \multirow{3}{*}{$\begin{array}{l}\text { Low Education } \\
\qquad \text { (2) }\end{array}$} & \multirow{3}{*}{$\begin{array}{l}\text { Medium } \\
\text { Education } \\
\text { (3) }\end{array}$} & \multirow{3}{*}{$\begin{array}{l}\text { High Education } \\
\text { (4) }\end{array}$} & \multicolumn{2}{|c|}{ High Education (Men) } & \multicolumn{2}{|c|}{ High Education (Women) } \\
\hline & & & & & \multirow{2}{*}{$\begin{array}{c}\text { Obtained in } \\
\text { Home Country } \\
\text { (5) }\end{array}$} & \multirow{2}{*}{$\begin{array}{l}\text { Obtained in Host } \\
\text { Country } \\
\text { (6) }\end{array}$} & \multirow{2}{*}{$\begin{array}{c}\text { Obtained in } \\
\text { Home Country } \\
\text { (7) }\end{array}$} & \multirow{2}{*}{$\begin{array}{l}\text { Obtained in Host } \\
\text { Country } \\
\text { (8) }\end{array}$} \\
\hline & & & & & & & & \\
\hline Australia & 1.07 & 1.11 & 1.02 & 0.98 & 0.99 & 0.93 & 0.94 & 1.02 \\
\hline Canada & 0.95 & 1.07 & 0.94 & 0.89 & 0.86 & 0.95 & 0.79 & 0.99 \\
\hline France & 0.90 & 0.94 & 0.96 & 0.90 & 0.88 & 0.86 & 0.77 & 1.10 \\
\hline Germany & 0.93 & 1.14 & 0.93 & 0.91 & 0.86 & 1.00 & 0.83 & 0.95 \\
\hline Netherlands & 0.85 & 1.11 & 1.02 & 0.98 & $\mathrm{n} / \mathrm{a}$ & $\mathrm{n} / \mathrm{a}$ & $\mathrm{n} / \mathrm{a}$ & $\mathrm{n} / \mathrm{a}$ \\
\hline Portugal & 0.94 & 1.00 & 0.76 & 0.80 & 0.49 & 0.88 & 0.52 & 1.00 \\
\hline Sweden & 0.93 & 0.91 & 0.94 & 0.92 & 0.81 & 0.88 & 0.89 & 0.95 \\
\hline Switzerland & 0.89 & 1.05 & 0.93 & 0.96 & $\mathrm{n} / \mathrm{a}$ & $\mathrm{n} / \mathrm{a}$ & $\mathrm{n} / \mathrm{a}$ & $\mathrm{n} / \mathrm{a}$ \\
\hline United States & 0.79 & 1.07 & 0.83 & 0.93 & 0.80 & 1.04 & 0.79 & 1.13 \\
\hline
\end{tabular}

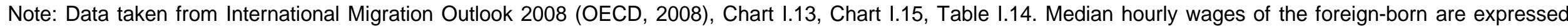

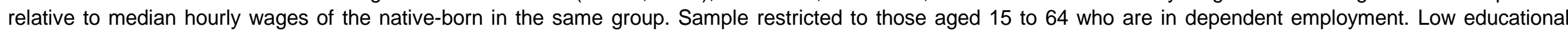

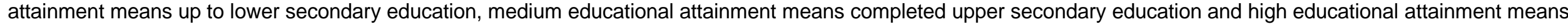
tertiary education. 
Table 5: Number and Share of Foreign Students in Tertiary Education in OECD Countries, 2008

\begin{tabular}{|c|c|c|c|c|c|}
\hline $\begin{array}{l}\text { Destination } \\
\text { Country }\end{array}$ & $\begin{array}{l}\text { Share Foreign Students } \\
\text { in Tertiary Education }\end{array}$ & $\begin{array}{c}\text { Share Foreign Students } \\
\text { in Advanced Research } \\
\text { Programmes }\end{array}$ & $\begin{array}{c}\text { Number Foreign } \\
\text { Students in Tertiary } \\
\text { Education }\end{array}$ & $\begin{array}{l}\text { Index of Change (1998. } \\
\qquad 2008)\end{array}$ & $\begin{array}{c}\text { Retention Rates } \\
\text { (2007) }\end{array}$ \\
\hline & (1) & (2) & (3) & (4) & (5) \\
\hline Australia & 20.6 & 23.3 & 230,635 & $211^{1)}$ & $30.0^{3)}$ \\
\hline Canada & 13.1 & 38.6 & 185,781 & 565 & 14.7-18.8 \\
\hline France & 11.2 & 39.8 & 243,436 & 164 & 27.4 \\
\hline Germany & 10.9 & $\mathrm{n} / \mathrm{a}$ & 245,522 & 143 & 29.5 \\
\hline Italy & 3.0 & 7.0 & 60,448 & 260 & $\mathrm{n} / \mathrm{a}$ \\
\hline Netherlands & 6.8 & $\mathrm{n} / \mathrm{a}$ & 40,795 & $300^{2)}$ & 15.0 \\
\hline Spain & 3.6 & 24.0 & 64,906 & 224 & $\mathrm{n} / \mathrm{a}$ \\
\hline Switzerland & 20.3 & 45.9 & 45,583 & 187 & $\mathrm{n} / \mathrm{a}$ \\
\hline United Kingdom & 19.9 & 47.7 & 462,609 & 221 & $27.0^{4)}$ \\
\hline United States & 3.4 & $\mathrm{n} / \mathrm{a}$ & 624,474 & $145^{1)}$ & $\mathrm{n} / \mathrm{a}$ \\
\hline
\end{tabular}

Note: Data taken from OECD iLibrary. Foreign students defined as non-citizen students except for Australia and the United States where they are defined as non-resident students due to missing information on non-citizen status. Index of Change 1998-2008 in the number of foreign students is given for total tertiary education and relative to $1998(1998=100)$. Data on retention rates taken from Table I.8 of the International Migration Outlook 2010 (OECD, 2010). Retention rates are calculated as the number of international students who change their legal migration status, for example from "student" to "work" or "family formation", divided by the number of international students who do not renew their student permit. 1) Base year figure in 1998 covers non-citizen students whereas figure in 2008 covers non-resident students. 2) Index of change calculated relative to 1999. 3) Figure for Australia estimated by Australian Department of Immigration and Citizenship. 4) Figure for the UK refers to 2005/2006 and is taken from ICMPD (2006). 
Table 6: Origin of Foreign Students in Tertiary Education in OECD Countries, 2008

\begin{tabular}{|c|c|c|c|c|c|c|}
\hline $\begin{array}{l}\text { Destination } \\
\text { Country }\end{array}$ & $\begin{array}{l}\text { Main Student Sending Countries (Share } \\
\text { of All Foreign Students in Percent) }\end{array}$ & Share Europe & $\begin{array}{l}\text { Share North } \\
\text { America }\end{array}$ & $\begin{array}{l}\text { Share South } \\
\text { America }\end{array}$ & Share Asia & Share Africa \\
\hline & (1) & (2) & (3) & $(4)$ & (5) & (6) \\
\hline Australia & China (25.0), India (11.5), Malaysia (8.1) & 4.4 & 3.5 & 0.9 & 79.3 & 3.2 \\
\hline Canada & China (19.5), India (5.6), U.S. (5.4) & 12.0 & 10.1 & 3.1 & 50.2 & 11.7 \\
\hline France & Morocco (11.1), China (8.6), Algeria (7.7) & 21.3 & 3.5 & 3.7 & 21.0 & 43.5 \\
\hline Germany & China (10.4), Turkey (9.7), Poland (5.7) & 47.5 & 2.5 & 2.7 & 37.5 & 9.0 \\
\hline Italy & Albania (19.5), Greece (7.5), Romania (5.2) & 56.5 & 1.9 & 7.6 & 15.0 & 10.8 \\
\hline Netherlands & Germany (40.6), China (8.4), Belgium (5.4) & 69.3 & 2.3 & 3.3 & 19.9 & 5.0 \\
\hline Spain & Colombia (8.7), Morocco (8.4), Peru (6.8) & 31.4 & 11.3 & 40.7 & 3.7 & 11.7 \\
\hline Switzerland & Germany (24.0), Italy (10.8), France (10.3) & 75.7 & 2.5 & 2.9 & 9.0 & 5.4 \\
\hline United Kingdom & China (11.1), India (7.1), Ireland (5.8) & 34.7 & 6.6 & 1.3 & 39.5 & 14.9 \\
\hline United States & China (17.7), India (15.2), Korea (11.1) & 11.2 & 10.1 & 5.0 & 67.2 & 5.7 \\
\hline
\end{tabular}

Note: Data taken from OECD iLibrary. Foreign students are defined as non-citizen students except for Australia and the United States where they are defined as non-resident students due to missing information on non-citizen status. Shares refer to students enrolled in tertiary education, both full-time and part-time. 
Figure 1: Origin of Foreign Students in Tertiary Education between 1999 and 2008

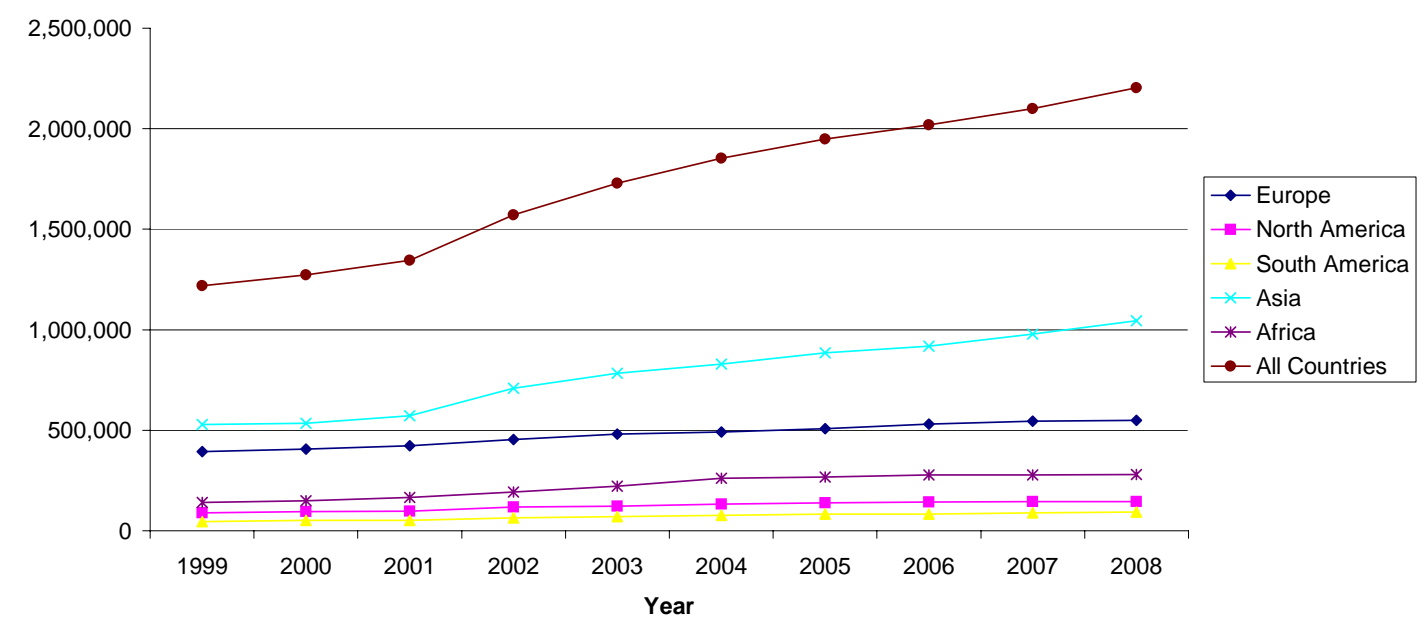

Note: Data taken from OECD iLibrary. Graph shows total number of students in the 10 main OECD countries listed in Table 6 by continent of origin. Foreign students are defined as non-citizen students except for Australia and the United States where they are defined as non-citizen students from 1998 to 2003, and as nonresident students from 2004 to 2008. Numbers refer to students enrolled in tertiary education, both full-time and part-time. Numbers for Australia in 1999 and Canada in 2001 to 2003 and 2005 are missing and were linearly interpolated using the numbers in adjacent years. 
Table 7: Share of Immigrants by Duration of Stay, Outflow/Inflow Ratio, and 5 Year Re-Emigration Rate (around 2000)

\begin{tabular}{|c|c|c|c|c|c|}
\hline \multirow[t]{2}{*}{$\begin{array}{l}\text { Destination } \\
\text { Country }\end{array}$} & Share Duration $<5$ & Share Duration $>10$ & Share Duration >20 & $\begin{array}{c}\text { Ratio } \\
\text { Outflow/Inflow*100 } \\
1998-2008\end{array}$ & $\begin{array}{c}5 \text { Year Re- } \\
\text { Emigration Rate }\end{array}$ \\
\hline & (1) & $(2)$ & (3) & (4) & (5) \\
\hline Australia & 13.6 & 77.5 & 55.0 & 9.8 & $\mathrm{n} / \mathrm{a}$ \\
\hline Canada & 14.8 & 70.0 & 50.2 & $\mathrm{n} / \mathrm{a}^{1)}$ & $23.7^{3)}$ \\
\hline Switzerland & 23.1 & 62.4 & 31.1 & 51.3 & $\mathrm{n} / \mathrm{a}$ \\
\hline Germany & 3.6 & 79.7 & $\mathrm{n} / \mathrm{a}$ & 86.0 & $\mathrm{n} / \mathrm{a}$ \\
\hline Spain & 40.4 & 49.0 & 34.6 & $14.3^{2)}$ & $\mathrm{n} / \mathrm{a}$ \\
\hline France & 8.1 & 82.7 & 65.9 & $\mathrm{n} / \mathrm{a}^{1)}$ & $\mathrm{n} / \mathrm{a}$ \\
\hline United Kingdom & 17.0 & 70.2 & $\mathrm{n} / \mathrm{a}$ & 42.6 & 39.9 \\
\hline Italy & 37.8 & 34.4 & 9.9 & $\mathrm{n} / \mathrm{a}^{1)}$ & $\mathrm{n} / \mathrm{a}$ \\
\hline Netherlands & 9.7 & 71.6 & $\mathrm{n} / \mathrm{a}$ & 29.3 & 28.1 \\
\hline United States & 20.1 & 63.7 & 35.7 & $\mathrm{n} / \mathrm{a}^{1)}$ & 19.1 \\
\hline
\end{tabular}

Note: Data taken from Database on Immigrants in OECD Countries (DIOC) provided by the OECD. Duration shares refer to the foreign-born population. Observations with unknown length of duration were excluded from the calculation. The ratio of the aggregate outflow to the aggregate inflow of the foreign population between 1998 and 2008 is calculated using data from the OECD's International Migration Database. Ratios are based on data of foreign nationals from population registers for all countries except Australia and the United Kingdom, for which data based on residence permits or other sources was used. Data on re-emigration rates after 5 years are taken from Table III.1 (p. 171) of the International Migration Outlook 2008 (OECD, 2008). Relevant entry period for the United Kingdom was 1992-1998, for the Netherlands 1994-1998, and for the United States 1999. 1) Data on outflows was missing for these countries. 2) Ratio for Spain refers to period 2002-2008. 3) Figure taken from Aydemir and Robinson (2008). 


\begin{tabular}{|c|c|c|c|c|}
\hline \multirow[t]{3}{*}{$\begin{array}{l}\text { Destination } \\
\text { Country }\end{array}$} & \multirow{3}{*}{$\begin{array}{c}\text { Reading } \\
\text { (1) }\end{array}$} & \multirow{3}{*}{$\begin{array}{c}\text { Mathematics } \\
\text { (2) }\end{array}$} & \multicolumn{2}{|c|}{$\begin{array}{l}\text { Difference of Performance between Students } \\
\text { with an Immigrant Background Who Speak a } \\
\text { Language at Home that is Different from the } \\
\text { Language of Instruction and Native Students }\end{array}$} \\
\hline & & & Reading & Mathematics \\
\hline & & & (3) & $(4)$ \\
\hline Australia & $8.8^{*}$ & $15.7^{\star \star}$ & -4.4 & -4.2 \\
\hline Canada & -2.4 & -2.7 & $-16.1^{\star *}$ & -1.1 \\
\hline France & $-25.4^{* *}$ & $-38.9^{* *}$ & $-31.7^{\star *}$ & $-66.7^{\star *}$ \\
\hline Germany & $-57.1^{\star *}$ & $-58.1^{\star \star}$ & $-81.6^{\star *}$ & $-92.8^{\star \star}$ \\
\hline Italy & $-60.7^{\star \star}$ & $-38.6^{\star *}$ & $-79.4^{\star *}$ & -22.2 \\
\hline Netherlands & $-52.1^{* *}$ & $-53.8^{* *}$ & $-61.4^{* *}$ & $-86.9^{* *}$ \\
\hline Spain & $-41.1^{\star \star}$ & $-47.8^{\star *}$ & $-46.0^{\star \star}$ & $-26.1^{*}$ \\
\hline Switzerland & $-57.3^{* *}$ & $-69.5^{\star *}$ & $-78.3^{\star *}$ & $-81.7^{\star *}$ \\
\hline United Kingdom & -11.5 & $-14.6^{*}$ & $-36.5^{\star *}$ & $-26.6^{\star *}$ \\
\hline United States & $-25.7^{* *}$ & $-22.9^{* *}$ & $-45.5^{\star *}$ & $-39.4^{* *}$ \\
\hline
\end{tabular}

Note: Source: PISA 2006; reading scores for the U.S.: PISA 2003. Native students are defined as those born in the country of assessment with both parents also born in the country of assessment. Immigrant students are either those born abroad with both parents also born abroad (first generation) or those born in the country of assessment but both parents born abroad (second generation). Students with a mixed background are excluded. Values are computed using the final weights provided by PISA. Stars indicate that the difference between the immigrant and the native average score is statistically significant at the 1 percent level $\left({ }^{* *}\right)$ and at the 5 percent level $\left({ }^{*}\right)$. 
Figure 2: Gaps in Educational Attainment and Log Wages of 1st and 2nd Generation Immigrant Men Relative to Native Men
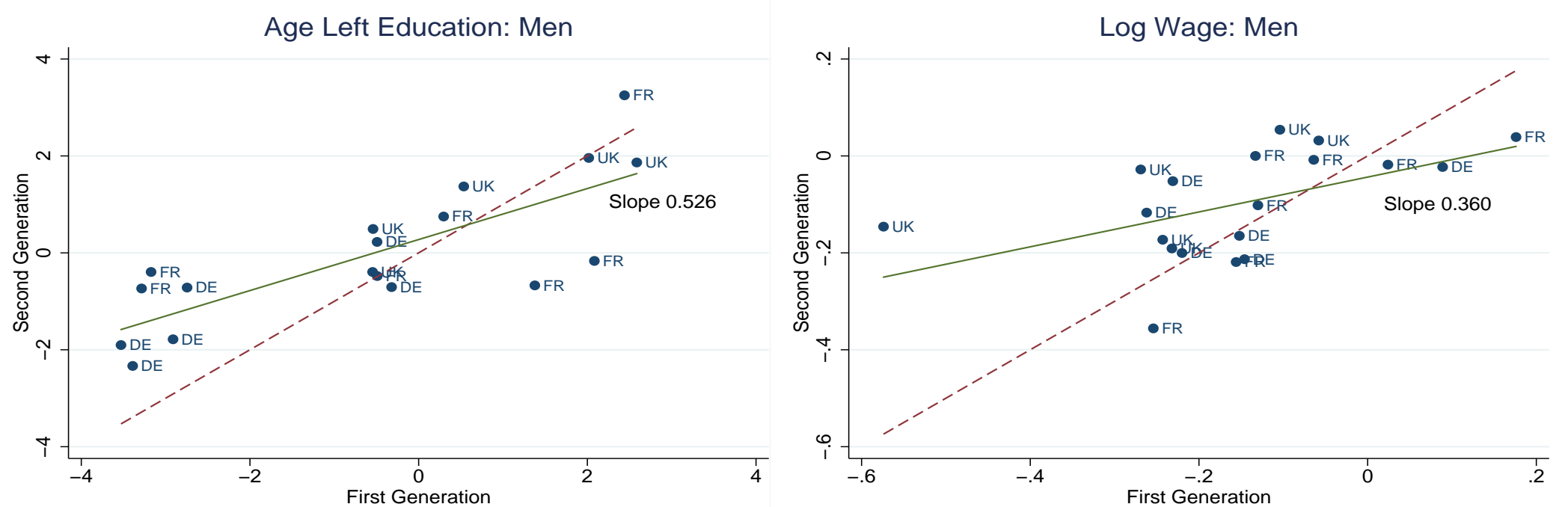

Source: Algan et al. (2010). Data sources are the French Labour Force Survey 2005-2007, the German Microcensus 2005-2006, and the UK Labour Force Survey 1993-2007. Data points reflect estimated gaps in age left education and log wages of different origin groups of first- and second-generation immigrant men relative to native men. Additional controls in the regressions from which these estimates were obtained are a quadratic in year of birth, region dummies and time dummies in the age left education censored regression, and a quartic in potential experience, region dummies and time dummies in the linear wage regression. 
Table 10: Summary of the Literature on Immigrants' Earnings Assimilation

\begin{tabular}{|c|c|c|c|c|c|c|c|c|c|c|}
\hline Authers & Country & Data & $\begin{array}{l}\text { Identification } \\
\text { Assumption }\end{array}$ & Sample & $\begin{array}{c}\begin{array}{c}\text { Dependent } \\
\text { variable }\end{array} \\
\text { val }\end{array}$ & $\begin{array}{c}\text { Main Immigrant } \\
\text { Groups }\end{array}$ & Main Results & 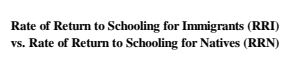 & 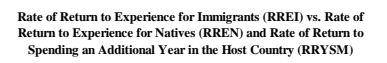 & Remants \\
\hline (1) & (2) & (3) & (4) & (5) & (6) & (7) & (8) & (9) & (10) & (11) \\
\hline $\begin{array}{l}\text { Baker and } \\
\text { Bejamini (1994) }\end{array}$ & Canda & 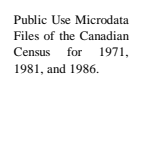 & Equal time effects. & 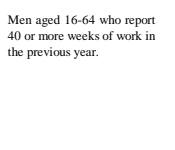 & 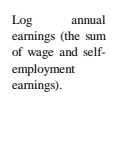 & 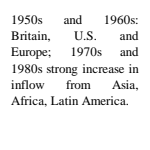 & 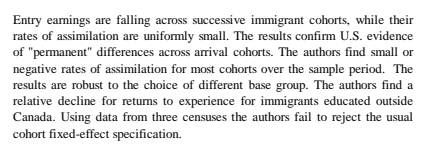 & 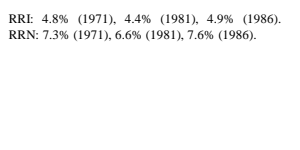 & 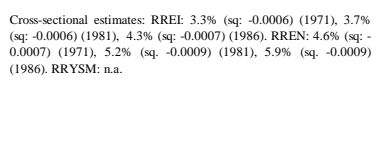 & 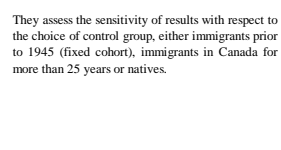 \\
\hline 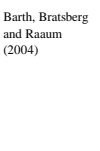 & Nonway & $\begin{array}{l}\text { Regiser data for } \\
\text { 19890, } 1999,1992 . \\
1996 .\end{array}$ & 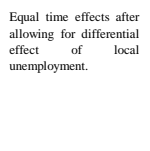 & Individualal saged 25-64. & $\begin{array}{l}\text { Log } \\
\text { eamingse }\end{array}$ & 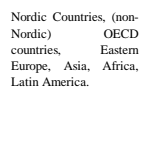 & 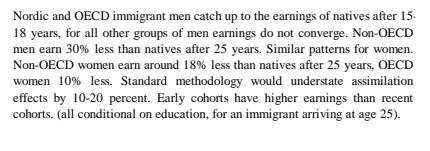 & na.a. & n.a. & 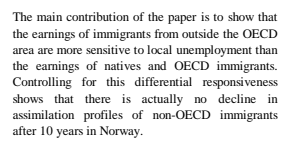 \\
\hline 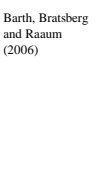 & United States & $\begin{array}{l}\text { Current Population } \\
\text { SSrvey (CSP) } \\
1979 \text { from } 2003 \text {. }\end{array}$ & 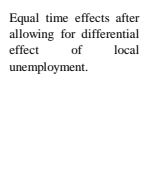 & $\begin{array}{l}\text { Individual aged 21-64 (and } \\
\text { not enolled in shool). }\end{array}$ & $\begin{array}{l}\text { Log hourly wage } \\
\text { rate (constructed). }\end{array}$ & 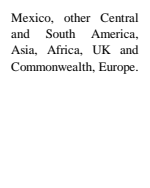 & 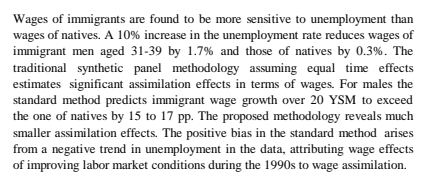 & n.a. & 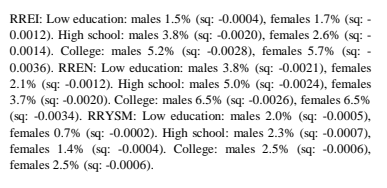 & 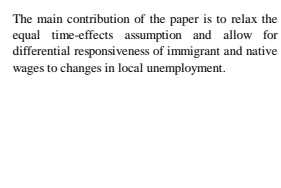 \\
\hline $\begin{array}{l}\text { Basilio and } \\
\text { Baur (2010) }\end{array}$ & Germany & 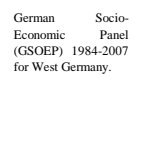 & Equal time effects. & Individual saged 16-64. & $\begin{array}{l}\text { Log hourly real } \\
\text { wage } \\
\text { constrocteded). }\end{array}$ & 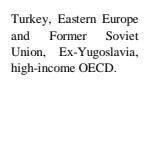 & 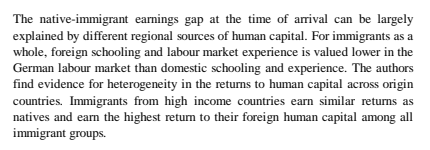 & 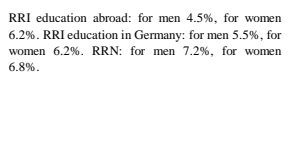 & 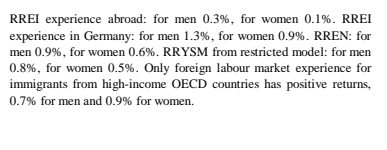 & 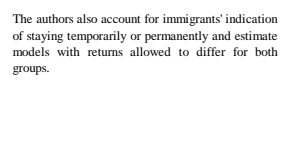 \\
\hline $\begin{array}{l}\text { Beggs and } \\
\text { Chapman } \\
\text { (1988s) }\end{array}$ & Australia & 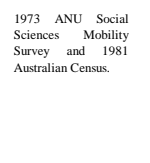 & Equal time effects. & $\begin{array}{l}\text { Wage or slaly-eaning men } \\
\text { aged 30.64. }\end{array}$ & $\begin{array}{l}\text { Log } \\
\text { income. }\end{array}$ hourly & 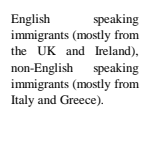 & 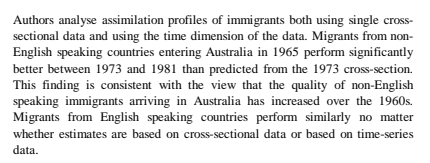 & 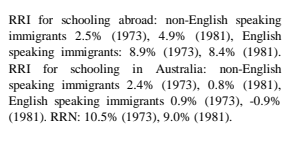 & 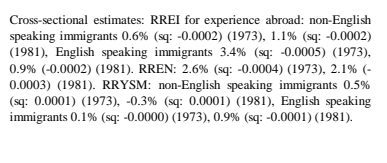 & \\
\hline Bell (1997) & ик & $\begin{array}{l}\text { General Household } \\
\text { Surveys (GHS) } 1973 . \\
\text { 1992. }\end{array}$ & Equal time efficats. & 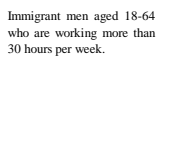 & $\begin{array}{l}\text { Log gross weekly } \\
\text { wagess }\end{array}$ & $\begin{array}{l}\text { Caribbean, } \\
\text { Euroe } \\
\text { Commonwealth. }\end{array}$ & 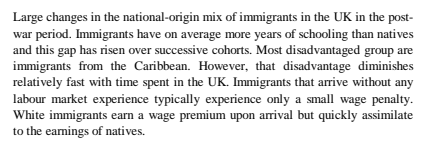 & 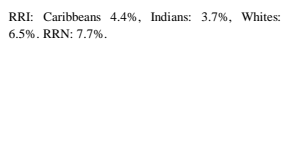 & 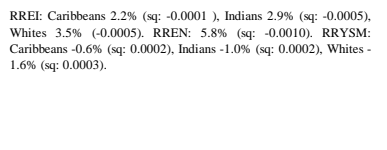 & \\
\hline Bojis (1985) & United States & $\begin{array}{l}1970,1980 \text { U.S. } \\
\text { Cenass. }\end{array}$ & Equal time effects. & $\begin{array}{l}\text { Men aged } 18.54 \text { in } 1970 \\
\text { and 28.64 in } 1980 .\end{array}$ & $\begin{array}{l}\text { Log hourly wage } \\
\text { rate (consunceled). }\end{array}$ & $\begin{array}{l}\text { Mexico, Cuba, Other } \\
\text { Hifspani, Asian, White, } \\
\text { Black. }\end{array}$ & 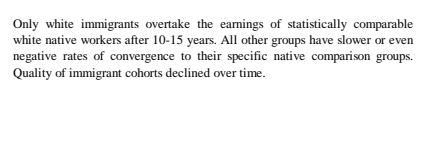 & 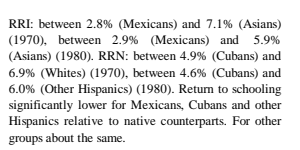 & 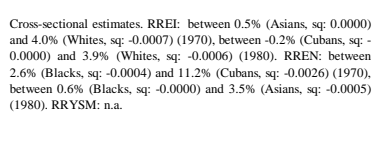 & 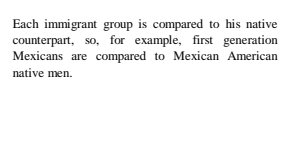 \\
\hline
\end{tabular}




\begin{tabular}{|c|c|c|c|c|c|c|c|c|c|c|}
\hline Bopiss (1995) & United States & $\begin{array}{l}\text { 1970. } 1980, \quad 1990 \\
\text { U.S. Census. }\end{array}$ & Equal time efficts. & Men aged 25-64. & $\begin{array}{l}\text { Log houly wage } \\
\text { rate consurncteded). }\end{array}$ & $\begin{array}{l}\text { Mexican, } \\
\text { Hispanic, Asian, Whiter }\end{array}$ & 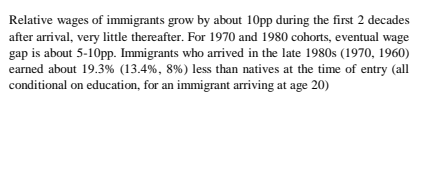 & RRI: $4.7 \%$, RRN: $6 \%$ & 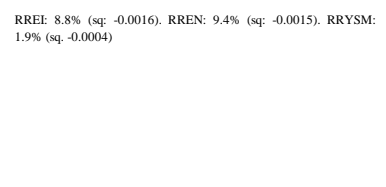 & 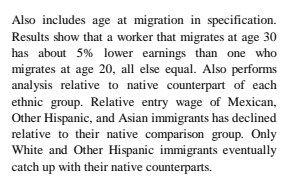 \\
\hline $\begin{array}{l}\text { Batubberg and } \\
\text { Ragan }(2022)\end{array}$ & United Satass & 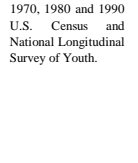 & Equal cohort effects. & 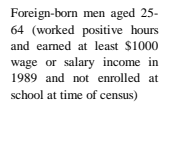 & $\begin{array}{l}\text { Log of weekly } \\
\text { eamingess. }\end{array}$ & 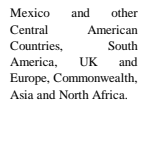 & 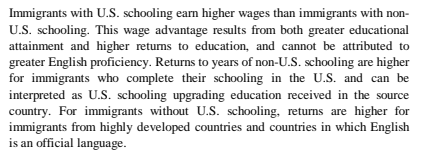 & 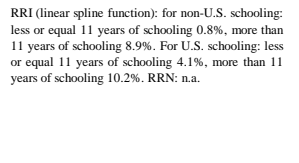 & 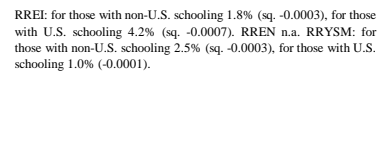 & \\
\hline Chiswick (1978) & United States & 1977 U.S. Cenus. & Equal cohor effects. & $\begin{array}{l}\text { White men (natives and } \\
\text { immigrants) aged 25-64. }\end{array}$ & $\begin{array}{l}\text { Log } \\
\text { eamings, }\end{array}$ & 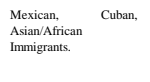 & 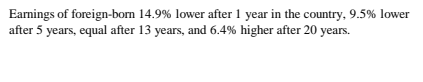 & 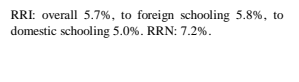 & 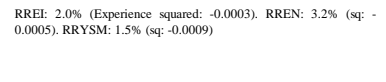 & 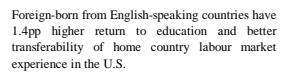 \\
\hline $\begin{array}{l}\text { Clark and } \\
\text { Lindley (2009) }\end{array}$ & uK & $\begin{array}{l}\text { UKK LLabur. Forec } \\
\text { Survey 1993-2004. }\end{array}$ & Equal time efficts. & Men aged 16-64. & 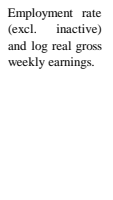 & 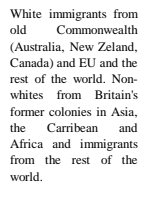 & 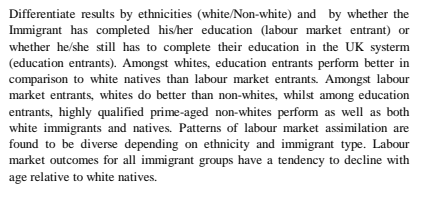 & 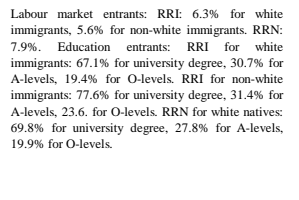 & na. & 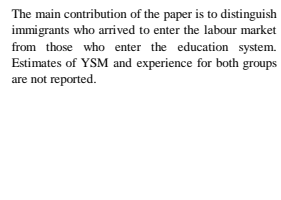 \\
\hline $\begin{array}{l}\text { Dustmann } \\
\text { (1993) }\end{array}$ & Germany & $\begin{array}{ll}\text { German } & \text { Socio- } \\
\text { Econonic } & \text { Panel } \\
\text { (GSOEPP. } & \end{array}$ & Equal cohort tefiects. & 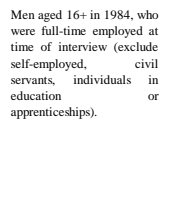 & $\begin{array}{l}\text { Log monhly } \\
\text { grose aninges }\end{array}$ & $\begin{array}{l}\text { Tukrey and Southern } \\
\text { Europe. }\end{array}$ & 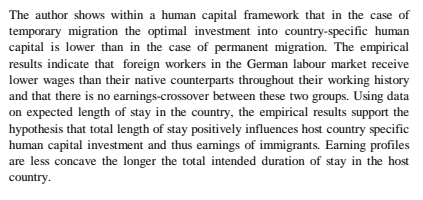 & 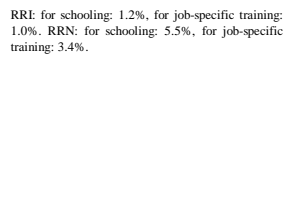 & 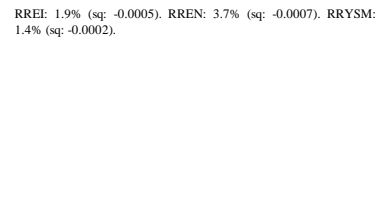 & 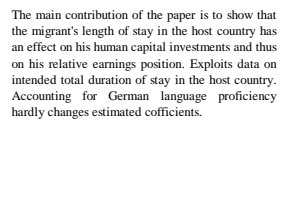 \\
\hline $\begin{array}{l}\text { Edin, Latuonde } \\
\text { and Alsumd } \\
(2000)\end{array}$ & Sweden & 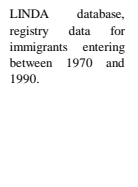 & Equal time effects. & $\begin{array}{l}\text { Individuals aged 18.55 at } \\
\text { the time of inmigization. }\end{array}$ & 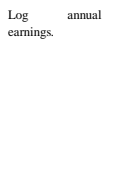 & 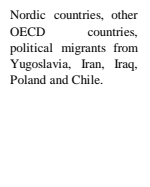 & 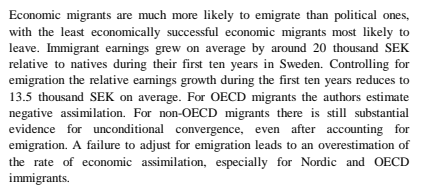 & & 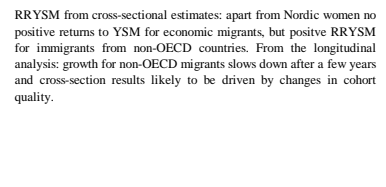 & 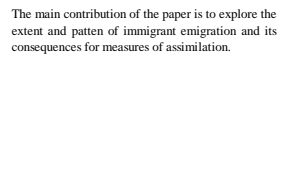 \\
\hline Friedberg (2000) & Irrael & $\begin{array}{l}\text { Iraeli Census of } \\
\text { Popoultion } \\
\text { Howisg } 1972 \text { and } \\
\text { and } \\
\text { and. }\end{array}$ & 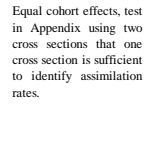 & 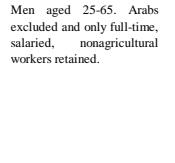 & $\begin{array}{l}\text { Log, Monhly } \\
\text { eaminges. }\end{array}$ & 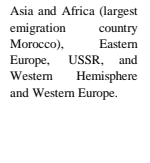 & 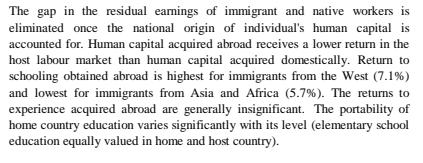 & 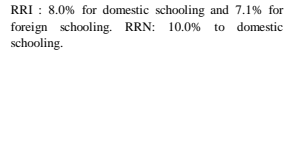 & 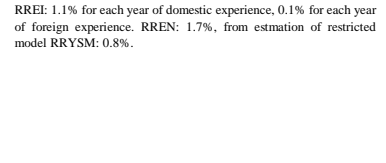 & 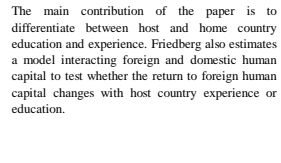 \\
\hline $\begin{array}{l}\text { Funkhouser and } \\
\text { Trejo }(1995)\end{array}$ & United States & 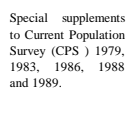 & Equal time efficts. & Men aged betwen 18-61. & $\begin{array}{l}\text { Log average } \\
\text { hourly annings }\end{array}$ & 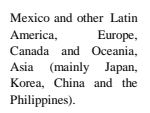 & 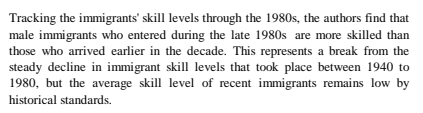 & RRI 5.1\%. RRN: 8.2\%. & 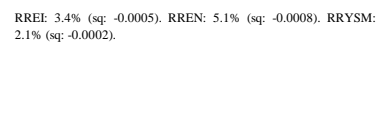 & \\
\hline
\end{tabular}




\begin{tabular}{|c|c|c|c|c|c|c|c|c|c|c|}
\hline 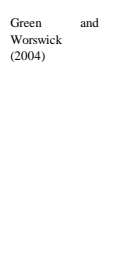 & Canata & 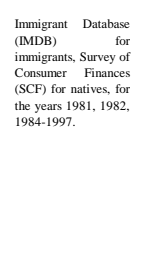 & 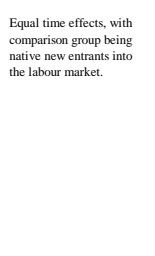 & Me aged 25.64t. & 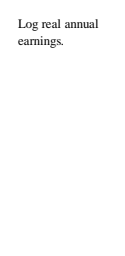 & 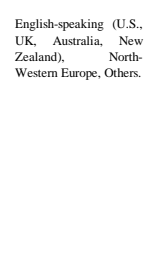 & 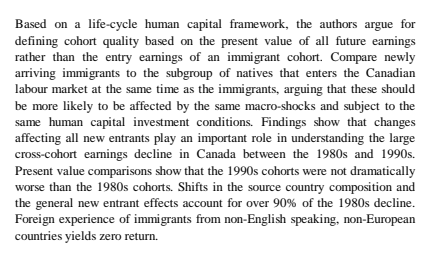 & na.a. & 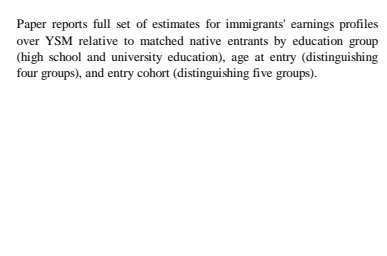 & \\
\hline Asfron (1998) & Nomay & 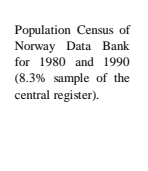 & Eamal hine efictacts & 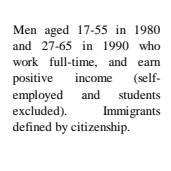 & 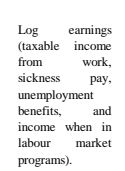 & na & 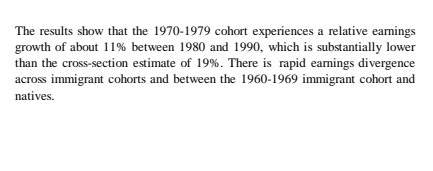 & 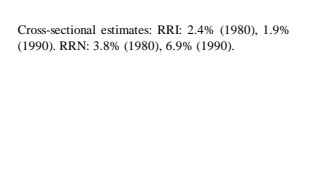 & 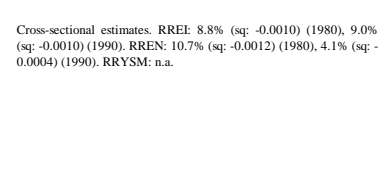 & na. \\
\hline 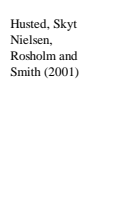 & Demanat & 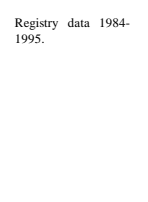 & Equal tine efrects & 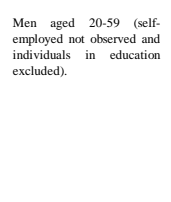 & 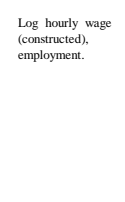 & 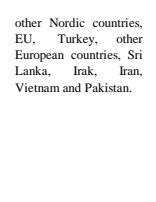 & 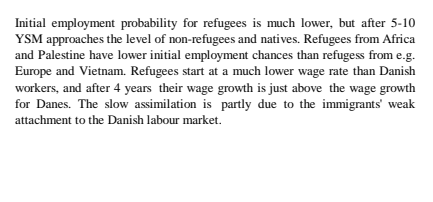 & 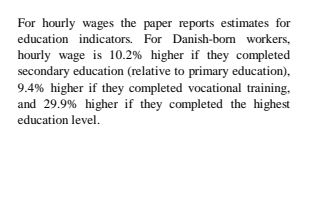 & 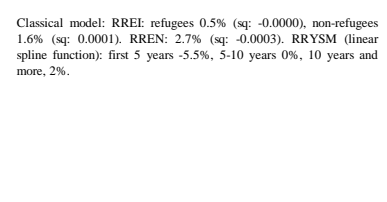 & 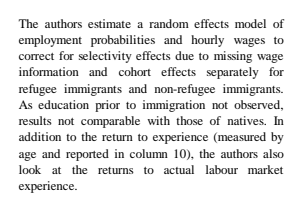 \\
\hline Kee (1995) & The Nentertands & 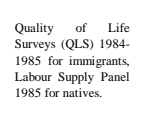 & Ekgual colono efficts. & Menages 1.6.5. & $\begin{array}{l}\text { Log bouly wage } \\
\text { rate. }\end{array}$ & 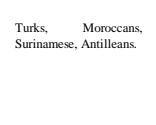 & 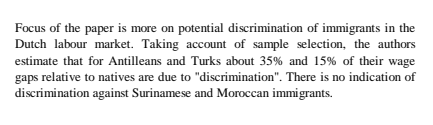 & 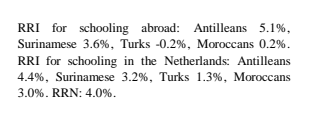 & 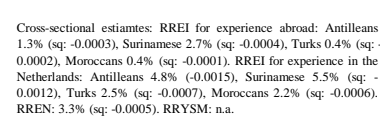 & \\
\hline 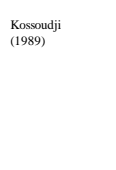 & Unines Sumes & 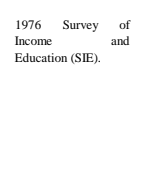 & 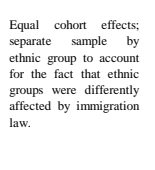 & 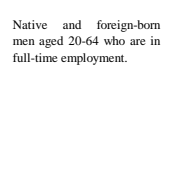 & 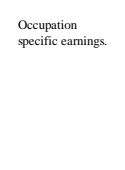 & 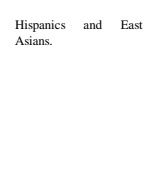 & 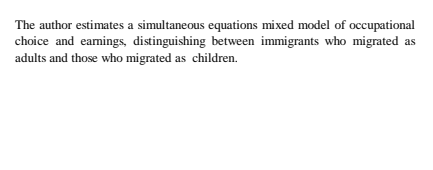 & 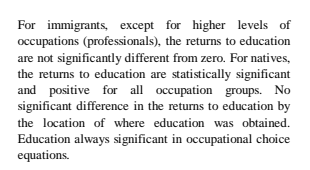 & 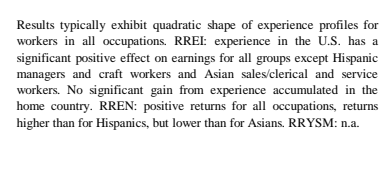 & 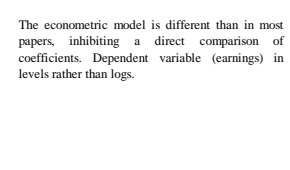 \\
\hline 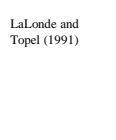 & vinied S Sules & $\begin{array}{l}\text { 1970 and } 1980 \text { us. } \\
\text { conase }\end{array}$ & Equal time efricts. & 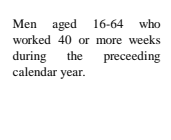 & 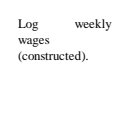 & 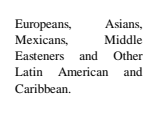 & 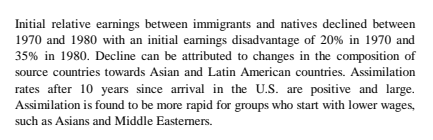 & na. & 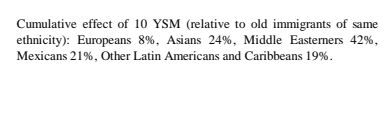 & 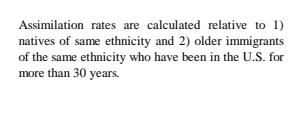 \\
\hline 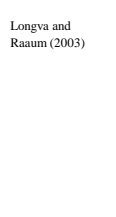 & Nomay & 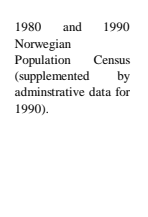 & Equal hine frefers & 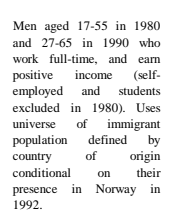 & 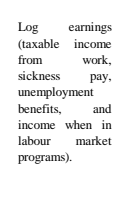 & $\begin{array}{l}\text { OECD, and now-OECD } \\
\text { counties, }\end{array}$ & 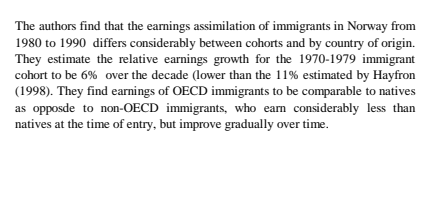 & 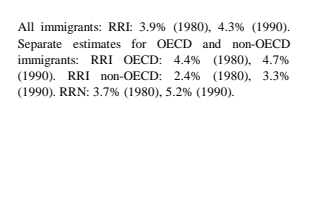 & 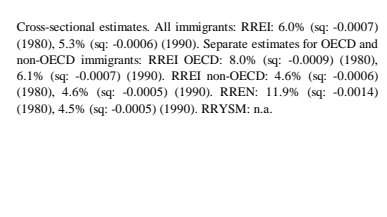 & 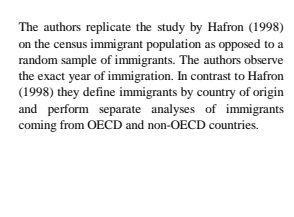 \\
\hline $4 y=0007)$ & Unied Suare & 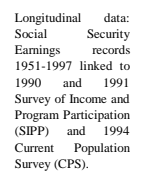 & 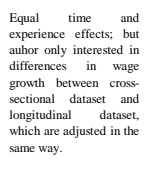 & $\begin{array}{l}\text { Men bom between } 1930 \\
\text { and 1969. }\end{array}$ & 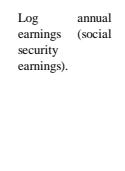 & na. & 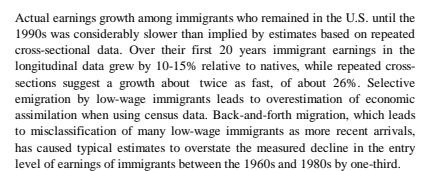 & na. & 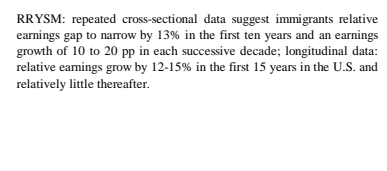 & 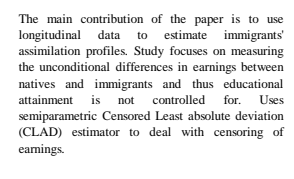 \\
\hline
\end{tabular}




\begin{tabular}{|c|c|c|c|c|c|c|c|c|c|c|}
\hline 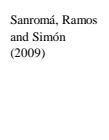 & Spain & 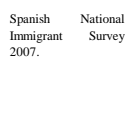 & Equal colone efficicas & 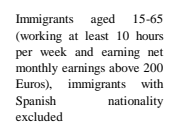 & $\begin{array}{l}\substack{\text { Log net monhly } \\
\text { wages }} \\
\text { wates }\end{array}$ & 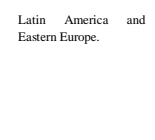 & 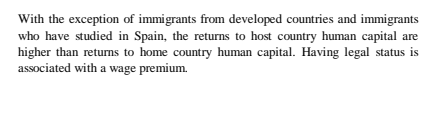 & 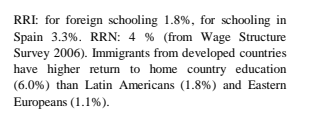 & 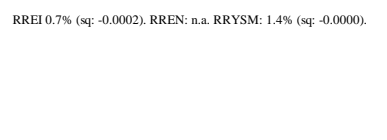 & 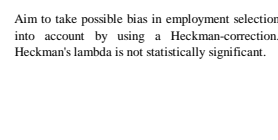 \\
\hline 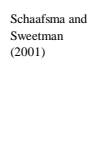 & camada & 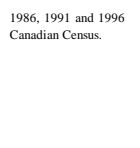 & 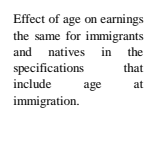 & 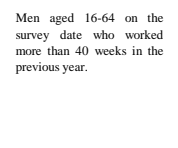 & 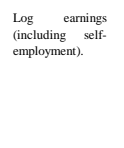 & na. & 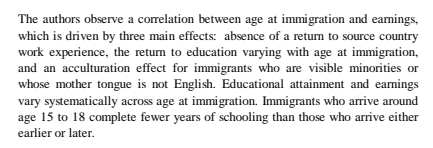 & 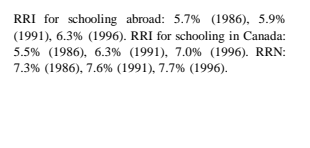 & 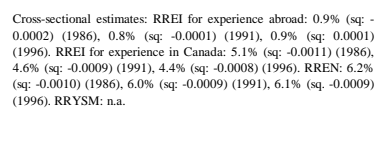 & 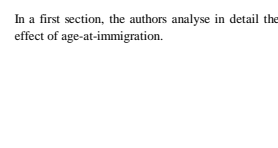 \\
\hline Schenein(1997) & Unied S Sules & 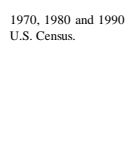 & Equal hine fificas & Men ased 25:60. & 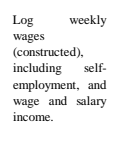 & 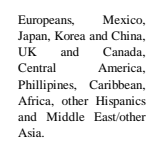 & 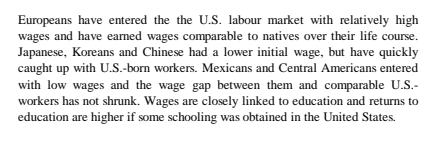 & 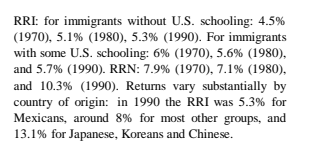 & 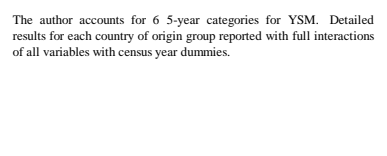 & 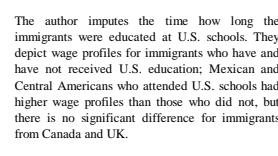 \\
\hline 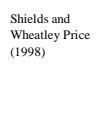 & Enegland & 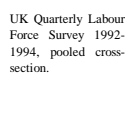 & Equal colone ffictats. & $\begin{array}{c}\text { Men aged 16-64, resident in } \\
\text { England }\end{array}$ & 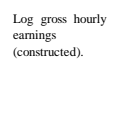 & 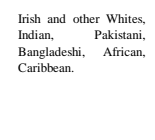 & 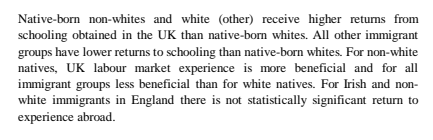 & 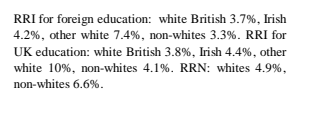 & 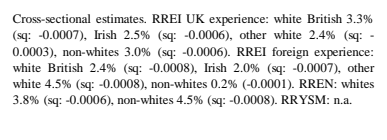 & 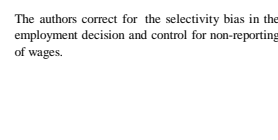 \\
\hline 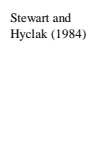 & Unied Sulus & 1970 us c comanc & Eumu colone efficale & $\begin{array}{l}\text { Inmizant males aged } 14 . \\
65 .\end{array}$ & $\begin{array}{l}\text { Log , } \\
\text { earnings, }\end{array}$ & 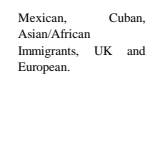 & 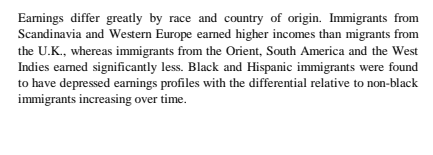 & 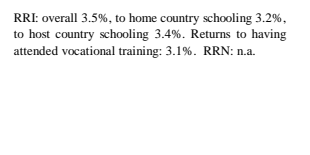 & 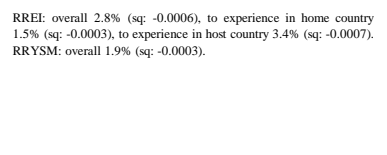 & 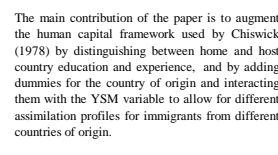 \\
\hline 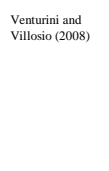 & laly & 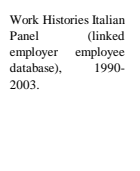 & 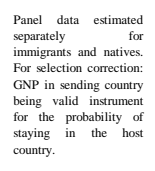 & 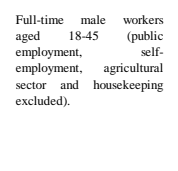 & 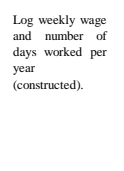 & 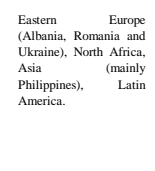 & 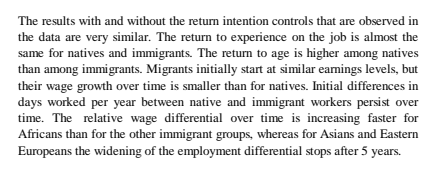 & na. & 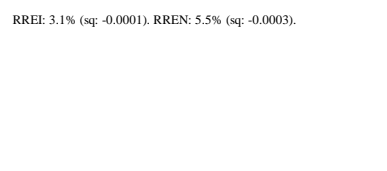 & 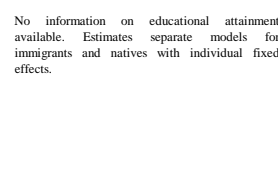 \\
\hline wilikis (2003) & Austratia & 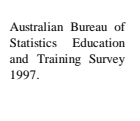 & Equal colone efficiers & 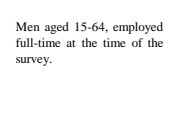 & $\begin{array}{l}\text { Log hourly wages } \\
\text { (constructed) }\end{array}$ & 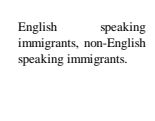 & 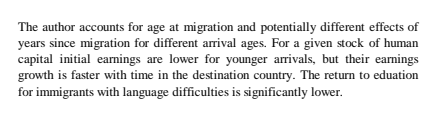 & 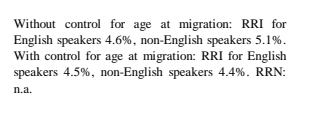 & 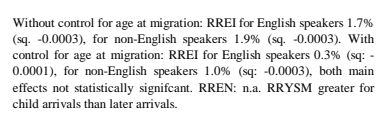 & \\
\hline
\end{tabular}

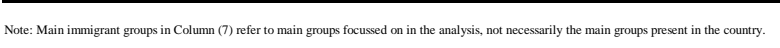


Figure 5: Selection Scenarios
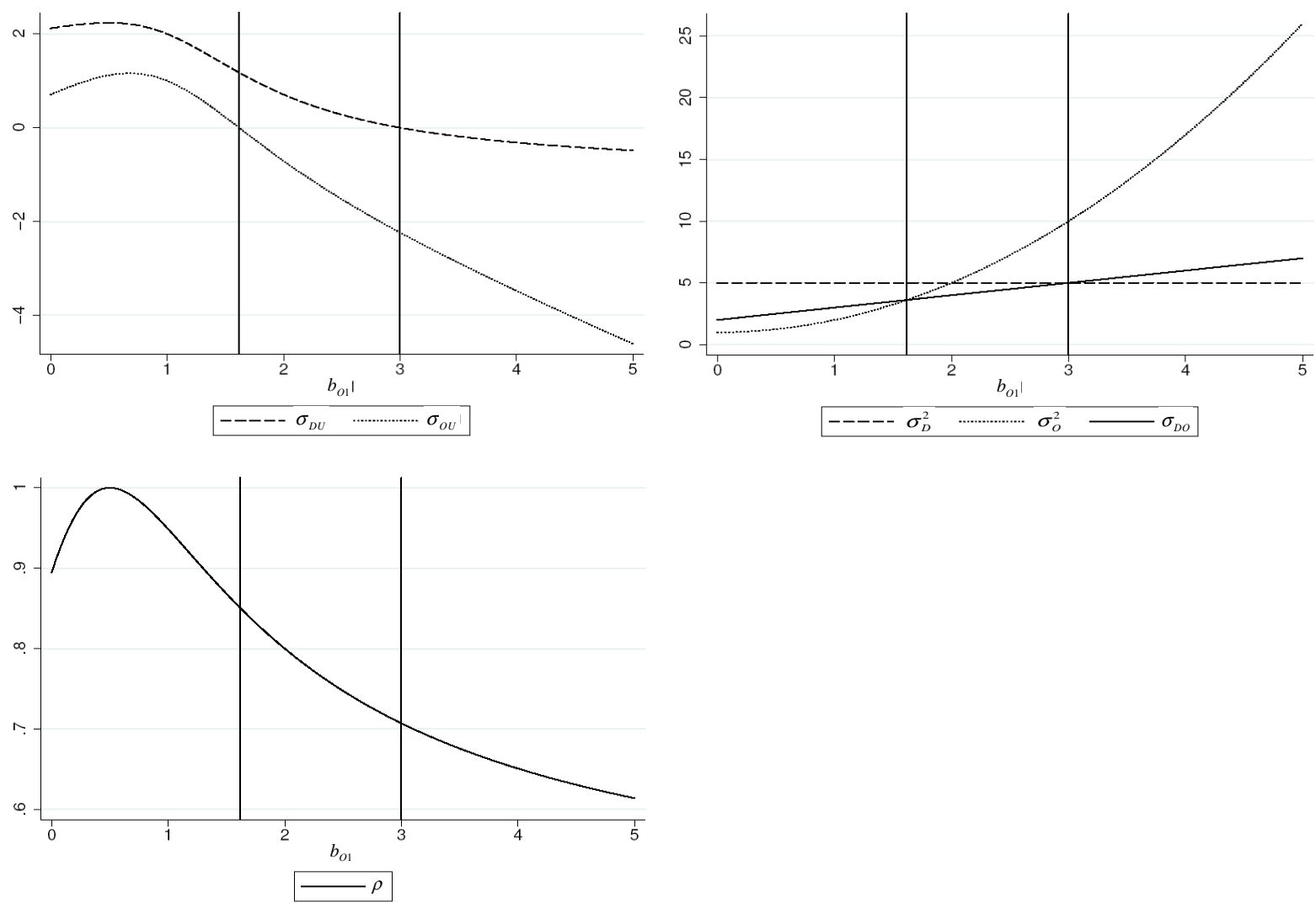
Table 11: Example Intermediate Selection

\begin{tabular}{lccccccccc}
\hline & $S_{1}$ & $S_{2}$ & $b_{D 1}$ & $b_{D 2}$ & $b_{O 1}$ & $b_{O 2}$ & $Y_{D}\left(=b_{D 1} S_{1}+b_{D 2} S_{2}\right)$ & $Y_{O}\left(=b_{O 1} S_{1}+b_{O 2} S_{2}\right)$ & $Y_{D}-Y_{O}$ \\
\hline Low & 1 & 0.5 & 1 & 2 & 2 & 1 & 2 & 2.5 & -0.5 \\
Medium & 2 & 2.5 & 1 & 2 & 2 & 1 & 7 & 6.5 & 0.5 \\
High & 3 & 2 & 1 & 2 & 2 & 1 & 7 & 8 & -1 \\
\hline
\end{tabular}


Table 12: PISA Outcomes - Summary Statistics and Regression Results

\begin{tabular}{|c|c|c|c|c|c|c|c|c|c|}
\hline \multirow[b]{2}{*}{ Destination Country } & \multicolumn{2}{|c|}{$\%$ of Student Population } & \multicolumn{2}{|c|}{$\%$ Foreign Language at Home } & \multicolumn{2}{|c|}{$\%$ Low Education Families } & \multicolumn{3}{|c|}{ PISA Test Score Gap (Mathematics) } \\
\hline & $\begin{array}{l}\text { Natives } \\
\text { (1) }\end{array}$ & $\begin{array}{l}\text { Immigrants } \\
\text { (2) }\end{array}$ & $\begin{array}{c}\text { Natives } \\
\text { (3) }\end{array}$ & $\begin{array}{l}\text { Immigrants } \\
\text { (4) }\end{array}$ & $\begin{array}{c}\text { Natives } \\
\text { (5) }\end{array}$ & $\begin{array}{c}\text { Immigrants } \\
\text { (6) }\end{array}$ & $\begin{array}{l}\text { Unconditional } \\
\text { (7) }\end{array}$ & $\begin{array}{c}\text { Conditional on } \\
\text { Language } \\
\text { (8) }\end{array}$ & $\begin{array}{l}\text { Conditional on } \\
\text { Language \& } \\
\text { Parents' } \\
\text { Education } \\
\text { (9) }\end{array}$ \\
\hline Australia & 60.7 & 21.2 & 0.3 & 33.9 & 11.0 & 9.3 & $15.7^{\star \star}$ & $15.3^{\star \star}$ & $11.1^{\star \star}$ \\
\hline Canada & 67.9 & 20.7 & 0.3 & 48.3 & 2.4 & 6.3 & -2.7 & -1.8 & -3.2 \\
\hline France & 76.8 & 19.7 & 0.3 & 34.8 & 10.9 & 38.9 & $-38.9^{\star \star}$ & $-32.5^{\star \star}$ & $-21.0^{*}$ \\
\hline Germany & 83.8 & 11.2 & 0.4 & 55.0 & 11.7 & 24.8 & $-58.1^{\star \star}$ & $-31.7^{\star \star}$ & $-29.3^{\star \star}$ \\
\hline Italy & 91.0 & 6.4 & 0.1 & 66.9 & 27.3 & 22.1 & $-38.6^{\star \star}$ & $-28.0^{\star}$ & -33.2 \\
\hline Netherlands & 82.5 & 10.6 & 0.1 & 46.1 & 8.3 & 29.7 & $-53.8^{\star \star}$ & $-52.4^{\star \star}$ & $-46.3^{\star \star}$ \\
\hline Spain & 89.1 & 6.9 & 0.3 & 33.0 & 37.5 & 25.3 & $-47.8^{\star \star}$ & $-49.3^{\star \star}$ & $-55.4^{\star \star}$ \\
\hline Switzerland & 62.5 & 3.4 & 0.1 & 56.9 & 14.9 & 35.8 & $-69.5^{\star \star}$ & $-47.1^{\star \star}$ & $-44.0^{\star \star}$ \\
\hline United Kingdom & 84.3 & 9.1 & 0.1 & 38.0 & 4.2 & 10.5 & $-14.6^{\star}$ & -6.7 & -7.2 \\
\hline United States & 80.1 & 13.7 & 0.4 & 62.3 & 2.4 & 25.0 & $-22.9^{\star \star}$ & -2.2 & 4.8 \\
\hline
\end{tabular}

Source: PISA 2006. Columns (1) and (2) report the share of native and immigrant students in the PISA student population. Native students are defined as those born in the country of assessment with both parents as well born in the country of assessment. Immigrant students are those born either in the country of assessment or in another country with both parents foreign-born. The missing category are students with mixed background. Columns (5) and (6) show the percent of families where both parents have low education. Values of summary statistics are computed using the final weights provided by PISA.

Columns (7) to (9) report the proficiency gaps in mathematics of immigrant relative to native students. The values are the estimated coefficients of a regression of PISA scores on a dummy for immigrants (the omitted category is natives). Column (7) reports unconditional regressions; column (8) adds a dummy for whether or not the language of assessment is spoken at home, and column (9) adds dummies for the higher educational level of either parent ("low" - no schooling, primary education, lower secondary education; "medium" secondary education, post-secondary non-tertiary education; "high" - tertiary education, post-graduate education). The regressions are run separately for each country. All coefficients and standard errors are estimated according to the "Unbiased Shortcut" procedure (OECD, 2009), using the replicate weights provided by PISA. Stars indicate that the difference between the immigrant and the native average score is statistically significant at the 1 percent level $\left(^{* *}\right)$ and at the 5 percent level $\left({ }^{\star}\right)$. 
Table 13: Summary of the Literature on Immigrants' Intergenerational Mobility

\begin{tabular}{|c|c|c|c|c|c|c|c|}
\hline Authors & Country & Data & Definition 1st Generation & Definiton 2nd Generation & Dependent Variable & $\begin{array}{l}\text { Generational Income Elasticity - Immigrants (and } \\
\text { Natives if avalable) }\end{array}$ & Remarks \\
\hline (1) & (2) & (3) & (4) & (5) & (6) & (7) & $(8)$ \\
\hline $\begin{array}{l}\text { Aydemir et al. (2009) } \\
\text { (2) }\end{array}$ & $\begin{array}{lcl}\text { Canada } \\
\text { Cand }\end{array}$ & 1981, 2001 Canadian Census. & $\begin{array}{l}\text { Foreign-born men with a } \\
\text { foreign-borm spouse who } \\
\text { have children aged } 5-17 \text { in } \\
1981 \text {. }\end{array}$ & 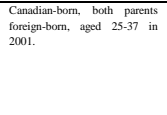 & $\begin{array}{l}\text { Log weekly } \\
\text { schooling. }\end{array}$ & 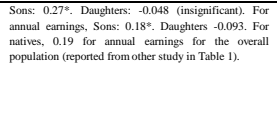 & 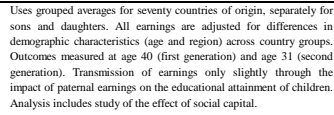 \\
\hline Borjas (1992) & United States & 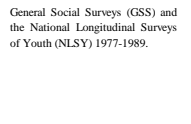 & Foreign-born men. & 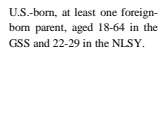 & $\begin{array}{l}\text { Educational attainment and } \\
\text { occupation (using Hodge- } \\
\text { Siegel-Rossi prestige score) } \\
\text { in GSS Educational } \\
\text { attainment and log wage in } \\
\text { NLSY. }\end{array}$ & 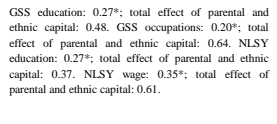 & 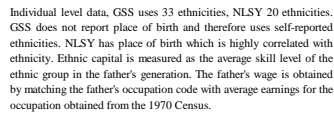 \\
\hline Borjas (1993) & United States & 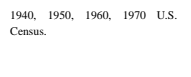 & $\begin{array}{l}\text { Forign-borm nen aged 25- } \\
64 .\end{array}$ & $\begin{array}{l}\text { U.S.-borm men, at least one } \\
\text { parent forcign-borm. }\end{array}$ & $\begin{array}{l}\text { Earnings relative to third } \\
\text { generation Anericans. }\end{array}$ & 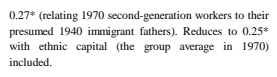 & 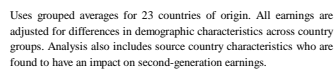 \\
\hline Borjas (2006b) & United States & $\begin{array}{l}\begin{array}{l}1940,4 \\
\text { Census. }\end{array} \\
\text { (1950, } 1960,1970 \text { U.S. }\end{array}$ & Forrign-bom, aged 18-64. & $\begin{array}{l}\text { U.S.-bom, at least one forigg- } \\
\text { bom parent, aged 18-64. }\end{array}$ & $\begin{array}{l}\text { Log weckly earnings relative } \\
\text { to third generation Anericans. }\end{array}$ & $\begin{array}{l}\text { Men: } 0.511 \text { for } 1940-1970 \text { and } 0.560 \text { for } 1970-2000 . \\
\text { Womenen: } 0.242 \text { for } 1940-1970 \text { and } 0.280 \text { for } 1970-2000 .\end{array}$ & 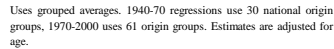 \\
\hline $\begin{array}{l}\text { Card, DiNardo, and Estes } \\
\text { (2000) }\end{array}$ & United States & $\begin{array}{l}1940 \text { and } 1970 \text { U.S. Census, } \\
\text { Poolded } 1994-96 \text { Curren Population } \\
\text { Survey. }\end{array}$ & $\begin{array}{l}\text { Foreign-borm nen, aged } 16 \text { - } \\
66 .\end{array}$ & 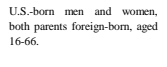 & $\begin{array}{l}\text { Mean log weekly wages and } \\
\text { mean years of schooling. }\end{array}$ & 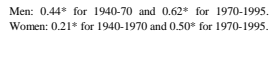 & 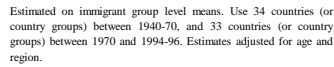 \\
\hline Carliner (1980) & United States & 1970 U.S. Census. & 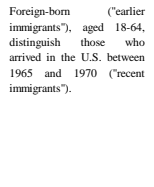 & 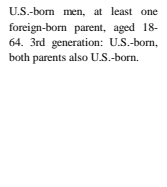 & $\begin{array}{l}\text { Log hourly wages and log } \\
\text { annual earnings. }\end{array}$ & n.a. & 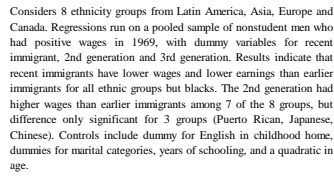 \\
\hline Deulsch (2006) & Bstael & 1995 Census of Irrael. & 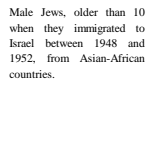 & 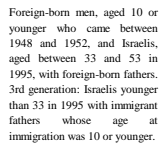 & Log monnhly gross wages. & n.a. & 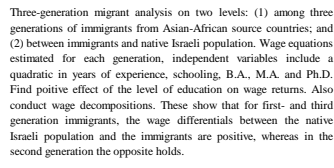 \\
\hline Dustmann (2008) & Germany & GSOEP 1984-2002. & Foreign-bom men. & $\begin{array}{l}\text { Germun-borm men, Ifather } \\
\text { forigg-born, aged 20.34. }\end{array}$ & $\begin{array}{l}\text { Log hourly wages } \\
\text { (constructed). }\end{array}$ & 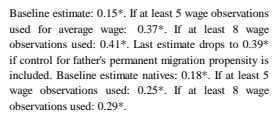 & 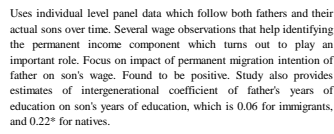 \\
\hline $\begin{array}{l}\text { Gang and Zimmermann } \\
(2000)\end{array}$ & Germany & GSOEP 1984-2002. & Foreign-bom men. & $\begin{array}{l}\text { German-born to foreign parents } \\
\text { or who arrived before the age of } \\
16 \text {, aged } 17-38 \text { in } 1984 \text {. }\end{array}$ & $\begin{array}{l}\text { Total years of education, } \\
\text { categorical schooling levels, } \\
\text { and receipt or atsbence of } \\
\text { wocational training. }\end{array}$ & 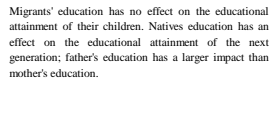 & 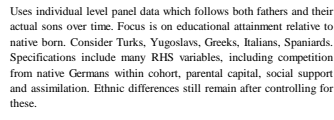 \\
\hline $\begin{array}{l}\text { Hanmmastedt and Pallne } \\
\text { (2006) }\end{array}$ & Sweden & 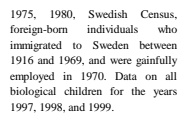 & $\begin{array}{l}\text { Foreign-borm nxn aged } 20 \text { - } \\
64 \text { in } 1975 \text { and } 1980 \text {. }\end{array}$ & $\begin{array}{l}\text { Swedishb-hom, father foreign- } \\
\text { bomn aged 20-64 in 1997, 1998 } \\
\text { and 1999. }\end{array}$ & Amual earnings. & 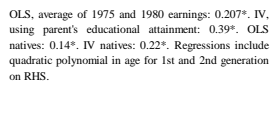 & 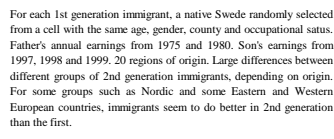 \\
\hline $\begin{array}{l}\text { Nielsen, Rosholm, Smith, } \\
\text { and Husted (2001). }\end{array}$ & Dennurk & 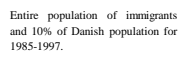 & $\begin{array}{l}\text { Foreign-borm men and } \\
\text { wonnen from less developed } \\
\text { countries. }\end{array}$ & 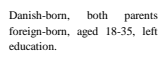 & $\begin{array}{l}\text { Log hourly wages in the first } \\
\text { job affer leaving education. }\end{array}$ & 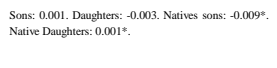 & 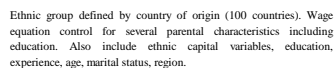 \\
\hline Osterberg (2000) & Sweden & 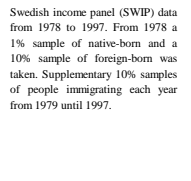 & 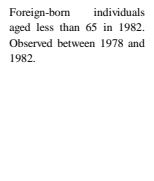 & 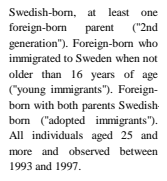 & $\begin{array}{l}\text { Log of average of son's and } \\
\text { daughter's reported annual } \\
\text { eamnings over the period } 1993 . \\
1997 \text {. }\end{array}$ & 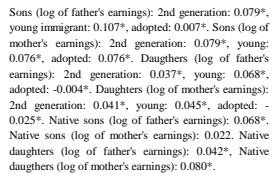 & 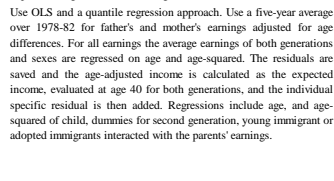 \\
\hline Riphahn (2003) & Germany & $\begin{array}{l}\text { Cermun Mikrocensuses for } 1989, \\
1991,1993,1995 \text {, and } 1996 .\end{array}$ & $\begin{array}{l}\text { Foreign citizen with a valid } \\
\text { year of entry into Germany. }\end{array}$ & $\begin{array}{l}\text { Germun-born with foreign } \\
\text { citizenship, aged 16-19. }\end{array}$ & $\begin{array}{l}\text { Currently attending advanced } \\
\text { school (Gymmasium), binary } \\
\text { variable. }\end{array}$ & 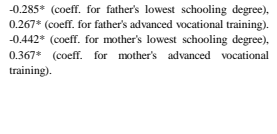 & 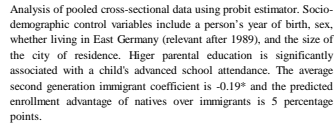 \\
\hline Smith (2003) & United States & 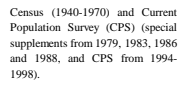 & Foreign-borm men. & $\begin{array}{l}\text { U.S.-borm men, at least one } \\
\text { foreign-borm parent. } 3 \text { rd } \\
\text { generation or more: bohth } \\
\text { parents U.S.-borm. }\end{array}$ & $\begin{array}{l}\text { Years of schooling and log } \\
\text { wages. }\end{array}$ & 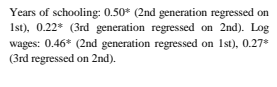 & 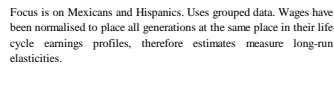 \\
\hline Trejo (2003) & United States & $\begin{array}{l}\text { Current Population Surrey, } 1979 \\
\text { and } 1989 .\end{array}$ & $\begin{array}{l}\text { Foreign-bom, parents also } \\
\text { foreign-bom, aged over } 16 \text {. }\end{array}$ & 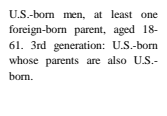 & $\begin{array}{l}\text { Log hourly earrings } \\
\text { (constructed). }\end{array}$ & n.a. & 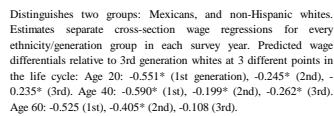 \\
\hline
\end{tabular}

